University of San Diego

Digital USD

2000-04-07

\title{
Cultural Factors Influencing Japanese Female College Students' Perceptions of Learning in a Web-Based Environment: Implications for Web-Based Instructional Designers
}

Theresa L. Lally EdD
University of San Diego

Follow this and additional works at: https://digital.sandiego.edu/dissertations

Part of the Leadership Studies Commons

\section{Digital USD Citation}

Lally, Theresa L. EdD, "Cultural Factors Influencing Japanese Female College Students' Perceptions of Learning in a Web-Based Environment: Implications for Web-Based Instructional Designers" (2000).

Dissertations. 663.

https://digital.sandiego.edu/dissertations/663

This Dissertation: Open Access is brought to you for free and open access by the Theses and Dissertations at Digital USD. It has been accepted for inclusion in Dissertations by an authorized administrator of Digital USD. For more information, please contact digital@sandiego.edu. 


\title{
CULTURAL FACTORS INFLUENCING JAPANESE FEMALE COLLEGE STUDENTS' PERCEPTIONS OF LEARNING IN A WEB-BASED ENVIRONMENT: IMPLICATIONS FOR WEB- BASED INSTRUCTIONAL DESIGNERS
}

\author{
by
}

Theresa L. Lally

\begin{abstract}
A dissertation submitted in partial fulfillment of the requirements for the degree of Doctor of Education
\end{abstract}

\author{
University of San Diego
}

April 7, 2000

\section{Dissertation Committee}

Paula Cordeiro, Ed.D., Chair

Fred McFarlane, Ph. D.

Eugene J. Rathswohl, Ph. D. 


\section{ABSTRACT}

The burst of the Japanese bubble economy in 1992 brought about many reforms in Japanese education. One example of these reforms is the recent introduction of web-based instruction into Japanese classrooms. Since traditional Japanese education has been greatly influenced by elements of Confucianism, many educators are concerned about the integration of web-based instruction with traditional Japanese teaching methods. The purposes of this study were to investigate Japanese female junior college students' attitudes and/or perceptions of learning in a webbased environment, and to measure performance between students in a traditional teacher-centered course with another group of students learning via web-based instruction.

This study utilized a mixed-methodology design to investigate the following two research questions: (a) What cultural factors related to Confucianism influence Japanese freshman female college students' perceptions of learning in a web-based environment, and (b) Are there significant differences between pre and posttest mean scores on the PreTOEFL Test of those Japanese female college students taking a TOEFL preparation course via web-based instruction, and the mean pre and posttest scores of another group of Japanese female college students taking a similar course in a teacher-centered class?

Sixty Japanese female college students aged 18-19 years old participated in the study. The students were randomly assigned by last name into a Treatment group which took a TOEFL course via web-based instruction, and a Control group which studied via a teacher-centered class. For the qualitative section, six students from the Treatment group were interviewed three times each; before, during, and after the treatment. 
Results indicated a movement away from cultural influences of Confucianism as the treatment progressed. For the quantitative investigation, a Pre-TOEFL test was given to both groups before and after the treatment. Results indicated there were significant differences of the pre and posttest mean scores at the .05 level within each group; however, there was no significant difference in the gain scores between the groups. Incorporating results from both the qualitative and quantitative sections provided implications for instructional designers of web-based courses for Japanese female college students. Because the study was limited to the sample population, results cannot be generalized to the larger Japanese population, therefore, recommendations for further research were listed. 


\section{ACKNOWLEDGEMENTS}

As a six-year old huddled with the rest of my family under my uncle's basement stairs, I was never sure if the twister would suck our house into the raging black cloud or if we would once again escape without even losing a hair. During those times I remember my Mother confidently telling me, "Don't worry honey, after the tornado passes over we will all forget how strong the wind blew." Years later as I was closing the shutters on my parent's mobile home before Hurricane Andrew hit Florida, Mom said the same thing with the same confidence, and once again we all survived. During the past five years, her spirit repeated those words to me many times, and gave me the encouragement and guidance I needed to persevere through the seemingly endless difficult times. Luckily for me, I used those past experiences and words of inspiration to hurl me into the future. While working on this degree, I often reflected on how strong the wind blew every time I huddled under the basement stairs, and I remembered how mighty the wind blew as I tried to secure the shutters on my parent's mobile home and now that this dissertation is finished and another wind has blown over, I know that I will never forget how difficult it was to complete this study. Yet once again, by the grace of God and my Mother's own words, I survived.

Therefore, this dissertation is dedicated to my late parents, Bernadine and Dale Lally, Sr., and my sister, Maggie, who without their posthumous spiritual guidance and help, it would have never been completed. I would also like to thank them for giving me faith in God who, together with my parents, supported me through the dark hours of doubt, landed all my planes safely, revealed answers to all my questions, and helped me keep my perspective and composure throughout this project. Also a big "Thank You" to all the Angels and Saints who 
have been watching over me and my family all these years, especially our family patron, St. Anthony, who continues to show me the way to find whatever I need. My sincerest gratitude to all!

As for the sentient beings who helped me, first to thank is my Americanbased support team. Warmest love goes out to all my older siblings - brother Dale Jr., sisters Monica, Deanie, Mary Ann, and Patti for their constant support for this and all my other life-changing projects. A special thank you goes to my little sister and brother-in-law, Kathleen and Michael Arena, for shuttling me back and forth to LAX, L. A. Union Station, and San Diego, and always providing me with a bed and something good to eat upon returning home from abroad.

Next, I would like to give kudos to lifetime friends, Dr. Sally Bass and Hollis Bass, Lowell and Elsie Bennett, Jeff, Angie, Paige, and Nick Pelaccio, and Brian Gill, for their constant support all these years, and especially during this project. In addition, I would like to sincerely thank Leslie Rott, Nancy Smith, Jennifer Belk, Jan Grimes, Dr. James Horine, and Janet Bishop for their constant support, all the good times we have had, and basically keeping me on the right track, and out of trouble. Also a big thanks goes out to my Canadian classmates especially Dr. Pat Makokis whose words of comfort and support from far away were a constant companion. Finally, it wouldn't be appropriate to end this paragraph without a big thank you to M.J. McCoy who started me on my vision quest to Asia 13 years ago and has been a good friend ever since. Way to go, M.J!

Next, I would like to thank my former Japan-based colleagues at Toyoko Gakuen Women's College, especially Professor Eric Johnson for his untiring help in keeping me employed through the whole process, his uplifting 
encouragement, and exquisite editing skills, Ms. Gaynor "Ed" Dowd for her wit and ability to help me keep the whole thing in perspective, my secretary Ms. Hitomi Tanikawa for her sleuthing skills in uncovering Japanese research articles, and basically getting me through each day, and Michiko Moteki sensei for going out on a limb and sponsoring me during my tenure at the college. A special thank you goes to the late President of Toyoko Gakuen Women's College, Dr. Masao Takatori, who, in spite of unbridled opposition, supported my efforts wholeheartedly. Without his help and encouragement I could not have succeeded. Finally, I would like to give a special thank you to special friends in Japan namely, Sue Chin-Keane for her wisdom and insight, and for providing both mental and professional support; Hiromi Kobori, Junko Shirahama, Reiko Segawa, and Duncan Macintyre, for their kind support on this and other projects all the years I spent in Japan. Domo arrigato gozaimashita to everyone in Japan! Last but definitely not least, I would like to sincerely thank several people in San Diego especially Ms. Georgia Belaire and her family for taking me in and making me feel like one of the family. Also, a special thank you goes to all my professors at San Diego State University and the University of San Diego, especially my dissertation committee, Dr. Paula Cordeiro, Dr. Fred McFarlane, and Dr. Eugene Rathswohl who tolerated my road warrior ethic throughout this project. Finally, a special thank you goes to Dr. Cordeiro for taking over the dissertation at a difficult time during the process, and seeing the project through to the end.

Cheers to you all!

T. Lally

April, 2000 


\section{TABLE OF CONTENTS}

Abstract

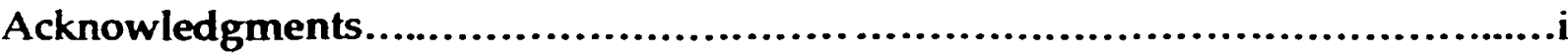

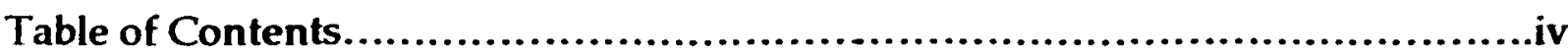

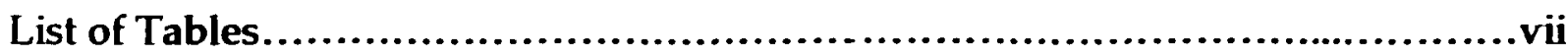

List of Figures.................................................................... vii

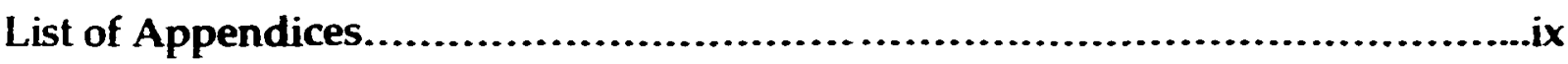

Chapter 1. Introduction ......................................................

Background of the Problem ..................................................

Statement of the Problem..................................................6

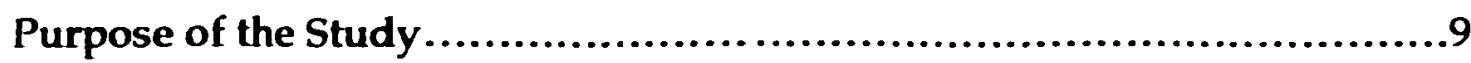

Significance of the Study ..................................................11

Definition of Terms.........................................................13

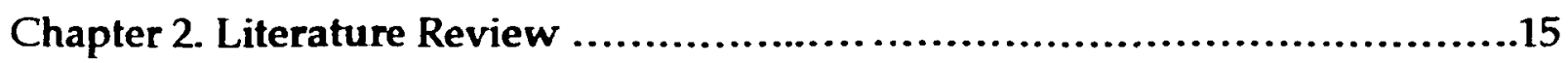

The Life of Confucius......................................................

The Influence of Confucianism in the Tokugawa Era.......................20

The Influence of Confucianism in Contemporary Japanese Education.....26

The Influence of Confucianism on Japanese Junior Colleges................43

Chinese and Western Technological Influences in Japan....................45

Post-war Japanese Educational Reform.................................48

Research on Computers in Japanese Education.............................55

Internet Usage in Japanese Education.....................................63

Japanese Educational Methods Versus Web-based Instruction..............66

Motivation and Self-directed Learning Theory ............................73

Chapter 3. Research Design and Methodology ...................................85 


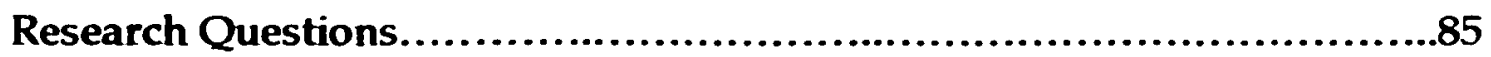

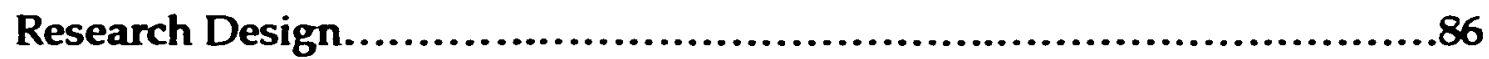

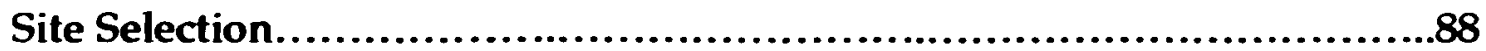

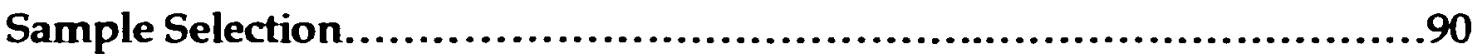

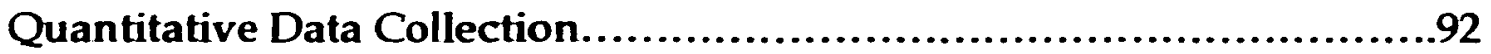

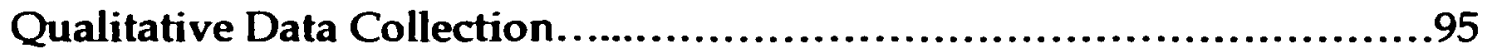

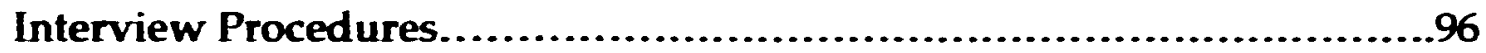

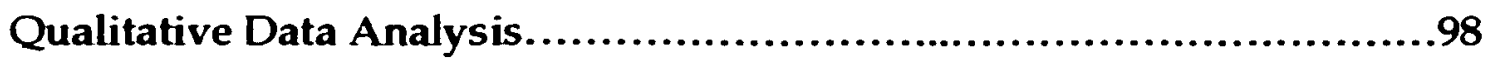

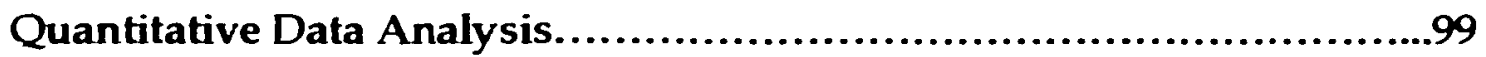

Delimitation and Limitations of the Study................................100

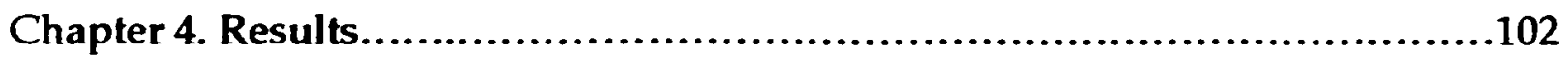

Pretreatment Data Gathering Procedures...................................102

Focus Group Questions and Responses......................................105

Quantitative Results..................................................108

Qualitative Results.......................................................111

Format for Reporting Results.........................................111

Pretreatment Interview Results...........................................112

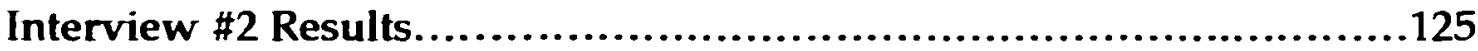

Posttreatment Interview Results.........................................144

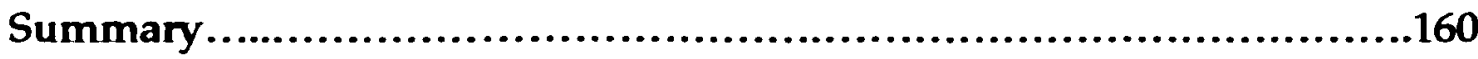

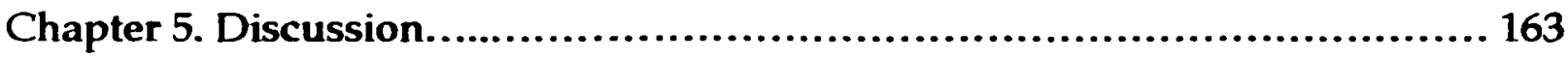

Restatement of the Problem..............................................163

Discussion of the Findings................................................167

Conclusions............................................................173

Conclusions Related to Motivation and Self-directed Learning Theory..178 
Implications for Instructional Designers..............................186

Recommendations for Future Research...............................188

Qualitative Recommendations..................................188

Quantitative Recommendations...............................189

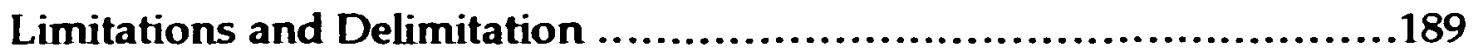

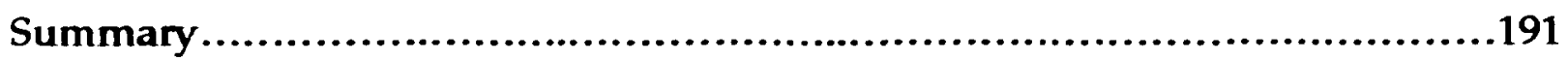

References.................................................................193

Appendices......................................................................209 


\section{LIST OF TABLES}

Table 1: $\quad$ Pretreatment questions regarding computer, Internet, and web-based experience

Table 2: $\quad$ Level of significance of pre and posttest mean scores within each group

Table 3: $\quad$ Level of significance of mean gain scores between each group....110

Table 4: $\quad$ Responses to expectations of relationship between teacher and student

Table 5: $\quad$ Student expectations of teacher actions 116

Table 6: $\quad$ Exam expectations of interviewees during treatment. 120

Table 7: Interviewees' expectations of needing a text for instruction 122

Table 8: $\quad$ Comparison of exam expectations between the preinterview and the second interview 


\section{LIST OF FIGURES}

Figure 1: Comparative influence of tenets in all interviews..................172 


\section{LIST OF APPENDICES}

Appendix A: $\quad$ Toyoko Gakuen Women's College Curriculum Guide.... .209

Appendix B: $\quad$ Student Weekly Logsheets.....................................212

Appendix C: $\quad$ Informed Consent Form....................................224

Appendix D: $\quad$ Interview Question Guides...............................227

Appendix E: $\quad$ Pre-TOEFL Pre and Posttest Scores..........................236 


\section{Chapter 1}

\section{Introduction}

The introduction of the Internet into Japanese schools came during the Japanese economic crisis of the 1990's. The burst of the bubble economy in 1992 caused the entire Japanese nation to reevaluate both business and educational objectives. At the turn of the 21st century as this dissertation is being written, the Japanese economy and educational system is in the process of undergoing a major overhaul both in theory and in practice.

This chapter briefly discusses several issues that served as the impetus for this study. Specifically reviewed are the main socio-economic problems encountered in Japan during the late 1990's, followed by an abridged look at the Japanese Government's proposed educational changes for the 21st century. Following that, a brief mention of the differences between web-based instruction and Japanese educational methods have been elucidated. Finally, the importance, purpose, assumptions, specific terminology, and limitations of the study have been explained.

\section{Background of the Problem}

Since the burst of the bubble economy in the early 1990's, corporate Japan has been wading in a pool of financial upheavals that have affected the entire social structure of the country. One direct result is a prolonged economic recession that caused traditional business practices to change. The first to be hit was the employment system which changed from one of lifetime employment with guaranteed raises based on age, to contract labor and merit pay. In fact in 1999, 
unemployment in Japan reached at an all-time high of 4.1\% (1999, Japan Information Network, paragraph 1), and layoffs and bankruptcies were common. According to Thornton (1999) “In August [1999] alone, Japan lost 170,000 jobs year-on-year" (p. 20). As reported by Business Week, Heizo Takenaka, a member of the Japanese government Economic Strategy Council, stated that, "On top of the three million already unemployed, an additional six to seven million surplus workers are being carried by Japanese companies. Nearly ten million will probably need job retraining. This means one in every six workers" (November 30, 1998, p. 47). Business Week further reported, "The trend signals the wrenching change Japan faces after an eight-year recession. It also suggests the pain many Japanese will suffer: older managers as they are forced from sinecures, younger ones as they confront dashed hopes for secure careers" (August 9, 1999, p. 27). A witness to this is Masayuki Otsuka. After working 30 years at Nippon Steel Corp and being shuffled to a subsidiary to make way for younger workers, Mr. Otsuka had some interesting things to say to new recruits. In Business Week he stated, "I tell them to develop skills they can take with them if they leave the company. Transferring employees to subsidiaries no longer solves problems" (August 9, 1999, p. 27). In addition, the unemployment problem has caused much stress on marriage life. Business Week proclaimed that greater numbers of women are either staying single or marrying foreigners because, "Salarymen are no longer the prize they once were now that lifetime employment is a thing of the past" (October 25, 1999, p. 59).

Another outcome of the recession is the merging and/or restructuring of Japanese companies with those related to the financial and telecommunications industries being severely affected. As a result of billions of dollars in uncollectable 
loans made during the bubble economy, many Japanese banks restructured, consolidated with other banks, or went bankrupt. Bremmer (1999) reported that Japanese banks were saddled with $\$ 600$ billion in bad debts. Furthermore, he stated that in 1998, “Japan's top banks were seen briefly as such poor credit risks that they had to pay a huge one percentage point more than Western banks to borrow dollars on global markets" (p. 21). In addition, banking services that had been protected in years past by the Japanese Ministry of Finance [MOF] were opened to foreigners as witnessed by Merrill Lynch, Goldman, Sachs \& Co., and Charles Schwab - all selling securities to the Japanese public. In addition, in 1999, $15 \%$ of the Tokyo

Stock Market was in foreign hands which surpassed the holdings of Japanese banks. Consequently, further consolidation of Japan's financial institutions is inevitable. According to Business Week, Kaneo Muromachi, president of Sanwa Bank Ltd. stated, “We aren't restructuring because MOF is telling us to. We are doing it because we need to survive." (October 25, 1999, p. 55).

Other signs of socio-economic change involve the direct foreign acquisition of Japanese companies. One of the many examples includes the acquisition of a Japanese telecommunications company, International Digital Communications, by Britain's Cable \& Wireless PLC. In addition to taking over the company, the new owners offered $10 \%$ of its employees stock options - something virtually unheard of in Japanese companies. According to a report in Business Week, "Such incursions would have been unthinkable a decade ago" (October 25, 1999, p. 56). Another major shakeup happened in the auto industry. A commentary by Thornton (1999) declared that Nissan Motor Company's foreign chief operating officer planned 21,000 job cuts, five plant closings, and a $50 \%$ cut in suppliers. 
Thornton stated, "They [Japanese] accepted the news. There was very little anger at the idea of a gaijin [foreign] boss acting so tough" (p. 20). Commenting in Business Week on the numerous takeovers of Japanese companies, Kaoru Yosano, Minister of Internal Trade and Industry stated, 'There isn't any sense of economic nationalism in this regard. That's a huge change in Japanese society" (October 25, 1999, p. 56). In addition to the severe economic conditions that affected the bottom line of many companies, there was also a mood change among the general populace. In Business Week, Noriyuki Ueda believed the opposite of the economic slide, "Is the collapse of our cultural and spiritual values rooted in Confucian deference to authority" (October 25, 1999. p. 55).

However, a silver lining to all this economic and social turmoil awaited those who were raised with computers and telecommunications. Many employees who lost their jobs due to restructuring or bankruptcy embraced Internet technology and started their own businesses. Hiroshi Mikitani is a good example. A previous employee for the now defunct Industrial Bank of Japan, Hiroshi is now running an online shopping mall. In Business Week he stated, "There will be a tremendous [jump] this year and next for the Internet economy" (October 25, 1999, p. 55). Fujitsu Ltd. president Naoyuki Akikusa agreed. Since restructuring the company last year, web-based software and services account for 39\% of revenues. Fujitsu Vice-president Yuji Hirose stated in Business Week, "We plan to offer everything on the Internet" (p. 21). After buying out its partner in Nifty Serve and then merging with InfoWeb, Fujitsu is now the largest Internet service provider in Japan with 500,000 subscribers nationwide. In the future they plan to offer digital imaging services to their Internet customers through Fuji 
Photo Film Company as well as a host of other services such as online financial services.

Like other foreign imports into Japan, for example McDonald's Inc., that take time to be assimilated into Japanese culture, the Internet is burrowing its way into Japanese society. Out of the 125 million people in the Japanese population, in June 1999, the Japanese Ministry of Posts and Telecommunications reported the number of Internet users reached 16.94 million as published by Headcount.com (1999, paragraph 1). This data contrasts with the 92 million Internet users, out of approximately 250 million people in the United States, also published by Headcount.com (1999, paragraph 1). In the near future, Access Media predicts that Japan will have 27 million Internet users by the year 2000 (Headcount.com, 1999, paragraph 1).

From this brief discussion, it is safe to say that economic situation of Japan in the 1990's affected Japanese business in a profound way. On account of the recent socioeconomic changes, it is likely that technology, specifically the Internet, will play a major role in continuing to change the paradigm of the Japanese workplace thus affecting Japanese education and lifestyle. In addition to the expected impact the Internet will have on corporate Japan, it is likely that many schools will be incorporating the Internet into current curriculums and/or creating new curriculums with an emphasis on web-based instruction. But how will students who have been trained in the traditional Japanese manner adapt to such technology? This question plus many more are now echoing in the halls of Japanese schools. It is time for educators in Japan to prepare for instructional transitions to the Internet age. 


\section{Statement of the Problem}

As Japan enters the next century many changes will occur in both the social and educational realm. Regarding the latter, the Japanese Ministry of Education, Science, Sports and Culture [Monbusho] plans to implement several reforms in Japanese education in the $21^{\text {st }}$ century, namely, "The principle of putting emphasis on individuality, the transition to a lifelong learning system, and coping with various changes in society including internationalization and the spread of information media" (Monbusho, 1997, paragraph 2). In a November 1998 Japan Times newspaper article, the Monbusho announced new guidelines for elementary and secondary curriculums with a goal of providing an education that fosters children's willingness to learn in a relaxed environment so that in the next century Japanese children may become more creative, considerate, and unique. In order to facilitate these curriculum guidelines, Monbusho decided the workload on students would be decreased, class hours in both elementary and junior high schools would be reduced by ten percent, and by 2002 a five-day school week would be standard. In addition to the changes in elementary and secondary schools, tertiary education changes would follow with more schools developing new curriculums and departments that would not only complement the changes in Japanese elementary and secondary education, but would also be tailored for a reduced number of students resulting from overall population decline. In short, in addition to helping businesses restructure, the Japanese government has plans to overhaul the complete educational system including all formal educational institutions as well as developing learning centers for lifelong learning for a rapidly aging population. 
Japan is a country of contradictions. To the uninitiated, Japan seems a place of high technology and supreme efficiency using the latest new gadgets that everyone rushes to buy. The reality, however, is quite the opposite. Even though Japan has a $99 \%$ literacy rate and one of the best-educated populations in the world, the use of computers on a wide scale in both education and home environments is just now starting to gain acceptance. As recently as the end of 1999, the Monbusho reported through the Japan Information Network website, that the average number of installed computer units in each elementary school, each lower secondary school, and each upper secondary school was only 12.9, 32.1, and 76.4, respectively (1999, paragraph 1). Moreover, in contrast to other developed nations, using web-based instruction in Japan on a wide scale is still in the early stages of implementation and as such, leaves many questions to ponder.

One of the main considerations is how will Japanese students adapt to web-based instruction when they have been educated in a meritocratic system based on elements of Confucianism? Those elements include the importance of adhering to proper behavior for all members within society, reward over effort, use of memorization as a major learning technique, dependence on textbooks for knowledge acquisition, and use of an extensive examination system for ranking purposes thereby encouraging competition among the students. Berge and Collins and Dillion and Gunawardena (as cited in Bielema, 1996), stated that, “Researchers maintain that teaching styles for the classroom are not directly translated effectively to on-line teaching techniques" (p. 21). Consequently, how the Confucian elements mentioned above will be incorporated into Internetbased education for Japanese students remains to be seen. 
At the opposite end of the spectrum, computer use and education via web-based instruction is becoming quite common in other developed countries especially in the United States. This type of education does not advocate any specific kind of method to guide learning or the relationship between students and teachers but it does complement the western Socratic method of individualized learning via inquiry, and the John Dewey philosophy of experiential education. This type of instruction is opposite from far-eastern methods of education that incorporate elements of Confuciansim into the education process. Below are three examples of the differences found between web-based instruction and education influenced by Confucianism.

First, contrary to education based on a ranking system such as that used in Japan, as yet there is no official ranking procedure for web-based courses and no stigma attached, either positively or negatively, to students upon the completion of web-based courses or specific curriculums of study. This is in contrast to the severe competition experienced by Japanese students within the entire Japanese educational system coupled with the social stigma attached to educational institutions and courses of study. Second, the development of relationships with other members of society is neither important for finishing a web-based course nor in determining what a student will do once his/ her web-based course and/or program is finished. In fact, depending on the objectives of the course, educational web designers use a variety of rationales to create web-based instruction, for example synchronous and asynchronous learning networks, collaborative learning, virtual learning communities, presuming learners possess certain characteristics for such instruction. On the other hand, in Japan it is not the knowledge that students possess, but the relationships students build while 
in school that helps to determine their future. Third, in utilizing web-based learning methods, students must be independent, willing to work at their own pace, and able to use the technology effectively and efficiently. However, under the influence of Confucianism in Japanese educational settings, these skills are not usually practiced. Consequently, these differences and others must be addressed as web-based instruction is introduced into Japanese schools.

To summarize, during the $1990^{\prime}$ s, the Japanese nation has experienced severe socio-economic changes that have affected all layers of Japanese society. As a result, Japanese businesses had to restructure, lay-off workers, and embrace technology in order to survive. In tandem, the Japanese government has proposed educational changes that advocate the use of technology and the Internet. However, there are many differences between traditional Japanese educational methods and those used in web-based instruction. Keeping in mind those differences, we now turn to consider the purpose of this study.

\section{Purpose of the Study}

The location of this study, Toyoko Gakuen Women's Junior College in Tokyo, Japan, became connected to the Internet in September, 1998. At the beginning of the academic year, April, 1999, every student was assigned an email address and had access to the Internet on a daily basis. Concurrently, webbased instruction was offered for the first time to students in the Intensive English Studies (I.E.S.) program. However, there was discussion between the I.E.S. teachers that because students had been previously educated via a teachercentered method influenced by elements of Confucianism, students' attitudes and / or perceptions of learning via web-based instruction would be different from their attitudes and/or perceptions of learning via traditional Japanese 
educational methods. Furthermore, these differences could have an effect on examination scores. Therefore, the purposes of this study were: (a) to investigate Japanese female junior college students' attitudes and/ or perceptions of learning in a web-based environment, and (b) to measure performance between students in a traditional teacher-centered TOEFL preparation course and that same course taught to another group of students via web-based instruction.

\section{Research Questions}

The following research questions guided this study:

1. What cultural factors related to elements of Confucianism influence Japanese female college students attitudes and/or perceptions of learning in a web-based environment?

2. Are there significant differences between the mean pre and post-test scores on the Pre-TOEFL Test of those Japanese female junior college students taking a TOEFL preparation course via web-based instruction and the mean pre and post-test scores of another group of Japanese female junior college students taking the same course in a teacher-centered class?

The null hypothesis postulated there was no significant difference between the mean pre and post-test scores on the Pre-TOEFL Test between one group of Japanese female junior college students taking a course taught by the traditional teacher-centered method and another group of Japanese female junior college students take the same course by web-based instruction. Methodology

This study used a mixed-methodology research plan that consisted of both qualitative and quantitative designs. This added complexity to the design, 
incorporated the advantages of both methods of research, and allowed for triangulation of results.

For the qualitative research question, structured interview methods were used as the theoretical framework for gathering, analyzing, and reporting subjective experiences of Japanese female junior college students' perceptions of learning toward web-based instruction. For the quantitative question, a quasiexperimental method was used. This method approximates a true experimental method which emphasizes objectivity of phenomena through design, statistics, and experimenter control. As a result, quasi-experimental design is useful in educational situations where groups are already predetermined with no allowance for randomization. For the purpose of this study, a quasi-experimental layout consisting of a non-equivalent pre and posttest control group design was employed.

\section{Assumptions of the Study}

This study assumed there were differences among Japanese students' attitudes and/or perceptions of learning influenced by Confucianism in a traditional Japanese setting compared to their attitudes toward web-based instruction. It also assumed that subjects would respond honestly to inquiries from the researcher regarding their attitudes and/or perceptions of learning in a web-based environment. Furthermore, it was assumed that, as a result of these differences, web-based instruction may be designed to fit expectations of Japanese students.

\section{Significance of the Study}

A review of the literature in both English and Japanese revealed limited data regarding Japanese female college students' perceptions of learning and/ or 
attitudes in a web-based environment, and no studies comparing mean scores from two groups of students: one group taking a course by web-based instruction and another group taking a course by traditional Japanese methods. Most likely this is due to the recent introduction of web-based instruction in Japan, and to a lack of reported research on the subject. As a result, this study added to the body of knowledge for Japanese education and specifically Japanese female college students, minority education, international education, educational diversity, and of course, web-based design.

\section{Delimitations and Limitations of the Study}

The overriding delimitation of this study was it being the first of its kind to focus exclusively on how Japanese culture related to Confucianism may or may not have effected Japanese female college students' perceptions of learning in a web-based environment. Consequently, research for the study focused on the effect of Confucianism on Japanese culture and especially Japanese education as well as studies, articles, and reports on using computers and the Internet in Japanese educational settings. Contrary to the one main delimination, however, this study had several limitations.

First, a small sample size of 60 participants and a population comprised of Japanese freshman, junior college women limits generalizing to groups other than the sample population. In addition, while every effort was made to identify possible biases of the non-Japanese researcher, a distinct cultural difference in social and educational background between the researcher and participants was noted. For example, in looking at Confucianism from the researcher's foreign perspective, the researcher determined which elements of Confucianism most influenced Japanese education and used those elements as a basis for designing 
interview questions. It was recognized by the researcher that the Confucian elements used were neither supported nor refuted by native Japanese educators. Furthermore, all interview communication between the researcher and participants was in the researcher's native language and not the participants'. This could have influenced the participants' responses to interview questions.

\section{Definition of Terms}

1. Bubble Economy - an economy that focuses only on growth at the expense of sound monetary policy, for example cross-holding of corporate shares, and allowing unsecured corporate loans.

2. Monbusho - The Japanese Ministry of Education. The agency responsible for the nation's educational administration with the chief executive officer being the Minister of Education.

3. Confucianism - an ancient Chinese philosophical system founded upon the teachings of Confucius (551-479 BC).

4. Chu Hsi (1130-1200) - a neo-Confucianist philosophy that emphasized rationalism as its main tenet.

5. Collaborative learning - an instructional method allowing students to work on joint projects together to accomplish shared goals.

6. Internet - a system of computer networks that are linked world-wide providing various communication services.

7. World Wide Web - a global hypertext system using HTML language to create documents and connected links using the Internet as their means of transport. 
8. Web-based instruction - an educational approach using a hyper-media based instructional design program transported over the Internet to learners at a remote site.

9. Asynchronous learning networks - a type of computer mediated interaction using one-way delayed communication between students and teachers and other students, for example, using e-mail as a means to complete and distribute an assignment.

10. Synchronous learning networks - a type of computer mediated interaction using two-way immediate communication between students and teachers, for example, using an Internet chat room as a vehicle for on-line discussion.

11. Active learning - a learning process involving activities such as collaboration, critical reflection, and authentic interactions with the real world.

12. Attitude - For this dissertation, Campbell's definition (1963) together with Fishbein \& Ajzen's (1975) definition of attitude (as cited in Long and Russell, 1999) will be used. In essence, attitudes will be viewed as "evaluative tendencies, either as an acquired behavioral disposition or as a learned predisposition that allows one to respond in a favorable or unfavorable manner" (p. 19). Note that in this study, the words "attitudes" and "perceptions of learning" will be used interchangeably. 


\section{Chapter 2}

\section{Introduction}

This literature review examines two factors of influence in Japanese education - culture and technology. Regarding the former, a brief look at the life of Confucius followed by his influence on education in the Tokugawa Era is discussed. Next, the cultural effect of Confucianism in contemporary Japanese education is considered. In looking at technology influences, to be reviewed are early Chinese and Western technological influences in Japanese society and education. Subsequently, post-war Japanese educational reform and research on attitudes toward technology use in Japanese educational settings are discussed. The final section investigates Internet use in contemporary Japanese education and Japanese educational methods versus web-based instructional methods will be investigated.

\section{The Life of Confucius}

The geographical closeness between Japan and China has helped to nourish Chinese influence on all aspects of Japanese culture. According to Li (1996), over the centuries the Japanese internalized many Chinese elements creating a "China in Japan" where Japanese self-perceptions were entangled with Chinese influence and awareness. (p. 1). Keene (1982) concurs and states, "At every cultural gathering of Japanese and Chinese it is customary for the Japanese to declare with humility that their entire culture was derived from China" (p. 9). As a result, the Japanese have formed a unique view of life by joining the philosophies of Buddha and the Chinese sage, Confucius, with the Japanese 
religious traditions of Shintoism. Of the three, however, it is the elements of Confucianism that continue to dictate Japanese behavior patterns in social and educational settings. For that reason, a look into the life of Confucius and his philosophy will be explored.

K'ung Fu-Tzu, commonly known as Confucius (551-479 B.C), was born into meager circumstances in the 22nd year of the reign of Duke Hsiang in the State of Lu, now called Shangtung Province, China. The name "Confucius" came from a 17th century Jesuit Latinization of the Chinese term of respect. (Levenson, 1969, p. 42). Hereafter, Master K'ung, as he was often called by his students, will be referred to by his Western namesake, Confucius.

Confucius grew up during trying times as the son of an aging governor of a small city in Lu. Unfortunately, when he was three, Confucius's father died and his mother supported him by farming a small plot of land that was given her by the government. During this time, the State of Lu experienced many social problems that were difficult to manage for the existing administration. Slote and De Vos (1998) state, “By Confucius's time the 'feudal' ritual system had been so fundamentally undermined that political crises precipitated a profound sense of moral decline: the center of symbolic control could no longer hold the kingdom from total disintegration" (p. 7). This continuous unrest resulted in disagreements between Lu and neighboring states. According to Hoobler and Hoobler (1993), Lu was invaded 21 times by warring neighbors between 722 and 481 B.C. causing unrest for Confucius most of his lifetime.

Hoobler and Hoobler (1993) also state that it is unclear exactly how and where Confucius received his education but it is thought that because he was the son of an official, he was educated at a school for boys of noble birth. McGreal 
(1995) claimed that Confucius set his mind to become a scholar at the young age of 15. During his years of study, Confucius edited the Five Classics which were written before his time. These books consisted of The Book of History, The Book of Poetry, Spring and Autum Annals, The I Ching, and the Book of Rites all of which formed the basis for his later teachings. At nineteen, he married a woman of similar background who bore a son one year later. Confucius remained in Lu and had various official positions including chief of police in the Department of Justice, stable manager, bookkeeper, and tax collector. During his tenure in the latter position, he supervised the collection of rice and grain making sure that it was stored properly. In all his government positions, but especially as a tax collector, Confucius saw how corrupt the system was and decided to try and rectify the situation. Frustrated in trying to change the government, he took another path and started a school by gathering young men of talent and began training them. According to Hoobler and Hoobler (1993), “His goal was to make them chun tsu, or gentlemen who could, in time, change society by serving in government" (p. 27). This would involve constant self-improvement as well as continuous social interactions. As a result, he believed that learning is for the sake of the self eventually allowing the person to achieve self-realization in all things. Slote and De Vos (1998) declare that, "Confucius is known as the first private teacher in China, for he was instrumental in establishing the art of teaching as a vocation, indeed a way of life" (p. 9). They further state that he was first to devote his entire life to learning and teaching in order to transform and improve society as he believed that all human beings could benefit from selfcultivation. 
In examining his teaching method, Hoobler and Hoobler (1993) state that Confucius taught a moral code based on ethics, humanity, and love emphasizing the ideals of order and harmony between man and nature. This lofty ideal could be attained though a system of interpersonal relationships and correct government. In his teachings, Confucius stressed two fundamental virtues - li and $j e n$. In $l i$ was the rules of proper moral behavior which included polite verbal conventions, court etiquette, state religious rituals, a gentlemanly code of conduct, ethical principles, and the practice of filial piety. The second virtue, jen, was benevolent love for fellow human beings which was broadened to include considerate love for others as exemplified in the attitude and actions of an ideal parent, teacher, or prince. Hoobler and Hoobler (1993) state that for Confucius, the five human relationships of father/son, husband/ wife, older brother/younger brother, friend/ friend, and ruler/subject provided the basis for achieving a harmonious society. With the exception of the friend/friend relationship, all others stressed the importance of age over youth causing the younger to be subservient to the older. Through observing correct behavior through relationships, Confucius' teachings enabled not only the common people to deal with problems but government officials as well. According to Hsu (cited in Hoobler and Hoobler, 1993) for Chinese, this arrangement of expected behaviors in relationships, "Gave a great sense of security and the wherewithal to deal with the problems in the world" (p.11).

Possessing a sincere love of learning, Confucius (cited in Hoobler and Hoobler, 1993), said, "Study as if you were never to master it, as if in fear of losing it" (p. 12). Confucius thought that it was through education that men learned to be gentlemen and, according to Hoobler and Hoobler (1993), this 
included developing the five virtues of courtesy, magnanimity, good faith, diligence, and kindness. Development of these qualities did not come from new ideas explored by Confucius but from examining past eras. Confucius states (as cited in Hoobler and Hoobler, 1993), "I transmit but I do not create. I am sincerely fond of the ancient" (p. 8). It was his study of Chinese tradition that provided the answers to man's moral and ethical questions and it was the student's job to memorize these traditions so as to preserve the social structure.

Confucius taught in Lu for several years but became frustrated at the many injustices and his inability to influence social change. At around fifty years old, he left Lu and spent several years wondering around the neighboring states accompanied by some of his faithful students. His dream was to find a ruler who would put his ideas into practice, but that was never to be realized. The great sage states (as cited in Hoobler and Hoobler, 1993), "In one year I would make progress; in three years I would succeed" (p. 30). But no offer came as no ruler possessed the sincerity that Confucius required. He returned to $\mathrm{Lu}$ and died in 479 B.C. thinking himself a failure yet he made more of a lasting impression than he would ever know. Over the course of many years, Confucianism became a state religion in China and formed the basis of Chinese education for two thousand years. A system of examinations was developed that challenged students' knowledge of Confucian thought. Competition was rigorous and those passing such exams were rewarded with government positions with the title of "Mandarin". Even though Confucianism changed over the centuries and is no longer considered the state religion of China, certain core elements, for example, the principle of harmony in all things through proper behavior, became the cornerstone of many eastern cultures and continues to this day. In contemporary 
Japan, for example, elements of Confucianism in the educational system can be traced back to the time of the samurai schools during the Tokugawa era which lasted 264 years from 1603 to 1867.

\section{The Influence of Confucianism in the Tokugawa Era}

The founder of the Tokugawa Shogunate, leyasu Tokugawa, ended the feudal wars of the 16th century in Japan and created a peaceful regime that lasted over two hundred years from 1603-1867. In his book on Tokugawa Religion, Bellah (1957) explains that this era, "Is distinguished perhaps most strikingly from the periods which preceded and followed it by its peaceful character and its relative isolation from the outside world" (p. 11). According to Dore (1992), like other conquerors before him, leyasu did not eliminate the old Imperial Court which sat in Kyoto but used them to grant him the title of Shogun, or head general, which granted Ieyasu and his successors basic control of the country. "Ieyasu was conscious that he was making history, and his intention was to build a governmental system that would last" (Dore, p. 16). He established a government built on morality, discipline, and personal loyalties. Needing a philosophy to support his government, he turned to Confucianism as the ideology for his subjects. The Tokugawa Jikki (as cited in Dore, 1992), states that, "He [leyasu] always had a great respect for the Way of the Sages and knew that it alone could teach how to rule the kingdom and fulfil the highest duties of man" (p. 16). Consequently, Ieyasu subsidized the publications of books, and funded libraries and schools which gave great impetus to Confucian studies in the $17^{\text {th }}$ century.

During the Tokugawa era there were 250 domains under the rule of their own feudal lord or shogun with samurai being protectors of the estate. Unlike 
European feudal vassals, Collier's Encyclopedia (1977) states that, "Samurai were dependent upon their shogun and were given a stipend depending upon their samurai class" (Vol. 20, p. 390). Indeed, samurai were not exempt from class structure and were ranked according to their hereditary status. Bellah (1957) explains that even though lower ranked samurai received a stipend, they had to supplement their income by various means and could exist only by carefully managing their money. Signs of samurai status were easily seen in their daily attire. "The most visible sign of the samurai's privilege was his sole right to wear swords, symbols of the samurai even after they ceased to be his major tools" (Schirokauer, 1993, p. 147). As a result of the lasting peace during the Tokugawa era, the once mighty samurai now focused their energy on being members of the governing class while still living under the supreme guidance and governance of their particular shogun.

At the time when Japan was purposefully disconnected from the rest of the world, leyasu Tokugawa, "Called upon the samurai to devote themselves to both learning and the military arts, learning, it should be noticed, being placed in the first position." (Passin, p. 13.) Schirokauer (1993), agrees and states that, "Samurai were sent to school to absorb the Confucian ethic of dutiful obedience to superiors and conscientious concern for those below him on the social scale" (p. 147). Except for the very smallest domains, almost all had at least one school for male samurai children, often referred to as a shogunal school. Male samurai children had their first taste of education in their homes usually from a private tutor as well as a committed extended family to support them. Their severe upbringing emphasized the development of Confucian character traits for potential rulers, for example, proper manners, frugality, perseverance, and 
moderation in all things. In addition, samurai children learned rudimentary military skills and most importantly, the self-image that was proper for their social class. These virtues were instilled in home-schooled male samurai children, and by the time the young samurai were ready for formal schooling, they were already well versed in their role of proper class behavior and manners. In samurai schools, the Chu Hsi version of Confucianism - sometimes referred to as Neo-Confucianism - which emphasized rationalism as its main element, was taught as official Tokugawa doctrine.

According to the Neo-Confucianist system Chu Hsi represented, all objects in nature are composed of two inherent forces: $l i$, an immaterial universal principle or law; and $c h^{\prime} i$, the substance of which all material things are made. Whereas ch'i may change and dissolve, li, remains constant and indestructible. In humans, $l i$ represents the unchangeable "human" nature whereas personality differences between human beings is attributed to the density of one's $c h^{\prime} i$. (Confucianism, 1999, paragraph 12).

In their book, Slote and De Vos (1998) note that Chu Hsi developed a pattern of examining and conveying the Confucian Way that defined Confucian thought for the Japanese and by the end of the 17 th century, virtually every educated person in Japanese society had read the Four Books., "Compilations of the sayings of Confucius and Menicus and of commentaries by followers on their teachings" (Confucianism, 1999, paragraph 5). Taylor (1988) surmises that a main consideration during the Tokugawa era was maintaining a stable and harmonious society which found support in the Neo-Confucian ideals of equilibrium between human beings. According to Lincicome (1991), "Neo- 
Confucianism had a pervasive impact on education throughout the Tokugawa period" (p. 9) with the shogunal schools for samurai children being the "Supreme institution of Confucian orthodoxy and were influential in both the domain and private Confucian academies that grew up later" (Passin, p. 17). As summarized by Dore (cited in Lincicome, 1991),

The means of education were provided by Chinese writings; especially the Confucian classics; its purpose was primarily to develop moral character, both as an absolute human duty and also in order to better fulfill the samurai's function in society; a secondary purpose was to gain from the classics that knowledge of men and affairs and of the principles of government which was also necessary for the proper performance of the samurai's duties (Lincicome p. 9).

In addition to studying the classics, depending on the rank of the young samurai, other studies were based on the six classical Confucian arts of music, archery, horsemanship, ceremonial rites, mathematics, and calligraphy, all taught by a qualified teacher. "The teacher was invariably a Confucian scholar and generally the position was hereditary" (Lehmann, 1982, p. 118). Furthermore, Lehmann (1982) states relationships within the school were personal with the key relationship between the sensi (teacher) and student following an expected pattern of behavior. "Devotion, dedication, loyalty were directed towards a person, not an idea; this basic general pattern continues to apply to Japanese academe to this day" (Lehmann, 1982, p. 119). "Confucius upheld the theory that education should be egalitarian" (Confucianism, 1999, paragraph 6) but during the Tokugawa era, this idea had been whittled down to 
equality within a rank with some samurai trying to better their rank through education. Bellah (1957) states that, "Lower ranking samurai were sometimes refused permission to go to other fiefs to study on the grounds that advanced learning was not proper to their stations" (p. 45). During the first hundred years of the Tokugawa era, schools maintained strict class divisions and a separate education was provided for different ranks of samurai. Higher-ranking samurai, for example, had a contempt for money and looked down on arithmetic as fit only for merchants. "The upper samurai were educated in the polite accomplishments while the lower learned mainly writing and arthimetic" (Bellah, 1957, p. 45). Swordsmanship, riding, and archery were taught to the upper-ranking samurai as a form of spiritual training, but lower-ranking samurai were taught more infantry skills such as lancemanship, group tactics, and shooting. After about 120 years, the study of military arts diminished and book learning became the order of the day with examinations determining one's rank. This was especially useful for ambitious lower caste samurai who were now able to achieve higher positions based on their knowledge of Chinese classics and other works. During the early Tokugawa era, the hereditary system severely limited the possibilities of advancement but towards the end of the era there was increased emphasis for schools to produce students with talent that improved one's chances in competition. According to Dore (1992), in the late 1700's, it was acknowledged that the bait of a good job was justified as a means to encourage the samurai to study. By the $1800^{\prime}$ s, ambition for promotion was seen as a path of proper expression of filial piety and as such was considered proper conduct for samurai. 
At the end of this discussion on samurai education, a mention of education for samurai female children must be made. Unfortunately there has not been much written on the subject, as it was not important at that time for female samurai children to be schooled in the Chinese classics. As reported by Dore (1992), there is a "Small amount of space devoted to the subject in Tokugawa educational writings" (p. 65). Like their samurai brothers, education for samurai girls also stressed moral education but, unlike their brothers who went outside to attend school, school for girls was attained at home as there were no outside schools for them to attend. Moral education for the boys consisted of studying the Chinese classics and also practicing physical feats, but for the girls moral education revolved around learning how to weave, sew, and master other domestic duties as well as learn social graces for their particular samurai rankexpertise needed for their inherited profession of wife and mother. In fact, learning domestic skills was essential as girls could be dismissed from their husband's home if their domestic skills were not up to par. Dore (1992) explains that in Japanese books of morals for women at that time, rules were explicit. "If you grow up to be a selfish girl; if you do not learn to obey; if you do not take care of your appearance; if you cannot cook or sew, you will be divorced" (p. 67).

Girls who did manage to get a more formal education were allowed to read the Japanese classics of the Heian period which, according to Dore (1992), would give them a knowledge of the heart, encourage an appreciation of the beauties of nature, refine their feelings, give them skill in literary expression necessary for social interactions. Reading such classics would not reduce one's femininity but could actually enhance it provided girls did not divulge what they had learned, especially as there were men who were fiercely jealous of women 
who cultivated an education. In summary, education for samurai girls was accomplished at home with moral education centering on domestic duties of wife and mother. What little book learning they acquired was not of the Chinese classics like their brothers, but of Japanese classics which taught the girls how to manage their emotions, and adhere to social patterns of behavior suitable to their rank.

To recapitulate, the dominant view of samurai education for males in the Tokugawa era was a focus on Chinese writings especially the Confucian classics. This provided moral development for the samurai to fulfill his function in society understanding both the common man as well as government duties - both of which he was responsible for. In addition, samurai were to develop technical skills such as swordsmanship and horseback riding which served to keep their physical abilities sharp in order to protect their lord. According to Slote and De Vos (1998), "By the late Tokugawa period, education was already established as a means to social mobiliby as well as a means of Confucianist self-development" (p. 113). From the previous discussion, it is apparent that Confucianism had a distinct effect on education during the Tokugawa era. We will now move 150 years forward to the proposed changes in contemporary Japanese education and see how Confucianism influenced those changes.

The Influence of Confucianism in Contemporary Japanese Education

Confucianism has had a profound effect not only on Japan but many other countries in East Asia. Hoobler and Hoobler (1993) delcare,

The Confucian values of close family, strong work ethic, and love of learning have produced tremendous results in the modern nations of East Asia. This 'Confucian ethic' is credited as being a driving force behind the 
economic success of such prosperous Pacific Rim countries as Japan, South Korea, Taiwan, Singapore, and Hong Kong (p. 16).

Thus in examining cultural influences in contemporary Japanese behavior in educational settings, the influence of Confucianism cannot be ignored. During the late $1980^{\circ}$ s and the $1990^{\circ}$ s, the rise of Japan and other newly industrialized Asian countries such as South Korea and Taiwan have provided much debate on the influence of ancient traditions on their recent successes. Slote and De Vos (1998) state,

This phenomena raises intriguing questions about how the typical East Asian institutions still laden with Confucian values, such as a paternalistic government, an educational system based on competitive examinations, the family with emphasis on loyalty and cooperation, and local organization informed by consensus have adapted themselves to the imperatives of modernization (p. 33).

Much has been written about the relationship between Confucianism and traditional Japanese educational methods. After investigating various sources, the following Confucian tenets have been chosen for their influence on Japanese education and will be further examined. Those tenets include the distinct behavioral roles between members of society, reward over effort, the use of memorization, emphasis on book learning, and the importance of examinations. While these can be studied independently from each other, in Japan they do not operate independently but are interwoven like new tatami, a kind of straw used for flooring which, once bound, is as strong as steel. As such, the above points will be examined in their relationship to each other. 
Regarding the first tenet, Confucian doctrine espouses that everyone in society should know his or her place and rank in society and act accordingly. “Good order prevails in the realm when each individual occupies a fitting position in society and acts in accordance with the duties and privileges appertaining to that position" (Collier's Encyclopedia, Vol. 6, p. 360). Good order, however, could only be achieved by learning behaviors that coincided with one's peers, superiors, and subordinates. Confucius stated how people should know what correct behaviors one should practice.

Confucius emphasized right behavior in one's relations; man should act in accordance with propriety. Thus one behaves ritualistically with the other. Such behavior is called $l i$; it refers to social and aesthetic norms that guide people in their social relations (Academic American Encyclopedia, p. 180).

In Western terms, li could be compared to power distance - a term used by Hofstede in examining the distribution of power within organizations. In discussing the boss-subordinate relationship, Hofstede (1980) says, "It is a basic human relationship that bears resemblance to even more fundamental relationships earlier in life: that of the parent and child and of teacher and pupil" (p. 97). He further states that values learned from early life experiences can be carried over into adulthood. In essence, in organizations as well as personal relationships, power distance is the interpersonal power or influence between two people as perceived by the least powerful of the two suggesting a vertical structure within the relationship. Confucianism advocates Hofstede's notion of power distance and in Japan this is easily observable as all relationships, from 
the emperor to the farmer, are based on a vertical structure stressing harmony in interpersonal relations and cooperation with others.

In examining closely how this ancient Confucian element actually functions in contemporary Japanese education, it is useful to take a brief look at the influence of the group and proper behavior among participants in the group as seen in elementary and secondary interactions between teachers and students. Below is a discussion of this influence from findings of researchers as well as from the popular literature.

As in the time of Confucius, in contemporary Japan both the Japanese student and teacher are quite aware of the appropriate behavior for his/ her social position. Dolan and Warden (as cited in Holmes, Mikhailova, \& Field, 1999) state that, "Modern Japan is a secular society in which harmonious relations with others through reciprocity and the fulfillment of social obligations is more significant for most Japanese than an individual's relationship to a transcendent god" (1999, paragraph 4). These social/ reciprocal behaviors are institutionally instilled from an early age. Slote and De Vos (1998) state, "The social institutions, not the mothers, enforce the stringent code of social and personal propriety. Thus the mothers retain their position as nonrestrictive and all-condoning. This particularly holds true for the sons" (p. 49). In a description of the group socialization process for Japanese elementary children, McCarty states that, "Kindergarten in Japan runs from age three or four to six, and the large but well-organized classes with school uniforms are the training grounds for 'becoming Japanese'" (1997 paragraph 3). White concurs and states,

Children are taught to think of themselves as members of a group....Children learn about social relationships: the way you behave 
with your teacher, with your elder brother, with your mom. In the first grade, before doing anything academic, the teacher spends the first part of the year getting the children socialized to the ways of the school and the habits of working together in groups (White, 1987, p. 65).

Other researchers agree with White and see the influence of the group as an important part of Japanese education. Leetsma (1987) reported that, "Daily life in a Japanese classroom requires considerable mutual assistance and adaptation of individual views and interests to group goals and standards of behavior. The heavy emphasis on group activities and social consensus results in considerable conformity in behavior" (p. 3). Learning correct behavior forms the crux of Japanese society and is taken very seriously. According to Leestma (1987), these traits consist of respect for society, valuing group over individual goals, disciplined study habits, self-evaluation, and diligence. Moreover, Leetsma (1987) states, "Japanese teachers believe that the proper development of these values, attitudes, and habits is fundamental to success in the classroom as well as in adult life" (p.3). If parents, however, become concerned about their children's social education within the regular school system, they have the option of “outside" training. In fact, "Parents who worry about summer vacation send their children to 'Work Hard Classes' where students learn to bow, speak clearly, and address their superiors in a proper manner" (Shoji, 1990, p. 22).

Opposite the elementary level, in higher education the Confucian element of conforming to behavioral roles has almost stifled any interaction between teachers and students. According to the research, students appear to show a lack of interest in any subject and an unwillingness to participate verbally in a joint 
learning experience between the teacher and the student. Stapleton (1995) points out that,

Students [have] a much lower status in this rigid vertical society, where relationships and duties [are] strictly defined.... In today's Japan, this ethos is clearly evident; to question a teacher's word would demonstrate a student's lack of awareness of his or her place in the hierarchy. The silence of students then, and the respect students accord teachers is still a strong component of class room behavior reflecting Confucian values (p. 14).

Japanese behavior based on the first Confucian element is further examined by Rockelman (1994) who described a study involving the analysis of 265 Japanese college students' role expectations in classroom. Surveys were administered to 110 males and 155 females. Statistical analysis consisted of using chi-square to determine the degree of acceptance or rejection for each survey item. Results were reported for four areas: (a) formal relationship, (b) touching patterns, (c) silence, and (d) format of lecture. He delcared that students expect a formal relationship with their teacher based on the way Japanese society is organized. 'Vertical relationships...[are] so strong that the students' identity is a result of their reciprocal obligations, social interaction and ritual with others, including teachers" (p. 135). Thus, because of the distinct difference of roles between teacher and students, students are given little room for questioning the teacher. Students do not dispute the words of the teacher and they reply to questions with modesty and respect because they are extremely sensitive to expected behaviors. Hiraga (1998), examined Confucian values in Japanese education and sees the behavior between teacher and student summed up in the 
following Japanese proverb, “Nanashaku sat-te shi no kage o fuma-zu which means 'Follow your master seven feet behind so that you don't step on his shadow"' ( $p$. 8).

In looking further at Japanese secondary student behavior patterns that can be traced to Confucian behavioral norms, Green and Hunter (1993) reported Japanese students believed instructors:

(a) should not address individual students, (b) should not acknowledge students outside the classroom, (c) should stay in front of the room and not approach students, (d) should not rearrange students' seating arrangement, (e) should lecture or read while students listen, and (f) should teach to the exam (p. 11).

Anderson (1993) supports this by noting that "Students rarely initiate discussion, seldom ask questions for clarification, seldom volunteer answers, and only talk if there is a clear cut answer to a question" (p. 102). He further states that these communication behaviors are not only relegated to the classroom, but reflect the socialization process of how children are raised in society leading to the same kind of interaction throughout the whole of Japanese society. Even when Japanese students are given an opportunity to offer criticism, they often back away from the situation and generally choose not to interact in a face to face manner. In a case study by White (1990) looking at the behavior of twelve Japanese university students in a summer writing program, it was noted that when given the opportunity to critique the course, Japanese students refused to directly criticize the course or the teacher. White states, "Although they are astute critical consumers of goods and services, Japanese will avoid face to face criticism, so eliciting student views directly was not likely to be successful, so we 
resorted to less direct means" (p. 23). This is not surprising. Like students in the Tokugawa era, today's students are well aware that within each rank and among the members of a rank, not only is there correct behavior, but also proper times for direct and indirect behavior. Therefore, throughout a student's entire educational process, he/she accepts, expects, and even depends on the teacher to be superior while learning the appropriate ways of behaving in deference to the situation.

In a case study on operating a virtual learning environment (VLE) in Japan, Holmes provides an example of how a Japanese high school teacher views his role in the classroom. He states, "In the Japanese system, control is very important. Students are controlled in how much they learn and what they learn, how they learn it, and how fast they learn it" (Holmes, 1999, paragraph 27). Moreover, as the student matures, the relationship between teacher and student becomes even more dependent. As alluded to by Hiraga (1998), the bond between the teacher and student is stronger than the bond between the parents and the child. This idea is illustrated in the following Japanese proverb: "Shi wa sanze no chigiri, oya wa isse no mutsubi." meaning, "The bond between the teacher and the student lasts from the former world to another world through this world, but, the caring between the parent and the child lasts only in this world" (Hiraga, 1998, p. 15). Through the above authors, it is clear that the influence of the Confucian element of acting according to expected behaviors between social ranks, is still flourishing in contemporary Japanese education.

Another element, rewared over effort, important in times of Confucius and the Tokygawa era, is also stressed in contemporary Japanese student behavior and complements the first element previously mentioned. Confucius 
believed that, regardless of one's birth and/or given ability, if the student persevered in his studies he would be positively rewarded, i.e., reward over effort with the possibility of upward mobility to a higher class. This can be traced back to the Tokugawa era. Slote and De Vos (1998) state that during that time,

In Japan, while the movement between social classes was indeed difficult, there was considerable mobility and rise and decrease of wealth within the classes of samurai, farmers, merchants, and artisans.

Within family groups there could be continual hope for change of fortune and for seeking opportunity for family betterment through individual effort (p. 111).

Indeed, we can observe this today in the almost universal way, regardless of ability, that Japanese raise their children. As reported in popular literature, Japanese view newborns as pieces of clay - each starting out alike, none smarter or dumber than another - to be molded at home and in school. Lord (1987), states that children in Japan are conditioned to become strivers, people who will work diligently in groups and show respect for leaders. Reward over effort, however, comes only by hard work. According to educational researcher, Diane Ravitch at Columbia University, "American parents believe their kids will get ahead if they're smart. Japanese parents believe kids will get ahead if they work hard" (as cited in Lord, p, 60). Working hard involves being in attendance all 225 days of the Japanese school year; the longest school year in the developed world. Stapleton (1995) comments on this by noting that, At 225 days per year, the Japanese school year is one third longer than the American school year. The implicit underlying belief for such a 
long school year is that more time in the classroom results in more effort and greater rewards" (p. 14).

To counter-balance the strict ranking system within society, Confucius believed that education should also be egalitarian thereby encouraging students to compete for the highest positions, preferably government positions. Regardless of physical or mental challenges, reward over effort would enable the students to succeed. In times of Confucius, individual differences in either the physical, mental, or emotional areas were not considered to be grounds for providing specialized education. In considering Confucian attitudes of reward over effort Slote and De Vos (1998) delcare, "The faith in the possibility of ordinary human beings' becoming awe inspiring sages is deeply rooted in Confucian heritage, and the insistence that human beings are teachable, improvable, and perfectible through personal and communal endeavor is typically Confucian" (p. 8). In contemporary Japan these views are still the norm. This statement is supported by the fact that while there are special schools in Japan for students with profound mental and/or physical challenges, in the average Japanese public and private school there are no special classes for students with less-profound or individualized needs, for example, students with learning disabilities or minor physical handicaps. Japanese believe that both individual determination and group work will overcome any difficulty a student may have. In a 1987 U.S. government research report on contemporary Japanese education, Leetsma (1987) stated that,

The Japanese believe that hard work, diligence and perseverance yield success in education as well as in other aspects of life. A certain amount of difficulty and hardship is believed to strengthen students' 
character and their resolve to do their best in learning and other important endeavors (p. 3).

In Japan, competition is encouraged thereby stressing reward over effort in all aspects of education. Without a doubt, competition in Japan can be observed at every corner - among students, parents, schools, after school cram schools, also known as juku schools, and also among districts and prefectures. For students, one of the greatest rewards over effort would be moving up to a higher-ranking school. Acceptance at a prestigious school reflects on the entire family, and often the measure of a good parent is the level of interest taken in the child's exam preparation. Japanese mothers are extremely aware of how much the effect of attending a top ranked school will have on their child's future. Competition starts early with students competing to pass entrance examinations beginning in pre-school or private nursery schools. The severe competition, however, can have negative effects on both parents and children, and in some cases, is fatal. For example, in November, 1999, a Japanese mother murdered a neighbor child because she passed an extrance exam that the mother's child failed. According to the Mainichi Daily News, Mitsuko Yamada told police she killed 2 year-old Haruna Wakayama because she had passed an entrance examination to a presitgious universityaffiliated kindergarten, wheras Yamada's 2-year-old daughter had failed the same test. Unfortunately, this type of pressure plagues parents and students throughout their school life. Howarth (as cited in Holmes, 1998) noted that, as entrance exams are usually mutually exclusive, it is essential that students have a very realistic idea about their rank which will help them choose the best school for their position. This is suppose to level the competition but 
students continue to compete fiercely through the entrance exam system. There is a price, however, to be paid for all this competition. As reported in popular literature,

According to a survey conducted in 1989 by the Japan Broadcasting Corporation, it was found that out of 15,000 Japanese elementary school students between the ages of nine and twelve, $34 \%$ don't sleep well because of worrying about junior high school and $25 \%$ feel uncomfortable at home because of parental pressure to perform well in class (Business Tokyo, 1990, 22).

As the child grows, competition increases and juku school becomes the order of the day. These after-school cram schools, designed to help students pass entrance exams, are also ranked according to the place where their graduates get accepted. As reported in popular literature, "Nearly three-quarters (71\%) of elementary and junior-high-school students attend juku or have tutors according to the Ministry of Education. By high school that figure jumps to $80 \%$ (Shoji, 1990, p. 23).

Even though there are very few chances for students to move to a higher social rank, the best way would be to pass the entrance exam of a prestigious university - a prime example of reward over effort. This would guarantee even the lowest social member advancement in society. In her book on Japanese society, Chie Nakane (1992) indicates that,

Going to a university, and specifically to a good university, is accepted as the prime prerequisite for upward mobility. The rank of the university from which [one] has graduated more or less determines the range of an individual's activities, the accessibility of certain levels of 
status and the degree of success [one] may expect for the rest of their life (p. 115).

In addition to parents, teachers and staff are also aware of the importance of reward over effort in relation to the Japanese entrance examination system. Not only does the success of the student passing an entrance exam to a prestigious school affect the students' futures but the perceived status of the school where the student prepared for the exam. Dore and Sako (as cited in Holmes, 1998) support this idea and say that, in the public sector, the ranking of a school is determined by those who leave it. For example, the high school that sends the most students to Tokyo University will rise to the top of the ranks. As indicated by Kuroda (1995), “After the entrance examination season every year in March, magazines report how many students from each high school passed the examinations of famous universities. They report even the rankings of high schools based on these numbers" (p. 7). She further remarks that those students who passed entrance exams for prestigious schools sometimes have their names printed in the newspaper. This, in turn, affects the next class of students because, if they can get accepted to even better schools, it determines the fame of both the school and teachers who work there. Therefore, according to Kuroda (1995), school-wide emphasis on positive performance and reward over effort is nationwide. Indeed, severe competition will most likely continue to be emphasized in the future. While expressing his opinion on current school reforms, Hashizume (1999) advocates that students should be able to choose which school to attend regardless of where they live. In addition he states, "This should lead to greater competition between schools and, consequently, improved levels of education" 
(p. 5). This remains to be seen but what is clear is that the Confucian element of reward over effort continues its influence in the Japanese educational process.

In the next Confucian element, instead of developing arguments and challenging acclaimed doctrine as Socrates did, Confucius advocated memorizing the wisdom gained from studying the classics. In a study of Japanese learning based on selected proverbs and metaphors, Hiraga (1998), a Japanese national, notes many similarities between contemporary Japanese learning via memorization and Confucianism. She quotes the Master saying, "Things old are important to study", and as the proverb from the Analects of Confucius goes, The Master said, He who by reanimating the Old can gain knowledge of the New is fit to be a teacher"'(p. 16). For Japanese, to follow the master is to imitate and memorize what the master offers as the model be it a physical skill or mental exercise. Hiraga (1998) further quotes Confucius, "The Master said, to learn and at due times to repeat what one has learnt, is that not after all a pleasure?" " (p. 14). Therefore, memorization still is a major method of learning in contemporary Japanese education. This can be observed in many aspects of Japanese "training" even in the traditional Japanese tea ceremony where there are no textbooks for advanced learners. Hiraga (1998) says that students must observe the master carefully, imitate and repeat until the master says they have passed the test.

Historian and Japanologist, Edward R. Beauchamp (1991) also acknowledges this phenomenon of extensive use of memorization in Japanese educational settings stating. "The Confucian legacy stresses the efficacy of memorizing the classics, and a number of scholars have pointed out how deeply inbred this approach seems to be in the Japanese psyche" (p. 39). 
Memorization is utilized with both the textbook and the lecture method of teaching. In a report published by the U.S. Department of Education describing teaching and learning in contemporary Japan, Antonoplos (1986) states that the Japanese learning paradigm is characterized by, "A lecture method oriented toward the transfer of factual information and the elements of solution rather than creative discovery and general problem solving strategies" (p. 52). This idea is exemplified today in Japanese college students' preference for memorization of the textbook over discussion. In short, opinions and creativity fall outside the domain of memory. To support this view, Beauchamp (cited in Stapleton, 1995) states that, "In modern Japan, memory work, as a legacy of Confucianism, continues to be used as an entrenched approach to education" (p. 15). Apparently the U.S. Office of Educational Research and Improvement agrees. In referring to Japanese education, according to their report authored by Leetsma (1987), "Repetition and memorization continue to be important in the learning process, particularly in preparation for the arduous and important high school and college entrance examinations" (p. 3). Interviewed by Holmes (1999), a Japanese teacher defends the memorization method and states, "With no time and so many students, the Japanese system is necessarily a teaching of knowledge rather than a discovery of knowledge by the students"(Holmes, 1999, paragraph 27).

Directly connected to the rigors of memorization, the next Confucian element of using books as the primary source of knowledge with the challenge to memorize that knowledge also continues to be the norm. It is realistic to say that, with a $99 \%$ literacy rate, book learning remains the cornerstone of Japanese education. In fact, in studying subjects from mathematics to languages, 
knowledge and subsequent examination questions from a predetermined book list continues to be the accepted policy. Indeed, books are the primary way students learn the centralized curriculum that is approved by the Ministry of Education, Science, Sports, and Culture (Monbusho). Horio (as cited in Gorsuch, 1999) states that, "In the Japanese system, Monbusho creates a list of 'approved' textbooks for all courses taught in secondary schools" (p. 7). Gorsuch (1999) concurs and found that in examining secondary textbooks for English classes, the [Japanese] National Institute for Educational Research states, "All secondary schools in Japan are required to use textbooks in the classroom teaching of each subject and all textbooks used in school must be authorized by Monbusho" (p. 7). In addition to secondary texts, all Japanese children are trained to be able to read, write, and do mathematics according to a curriculum that uses Monbusho approved texts, complete with standardized exams. Furthermore, most Japanese teachers use the Ministry-approved teacher guidebooks that accompany the text to ensure standardized instruction. Schoppa (1991) notes that, "This central curricular control tends to have a dampening effect on creativity because the factual orientation of the curriculum and textbooks encourages teachers to emphasize learning by rote" (p. 56). As stated by Kuroda (1995), one of the teacher's main duties is to see that students stay above the nationwide standard and with many classrooms averaging $\mathbf{4 0}$ students, teachers sometimes have to neglect brighter students in order to concentrate on keeping less talented students above the standard. Learning by rote through the use of textbooks levels the playing field and unfortunately, those students who do have sparks of creativity, are not encouraged to express it because it will detract from the memorization of facts, create difficulties for the teacher, and cause social 
disharmony among class members. Basically, books are used as utilitarian devices and not as creative devices, containing facts that one can remember. Clearly the Confucian elements of memorization and knowledge from textbooks is still advocated in contemporary Japanese education.

Finally, the last Confucian element which advocates the importance of examinations, continues to separate students into ranks and influences their future. Van Wolferen (cited in Stapleton, 1995). states that, "Examinations are a natural outgrowth of Confucian thought. First and most importantly, they promote virtues such as diligence, persistence, and memory, all Confucian strongholds" (p. 15). This can be related back the first principle of social harmony through rank and the proper behavior within that rank. Within each level there is a top and a bottom, and like tea leaves floating to the top, it is natural to want to reach the highest point within one's rank. Rigorous examinations allow for structure within each rank and also provide the motivation for students to reach the top of their class as students believe that perseverance will be rewarded through movement to a higher rank. Schoppa (1991) expounds by saying, "In a nation which assigns social status and employment prospects largely on the basis of where one went to high school and university, these examinations exercise enormous influence over the content of what is taught in Japan" (p. 57). Examinations are based on a Monbusho-approved textbook that is used by the teacher as lecture material. Consequently, a nationally accepted classroom procedure is for the teacher to lecture from the textbook, make sure the students know which facts to memorize, and administer an exam that will test students' memories of the facts. In his chapter on Japanese educational reform, Schoppa (1991) concurs by acknowledging that, "In the entrance exam, attainment is more 
important than aptitude," consequently, "Secondary teachers tend to teach to the test rather than to inspire their students to think" (p. 57).

A research report by Hoke (1984) that surveyed the Japanese educational system, illustrates the design of this type of "examination" classroom which is almost exclusively lecture-driven based directly from textbooks. She states that, Classroom instruction consists almost exclusively of lectures by the teacher, which are drawn directly from the textbooks. Most teachers design their lectures with only entrance examinations in mind. Instructional independence from exam preparation is rare and is not necessarily welcomed by the students, who want to pass the entrance exams. Debate and class discussion is not part of the regular instruction - instruction almost entirely by lecture is a thoroughly entrenched pattern (p. 8).

As a result of being members of basically a homogenous culture, parents, indeed, the entire community which possess the same fundamental values and goals, instill these Confucian educational elements into students from their earliest days. It is no wonder that when students reach the university level their preferred method of learning is not through discussion and creativity but through regurgitation of previously learned facts for the purpose of passing exams.

The Influence of Confucianism on Japanese Junior Colleges

The Japanese educational system is considered egalitarian for men and women, however, paths to higher education chosen by each gender greatly differ. For example, at the beginning of the 1990's it was reported by the Foreign Press Center (1991) that, " $22.2 \%$ of female high school graduates went on to 
junior colleges and $15.2 \%$ entered university while for men the ratios were $1.7 \%$ and33.4\%, respectively" (p. 11). Like the Tokugawa era, attitudes of today's parents have a significant effect on women's choice of educational path as parents are more likely to encourage a son, rather than a daughter, to enter university. "Junior colleges are designed to develop the abilities required on the job and in everyday life" (Foreign Press Center, 1995, p. 17). Consequently, junior college education for women often stresses a liberal arts curriculum with an emphasis on basic skills that are needed in an office environment plus, as in Tokugawa Japan, domestic courses in household management and/or the arts. Graduates from junior college are most likely to find a job in a clerical position at a bank, in a hotel, or other medium-sized company with many resigning when they marry. The Foreign Press Center (1991) reported that the average number of years of continuous employment for women is 7.2 years (p. 16). In a word, a junior college liberal arts education is seen as a stepping stone to a clerical job in a company, preferably one with a good reputation as well as a sufficient number of single men as prospective husbands. From the above, it can be surmised that the influence of Confucianism in the Tokugawa era with its implicit social behaviors, continues to influence students' choices of educational institution as well as their perceived future successes in life.

In summary, inherent in the traditional Japanese educational system are Confucian elements that continue to influence the methods of education. Operating within a teacher-centered environment, these elements include (a) appropriate behavioral norms for each member within their social rank, (b) reward over effort, (c) use of memorization as a major learning technique, (d) reliance on textbooks, and (e) use of examinations. By the time their school career 
is finished and their work career begins, Japanese students have learned to endure intense competition, long hours, and strict discipline, all qualities needed to do battle in corporate Japan. Following this discussion on the influence of Confucianism in the Japanese educational system, the next section constitutes an overview of the influences of importing technology into Japan both from China and the West.

\section{Chinese and Western Technological Influences in Iapan}

Historically, Japan has looked to the outside world, especially to China for improvements in Japanese technology and society. Even though earlier envoys into China between 413 and 502 were successful, systematic large-scale imports accompanied by institutional changes started in the 7th century during the $T^{\prime}$ ang dynasty. During this time, Confucianism occupied a central position in Chinese society with Confucian doctrine guiding the larger political framework consisting of a central government with a hierarchical bureaucracy, administrative codes, and civil examination system. Beginning in 630, for 265 years, this framework along with Chinese technology was exported to Japan via diplomatic missions between the two countries. Overall, 15 out of 18 missions were successfully sent to China with the eventual result being a full-scale adoption of the structure of Chinese learning "without significant alteration of its [Japan's] intellectual and institutional characteristics" (Sugimoto \& Swain, 1989, p. 29).

Importing ideology and technology into Japan has a history of starts and stops. After almost three hundred years of Chinese influence, at around the 9th century Japan entered a period of semi-isolation which continued through the 14th century. Even through this period, however, Chinese culture still had 
considerable influence in Japan but other new explorers and traders from the West were sailing to Japan's shores. Around the middle of the 15th century, Portuguese traders and Jesuit missionaries arrived in Japan bringing both new technology in the form of guns and new ideology in the form of Christianity. Both were short-lived, however, as Ieyasu Tokugawa, head of the Tokugawa government, renounced the gun in favor of the traditional Japanese sword and advocated Confucianism as the favored ideology over Christianity. Thus, at the instruction of the Tokugawa government, around the beginning of 1639, Japan once again isolated itself from the outside world. Japanese citizens were prohibited from overseas travel, and those already abroad were barred from returning home on penalty of death. With the exception of limited contact with Dutch traders at Nagasaki, Japan remained sealed for over two hundred years. In 1853, Commodore Perry and his Black Ships arrived in Tokyo Bay and reopened the country through a series of treaties permitting trade and technology exchange with the United States. One significant result of the treaties was educational reform, the first occurring in the early Meiji period around 1868 when Meiji reformers sought to borrow the best of several Western educational systems and adapt them to Japan. Following that, the official Japanese education ministry was established. Aramashi reports, "In 1871, the Monbusho was established, and in the following year, a modern system of national education was introduced" (1997, Japanese Ministry of Education, Science, Sports, and Culture, paragraph 1).

Once again, in the $1870^{\prime}$ s, a Japanese mission was sent abroad to gain expertise but instead of China, the mission went to North America and Europe to study their educational systems ultimately exporting and copying ideas and 
administrative functions from several countries. For example, from France the Japanese borrowed techniques to operate a centralized administration system and state-run schools, from Germany came the system of higher education, from England came the character-building prep schools stressing moral discipline, and from the United States came the model for elementary education and an interest in vocational education. In addition, Western textbooks and teachers were brought back to Japan to be utilized in Japanese schools. But despite these efforts, traditional Japanese education methods based on inherited Confucian education practices utilizying memorization, were still practiced. In fact, Western texts and ideas were often not understood as students were instructed to memorize passages without discussing the meanings of the passages. In addition, Western social thought introduced by foreign teachers accompanied by texts centering on individualism also threatened the centuries of Confucian thought now ingrained in Japanese society and,

Steps needed to be taken to recapture the essence of such traditional values as Confucianism which taught that the meaning of social life lay in cultivating relationships among members of society built on trust, a fundamental sense of one's humaness, and a commitment to loyal action on behalf of others. This should be reintegrated as a nutritive value into modern Japanese life (Beauchamp, 1991, p. 28).

Even more than the resistance to Western textbooks and teachers being imported to Japan, the attempted educational administrative change which called for the local people to finance educational reform had severe repercussions, eventually resulting in a back-lash against modernization, specifically imports from the West. By 1875 , the idea of Western individualism 
was found not to be suitable to the Japanese environment and reform efforts were slowed down. In 1890, an Imperial Rescript on Education promulgated by Emperor Meiji was initiated. This document, “Paraphrases the acceptable and highly moralistic Confucian virtues to which all loyal Japanese were expected to adhere and sets down the principles from which much of the militaristic and ultranationalistic emphasis in education developed"(Beauchamp, 1991, p. 29). This document combined with the backlash against the West, contributed to a rise in nationalism and subsequent militarism in the $1920^{\prime} \mathrm{s}$ and $30^{\prime} \mathrm{s}$, eventually leading to Japan's involvement in World W ar II (WWII). It wasn't until after the war that Japanese educational practices embraced western ideals that had been introduced almost 90 years before. The next section will synthesize post-WW II Japanese education reforms.

\section{Post-war Japanese Educational Reform}

For about ten years after the war, the American Occupation Forces dictated education and social reforms. Occupation forces were faced with the challenge of transforming the prewar educational ideology of the Japanese, which included an emphasis on Confucian ethics such as filial piety, correct behavior within a rank, group harmony, and obedience to the emperor. As a result, the Fundamental Law of Education promulgated in 1947 by the Occupation, was adopted.

This law "[which] represented a 180-degree change from the 1890 Imperial Rescript, declared that 'education shall aim at the full development of personality, striving for the rearing of the people in sound mind and body, who shall love truth and justice, esteem individual value, respect labor and have a deep sense of responsibility, and be imbued with the 
independent spirit, as builders of a peaceful state and society"" (Beauchamp, 1991, p. 31).

In addition to educational reform, technology reform was also introduced by the Occupation forces, for example, improvements in building construction, energy, and auto technology were all transferred to the Japanese who adapted them to fit their culture. Consequently, Japan experienced a distinct paradigm shift from historically looking to China for both social reform and technological guidance to adopting, copying, and transforming Western ideology, specifically American technology, to fit the Japanese lifestyle. As a result, the current education system, like an upside down cake, has many layers: the bottom layer representing Japanese historical, cultural, and social values with the second layer being an overlay of centuries of borrowed Chinese technology and Confucianistic ideology, and the top layer constituting the recent post-war American technological influence .

Post-war Japanese education focused on providing educational programs that would ultimately provide good workers for rebuilding Japan; however, that focus started to change in the 1970s. "Falling back on its traditional practice of actively seeking outside advice, Japan invited the Organization for Economic Cooperation and Development (OECD) to send a team of education experts to ad vise it [Japan] on future directions" (Beauchamp, 1991, p. 43). The OECD report praised the role of education in Japanese industrial development but criticized the conformist nature of the Japanese system, overcentralized control, and overemphasis on egalitarianism. The 1971 OECD final report encouraged the Japanese to devote more attention to develop students' personalities, create more free time, diversity, and creativity in both curricular and extra-curricular 
activities. These recommendations were not totally lost on the Monbusho. According to a report by the National Institute for Education Research (NIER), "The rationale of educational policies and strategies changed from one of rigid manpower planning to a flexible human development system" (NIER, 1991, p. 17). Thus Japanese educational policies, attempting to meet major socioeconomic changes during the early 1970 s, strived to move from a stage of quantitative expansion to qualitative fulfillment.

While reforms were moving forward, the first oil shock hit Japan in 1973 causing the economy to halt and the nation to experience a brief period of negative growth. As a result, the government was hard pressed to continue many of its education reforms and had to find ways to reduce its financial support. In addition to the economic crisis, social problems were increasing, for example, the birthrate began declining and school dropouts and school violence increased considerably. Even during these changing times, the influence of Confucianism was still considered an integral aspect of Japanese education. In commenting on the problem of dropouts and school violence Nishimura, (as cited in Beauchamp, 1991) states, "The actions of this....tiny minority have shocked adult Japan because 'their behavior violates the most fundamental code of Confucian-influenced traditional educational values - namely, respecting and obeying teachers'" (p. 45). In addition to the social and economic problems of the 1970 's, the Japanese government was getting ready to make sweeping changes in the educational system by the introduction of western computer technology into the schools. Holmes (1999), declared that the introduction of microcomputers in education and into society goes well with the Japanese preoccupation with catching up with the West - a preoccupation left over from the Meiji era. 
Unfortunately, no one knew how western technology would meld with the entire educational process as influenced by Confucianism.

By the late 1970s, amidst economic and social turmoil, the Japanese government made a series of reform statements, including technology reforms, calling for change in the education system. "Computers entered schools in Japan as part of a series of reforms proposed in the early 1980 s in an attempt to achieve a freer and more flexible educational system" (Holmes, 1998, p. 184). However, according to Watanabe (1990), most were used by researchers experimenting with Computer Assisted Instruction (CAI) in university laboratories. He further states that because computers were not part of the official Monbusho curriculum, "Computers have not been treated as a part of the teaching content except for the curriculum of vocational upper secondary schools, so only a limited number of schools have been using and giving instruction about computers" (Watanabe, 1990, p.1). More reforms would be needed if computers were to be utilized into mainstream Japanese education. Lee (cited in Holmes, 1998) states that in systems that are uniform in content and teaching methods, reform is a difficult process. Because Japanese education was uniform in both content and teaching methods, reforms would face difficult challenges; however, that did not discourage the Japanese government. In 1984, a new advisory body called the Ad Hoc Council on Education was created. "During its three-year term, the Council held 668 meetings, 14 public hearings in different regions of Japan, ard as in historical times, sent seven missions to 13 countries in Asia, Europe, and North America to study educational practices" (NIER, 1990, p. 70).

“In 1987 after three years of deliberation and extensive research, the Council presented three basic points for educational reform which are 
directly or indirectly related to technology: (a) creation of a lifelong learning system, and (b) internationalization, and (c) increase of information media" (1996, Japanese Ministry of Education, Science, Sports, and Culture, paragraph 1).

Concerning the second reform point of internationalization, Schoppa (1991) states that council members tried to achieve a balance between the goals of traditionalists who wanted to return to traditional Japanese values, and internationalists who wanted schools to nurture an ability to understand and appreciate diverse cultural values found in the world. Clearly there was a tension between the two groups, the main problem being that Western individualism threatened the Japanese emphasis on being responsible to the group, a dichotomy based on the conflict between Western and Confucian values. With regard to the council's third reform statement on information media; however, there was much less conflict and more action. On their website, Monbusho states,

In the area of elementary and secondary school education, for the school system to cope smoothly in an increasingly information oriented society, Monbusho is promoting the systematic installation of computers designed for school use, providing and improving software, and providing teachers with opportunities for training and research (1997, Japanese Ministry of Education, Science, Sports, and Culture, paragraph 1).

In 1987, even though the Monbusho mandated an increase in computers in schools providing the subsidies for such installations, as of 1993 there were still fewer than fifty computers in each upper secondary schools This did not, 
however, deter the reform movement, in fact the Japanese government encouraged even more technology reforms both in the field of education and in various government sectors. In 1994, the Japanese government published an article on trends and development declaring that the Ministry of Education, Science, Sports, and Culture,

Is working to accelerate the shift to an information-oriented society in the field of education. In fact, the entire government sector is now moving in the same direction. The Ministry of Posts and Telecommunications aims to establish a fiber-optic communications network linking schools, libraries, and other facilities throughout Japan by the year 2000, while the Ministry of International Trade and Industry has proposed a plan to promote the use of advanced information technology, especially in the fields of education and research and in libraries (1994 Japanese Ministry of Education, Science, Sports, and Culture, Section 1, paragraph 8).

Also in the same report, new targets for computer installation were introduced calling for the installation of computers in elementary schools to be 22 per school, 42 each in both lower and upper secondary schools, and eight computers in special education schools with the student/computer ratio being 1:2, 1:1, 1:1, respectively (1994 Japanese Ministry of Education, Science, Sports, and Culture, Section 2, paragraph 4). In addition to computer installation, the government provides subsidies for large-scale remodeling projects involving the installation of computers into surplus classrooms that were available as a result of the decreasing in student population. As prescribed by the reforms from 19871994, the rate of increase in computer installation in Japanese schools in 1987 in 
elementary, lower secondary, upper secondary, and special schools was approximately $12 \%, 35 \%, 92 \%$, and $50 \%$, respectively. By 1995 , the rate of increase in elementary, lower secondary, upper secondary, and special schools was approximately $85 \%, 100 \%, 100 \%$, and $98 \%$, respectively.

As of 1997, Monbusho had the same technology targets in 1994 for computer installation in schools but, for the first time, in 1997 Monbusho called for additional telecommunication measures to be implemented such as promoting the effective use of the Internet for practical research, promoting a school networking system, the systematic installation of software, and research examining the relationship between an advancing information society and education. In addition, Monbusho stressed that information-related curriculums for elementary, lower secondary, and upper secondary should be carefully considered and possibly standardized for each level. Finally, Monbusho also emphasized that a revised teacher training curriculum for an informationoriented society should be considered (1997, Japanese Ministry of Education, Science, Sports, and Culture, 1(4), paragraph 3).

After these recent directives by the Monbusho, Internet connections in colleges and universities soared with many schools getting connected within the past two years. Not only have schools connected to the Internet, but office and home Internet use has also skyrocketed. According to Linc Media, Inc. (1998), in 1997 and 1998 the number of Internet users in Japan grew at annual rates of 73\% and $57 \%$, respectively. By the end of 1999, AccessMedia, as published by Linc Media, Inc. (1999), projects the number of Internet users to grow an additional $44 \%$, reaching 20 million [out of approximately 125 million] individuals. It is clear that the Japanese government plans for the Internet to play a pivotal role in 
the future of Japanese education. Monbusho stated in a report published by the National Education Research Center (1998),

During 1998-2001, all the junior high, high, and special education schools will be on-line with the Internet, and during the coming six years from 1998-2003, all the elementary schools will be connected to the Internet, therefore all the expenses, communication fee, Internet fee, etc., shall be processed by local issuing tax (p 15).

In conclusion, the previous two parts of this literature reviewed how Japan imported technology from China and the West followed by a look at postwar Japanese educational technology reforms. With the advent of the Internet in Japanese homes and schools, what remains to be seen is how this new technology will be integrated into the current cultural and social system - a system still under the influence of Confucianism. Holmes (1998) comments on this situation by stating,

A brief look at the process by which ideas and technologies have been absorbed through the ages suggests that new technologies and innovations are generally first borrowed in their entirety but then undergo a period of adaptation to Japanese needs and circumstances (p. 183). With this in mind, the next section investigates research findings on Japanese attitudes toward technology in Japanese education, specifically use of computers and the Internet.

\section{Research on Computers in Japanese Education}

As a result of the Internet being used in Japanese schools for only a few years, a review of the literature in both English and Japanese revealed few 
published research articles specifically focusing on Japanese attitudes toward web-based instruction compared to traditional Japanese ed ucational methods. However, from the mid-1980's, there were many Japanese research articles published on Japanese attitudes using computers. The reader should be aware that Japanese research, through western eyes, often falls under the heading of reported observations of behavior without any theory to support the conclusions of the researcher. In comparing Japanese and British research reports, Holmes states, "UJapanese] Writers have published papers based on anecdotal and observational data. They do not tend to carry out as structured research as their British counterparts" (1998, paragraph 24). With all due respect to Japanese educators / researchers, the reader should assume the Japanese research studies presented here were conducted to the highest standards of the Japanese research community and will be viewed as quality research studies. Every effort has been made to thoroughly describe each research project so the reader will have a complete understanding of the process involved and the conclusions presented. Following this brief introduction, two sections will follow. The first section will chronologically examine Japanese attitudes towards using the computer in various educational settings. This is followed by an examination of research articles discussing how the Internet has been used in Japanese education.

In March 1984, a Japanese research report presenting the attitudes toward computers was published. Yoshimori (1983) describes a study using a crosssection of 379 subjects divided into six groups from the Hiroshima University system and government employees of Hiroshima City. The purpose of the study was to evaluate the social-psychological viewpoint of Japanese attitudes towards human-computer relationships. The study took place at the Social Psychology 
Laboratory of the Education Department of Hiroshima University. Data collection consisted of a 17-item survey using factor analysis and multivariate analysis as the statistical methods. Survey questions centered around the following themes: (a) personal feeling toward computers, (b) attitudes towards computerized society, (c) personal experience using computers at school and at work, (d) degree of involvement with computers, (e) knowledge about computers, (f) desire to study about computers, (g) effect of computer use on others in the same environment, and (h) effect of group response to questionnaire. Results revealed the following: (a) males generally had more favorable attitudes than females toward the computer; however, in the junior high population there was no difference in attitude between males and females, (b) adult workers had more favorable attitudes than junior and senior high school students, (c) subjects with previous computer experience responded more favorably than those who had no experience, and (d) correlation between attitude and knowledge of computers was significant.

Oda (1985) also researched the attitudes toward computerized education. The study examined attitudes of 555 subjects ranging from 2 nd year university students through post graduate students and teachers at the Educational Technology Center of Mie University, Mie, Japan. Using a 35-item survey, a summary of the results indicated that the more subjects were interested in studying the computer, the more affirmative and aggressive they were toward the introduction of computers into school education. In addition, regardless if the subject had a positive or negative attitude toward the introduction of computers into school education, subjects felt a negative affect would be a weakening of human relations and a weakening of the current formal administration style to 
which they had become accustomed. As a result, Oda concluded it was important to put more emphasis on why education should be computerized rather than how to use a computer in school.

Another Japanese study (Takayama, 1988) duplicated Oda's study (1985) where student attitudes toward using the computer were analyzed. Takayama researched the general attitudes of 127 students enrolled in the Department of Education (DOE) at Shimane University, Japan. Data collection consisted of using Oda's survey of 35 questions in their original form with questions being further divided into four thematic groups: (a) anxiety about using computers, (b) utilization of higher technology, (c) effect of computer utilization on educational administration and, (d) improvement of education. Statistical examination consisted of using cluster analysis for each item and between each group. Similar to Oda's findings, results for all four groups indicated that using the computer for education purposes reflected both positive and negative attitudes. On the positive side, $77 \%$ stated that learning how to use the computer is essential, $76 \%$ of respondents stated that teachers should be able to use the computer, $65 \%$ stated it is necessary to have a positive attitude toward new technology and $60 \%$ stated that learning of knowledge and technology should be done by computer. On the negative side, $81 \%$ of students felt using computers had an inhumane and uneducational effect on their education, $74 \%$ said computers did not respect man's dignity, 69\% said that the current [traditional] method of education was efficient, $66 \%$ felt that education would be ruined by computers, $64 \%$ felt that education would be abandoned by teachers, $76 \%$ said they felt a decrease of humanness when using the computer. 
Matsuda (1989) reported on a study that measured 108 Japanese female junior college students' attitudes toward computers after one semester of basic computer intruction. Using a 32-item survey followed by a factor analysis statistical procedure, results indicated that Japanese female junior college students did not demonstrate any significant change in attitude towards computers after one semester of basic computer instruction. Matsuda concluded that changes in attitudes for this particular population will not be affected by computer training only, but by computer education within the overall school curriculum.

In a study (Watanabe, 1990) using an opinions and attitudes survey of Japanese teachers, reactions were mixed with regard to using computers in the schools. Of a total of 954 vocational, technical, and college teachers, $32.5 \%$ stated that advanced technical equipment was too difficult to get along with, $47.2 \%$ were uncertain if computers harm relations between people, $33.6 \%$ stated that computers reduce humans to numbers, $55 \%$ said it would take too much time to learn how to use a computer successfully, and $19 \%$ stated computers can only be useful in a few subjects. Only $11 \%$ stated their way of teaching was positively affected when using a computer for teaching. Also, $42 \%$ of the teachers believed that children should begin to use computers at an early age, and $29.1 \%$ agreed that computers in schools enhance students' creativity. Lastly, $42.7 \%$ stated that computers help to teach more effectively, and $69.5 \%$ stated they did not mind learning about computers.

Nakata (1990) illustrates a study on attitudes toward using computers of 466 higher education Japanese students associated with Hiroshima Industrial University divided into five different groups. Using Matsuda's (1989) 32-item 
Likert-scale survey, the purpose of the study was to measure student attitudes toward the computer and how they viewed a computerized society in order to see how future courses related to information processing should be taught. The groups were (a) 84 students from the Literary Department, (b) 85 students from the Scientific Department of the four-year university, (c) 89 women's junior college students who had previous information processing courses, (d) 79 female junior college students who had not taken courses on information processing, and (e) 129 students from a technical college specializing in information processing. Analyses of responses was studied using factor analysis which divided the survey statements into five factors about attitude toward the computer: (a) loss of human nature, (b) development of personality, (c) active use toward the computer, (d) friendly contact, and (e) suspicious attitude. Of the five groups, results for factor 1 indicate that between $1.27 \%$ and $2.38 \%$ of students in groups $1,3,4$, and 5 felt a loss of personality using the computer while group 2 felt no loss of personality. Results for factor two indicate between $3.57 \%$ and $22.48 \%$ of students in all groups felt that personality was developed by making the best use of the computer. Data for factor three reveals for all groups that between $1.27 \%$ and $11.76 \%$ students have a positive attitude toward utilizing the computer, while for factor four, only the first group expressed $1.19 \%$ friendly contact with the computer. Details about factor five reveal a suspicious attitude for all groups ranging from $0.78 \%$ to $8.86 \%$. These results suggest, according to Nakata, as technical training advances, people will feel more comfortable using the computer. In the general education department, those students who have not studied information processing very often think that the computer will not play an important role in the development of human nature, and they have a strong 
tendency to have suspicions about using the computer. Furthermore Nakata states that even if students learn how to use the computer but don't see the necessity of using it, they will not feel comfortable using the computer. Nakata states that students should not only learn how to operate the computer but teachers should create a comfortable environment for learning about and using computer technology.

Continuing with her research, Nakata (1993) describes another quantitative research study on higher education student attitudes towards computers. As in her pervious study, she employed the same 32-item questionnaire (Matsuda, 1989), to 454 male and 18 female students at the Hiroshima Electrotechnological University and the Hiroshima Automobile Industrial College. The purpose of the study was to examine pre and post attitudes toward the computer for those students enrolled in a two-semester general education information processing class. According to the average score of the final exam of the first semester, students were divided into two groups: high score and low score group. Investigation of the pre and posttest questionnaire for each group was completed by the factor analysis method, dividing the survey items into five factors as mentioned in her previous study. As the students progressed through the year, their attitudes changed. At the end of the year, results for the high score group indicated that students understood the pros and cons of using the computer for educational purposes while the low score group were in between stages of having no knowledge of the computer and having an interest and trying to understand the computer. Attitudes of students for the high score group showed that if computer program language learning is the main part of the curriculum of information processing, it is difficult for 
students to feel comfortable with computers. For the low score group, attitude results indicated that the utilization of the computer will improve creativity and productivity which outweighs any perceived loss of humanness from using computers.

In 1996, the Japanese Government General Affairs Agency published a book outlining extensive studies on the comparison of attitudes toward information and computers between juveniles and parents. In one particular study that looked at the negative effects of the personal computer, the attitudes of 1,771 children aged 12-17 were compared with attitudes of 1,642 parents. Results show that $56 \%$ of children vs. $48.2 \%$ of parents thought it was difficult to use the computer, but only $9 \%$ of children vs. $17.1 \%$ of parents said it was troublesome to use the computer. $8 \%$ of children felt that the computer controls people and $16.2 \%$ of the parents agreed. Of the parents, $12.3 \%$ felt the computer was inferior to man while $9.3 \%$ of the children concurred. A very small percentage, $3.5 \%$ for children and $6.5 \%$ for parents, felt the computer was a troublesome tool and an even smaller percentage, $0.8 \%$ of children and $1.6 \%$ of parents though the computer was not reliable. With the exception of the feeling toward the difficulty of using the computer, these results suggest positive attitudes for both parents and students in using the computer. In a dissertation on a comparative study of computer use in Japanese and British classrooms, Holmes (1998) lists several studies that indirectly relate to user attitudes about use of computers in Japanese classrooms. For example, in discussing motivational characteristics of the computer, Norikazu (1987), Shinichi (1994), Hisao (1992), Takahiko (1992), and Ide (1994) (as cited in Holmes, 1998) all point to positive experiences for learners when using the computer. Explicit examples 
of responses are that computers make the classroom more fun, efficiency of studying increases because children are more willing to study, students produce interesting work by using the computer, students are positively motivated, and their listening ability increased (Holmes, 1998, paragraph 20). The next section will look at research articles that discuss how the Internet has been used in Japanese education which, in turn, could affect student and teacher attitudes toward the new medium.

\section{Internet Usage in Japanese Education}

There are a small number of research studies on how the Internet has been used in Japanese education. Koshigiri, Shinkei, Hongo, Teraguchi (1996) used a five-question survey to study how to develop Internet homepages and Internet education. Questions included the following: how often do you use the school server, what are the necessary conditions of school server, i.e., accuracy, speed, and volume of information, what is your preferred information access method, what educational info would you like to access via the Internet, what is your choice of information from the school server? Questionnaires were sent to 222 individual teachers with 94 teachers responding. These educators came from elementary, junior high, high schools, and special schools who had established home pages on the Internet. The respondents indicated the administration of information using the WWW server needs time and labor and, as the accumulation of information advances, more labor would be necessary. Consequently, it is necessary to study automatic access and responses by various kinds of robots. Finally, respondents questioned if the utilization of PC's in schools will really change education and would advance education endeavors in the future. 
In a different vein, Tanaka (1997), examined how the Internet could be used by first grade elementary children in an "open-school" activity - one that would be viewed by parents, local citizens, as well as the nation. Tanaka utilized a science project whereby children collected survey data on what families did with their used plastic PET containers, for example, plastic water and/or soda containers. Students used a five-point questionnaire to gather data and worked in groups to present their findings and exchange opinions. All information was posted on the class's homepage with children providing the necessary data. According to Tanaka, results showed that children realized that they were evaluated not only by the teacher, but by the entire community and nation. Tanaka surmised that this type of learning facilitated the open-school concept that the institution had been trying to establish.

As a result of eleven computers being installed in an elementary school in Itabashi Ward, Tokyo, another elementary teacher, Nobuo Hasumi (1998), reported on how the Internet could be used effectively in four-member group learning situations. At the end of his observations, he concluded that because the Internet has such a large volume of material, information can not be obtained within the alloted class time. Moreover, even though they were working in groups, many elementary students had difficulty reading the words and/or kanji characters on the site. Consequently, it was up to the teacher to preselect the websites and pages that were suitable for the children. Next the children couldn't use the Internet at their own pace. Instead, they had to get the information and print it and then give the computer to another group member. On a different note, however, Hasumi states that the Internet has a richness of information that can be accessed not only by Japanese but by citizens of the world. 
Sixth grade students in a Toyama City school learned how to publish a multimedia science project on the Internet. In an attempt to marry book learning with actual experience, their teacher Takito Totsuka (1998), reported on how this combination produced a synthesis of learning for the world to view via the Internet.

According to Totsuka, a "Breeder Committee" consisting of a group of sixth-grade students established a breeding pen for domestic chickens and completed a research project on the hatching process and growth of the chickens. One female student followed the chicks' growth using a digital camera. In addition, the students kept notes on the chickens' progress and eventually became quite attached to the young chicks. Then one of the chicks died and the students decided to make a picture book in memory of the chick. They made a slide show using a combination of pictures and videotape they had previously taken during their data gathering sessions. Another student became adept at using software and helped to create an animated picture book of their chickens. According to Totuska, results of this project showed a willingness for students to work together with groups assisting each other for a successful outcome with the final result being published on the Internet. Totsuka testifies that this project is a good example of how multi-media and the Internet can be used to support book learning.

In utilizing an older Japanese population, Holmes (1999) researched student on-line perception and identity. Over 100 co-ed Japanese first-year university students were asked to write how they perceived themselves on screen. Results showed students believe the Internet will have an effect on their lives. In addition, students said they expressed themselves differently, namely, 
being able to show their inner feelings which is not always possible in face-toface communication. According to Holmes, this suggests that, “Not only is the way of communicating changing, but the style or form of that communication may also be changing in response to the new opportunities for social engagement (1999, paragraph 15)". In another study by Holmes, Jussila, Arachi, \& Field (1999), 30 virtual learning environments (VLE) on the Internet were selected and evaluated for versatility of interaction. According to Holmes, a VLE is, "An interactive study system that is mediated by the Internet and can be used for both distance and classroom education." (1999, paragraph 8). Results showed that even though there are limitations to large-scale use of VLE's in Japan, VLE's are actively being produced for the Internet. According to Holmes, et. al, Japanese feedback on VLE's show that some are popular among ordinary people and that positive attitudes toward virtual learning are evident.

In conclusion, from the previous descriptions of research conducted on computers and technology use in Japan, it is obvious that more work is needed in various areas but specifically perceptions of learning and/or attitudes of Japanese of web-based instruction. The next section will compare and contrast Japanese educational methods and those used in web-based instruction. Japanese Educational Methods Versus Web-based Instruction

The next section will compare Confucian ideology as a foundation of traditional Japanese education, with principles of web-based instruction. Points to be discussed are: (a) roles of behavior between a traditional teacher-centered versus web-based student-centered class, (b) use of memorization as a major educational method in traditional Japanese classes versus use of higher cognitive skills in web-based instruction, (c) elements of motivation theory and self- 
directed learning as they relate to Japanese education and web-based instruction, and (d) aspects of communication found in traditional Japanese education compared to the effects of communicating with a diverse population found in web-based courses.

For our purposes, Khan's definition of web-based instruction will be used when comparing it to traditional Japanese educational practices. Khan (1997) states, "Web-based instruction (WBI) is a hypermedia-based instructional program which utilizes the attributes and resources of the World Wide Web to create a meaningful learning environment where learning is fostered and supported"(p. 6). In Japan, the recent introduction of web-based instruction has made teachers in Japan consider how web-based instruction could best be utilized. One area of concern is how Japanese students will adapt to this new mode of instruction after being educated in a traditional Japanese classroom. In other words, how will Japanese students who have been socialized along Confucian lines, adjust to web-based courses? In fact, does web-based instruction support the Confucian elements of education found in traditional Japanese education? Futhermore, what affect will individualized instruction found in web-based courses have on Japanese learning styles? Tung and Cheung (as cited in Holmes, Jussila, Arachi, \& Field, 1999) state that importing Western educational technologies into the Asia-Pacific area may face some obstacles. As a result, it is hoped that this study will act as a bridge to overcome such obstacles. Therefore, the first point of discussion is a comparison of the differences between student-teacher behavior in a web-based class versus student-teacher behavior in a traditional Japanese class. 
As previously mentioned earlier in this chapter, Japanese society and its educational system support the Confucian tenet of strict adherence to behavior according to social roles which includes distinct roles played by both teacher and student. To review, in a traditional classroom environment in Japan, the teacher lectures and the students listen. Use of class time is determined by the teacher, and small group or individual instruction rarely occurs. Interaction between teacher and student is minimal inside of class and almost nonexistent outside of class. This type of teacher-centered environment encourages passive learning, ignores the needs of individual students, and inhibits the higher cognitive skills of critical analysis and problem solving. But it does promote the memorization of facts in order to pass entrance exams, and previously mentioned research has demonstrated that this is what Japanese students have been socialized to expect from their educators. Kato, Takaura, and Ishizaka (1989) state that while there are a few schools in Japan that endorse individualized instruction, "In Japan, the traditional teacher-centered method of instruction is common, and there is little understanding of individualized instruction" (p. 8).

Web-based instruction, in contrast, sees more of a facilitative role of the teacher. Relan and Gillani (1997) state that, 'The teacher 'dethrones' him/ herself as the disseminator of information, and becomes a facilitator for finding, assessing, and making meanings from the information discovered from a variety of media" (p. 43). Lamb, Smith, and Johnson (1997) support this view of teacher/facilitator in their study of students using the Internet as a resource for project development. They mentioned that, "When we observed students...we noticed that the most successful learning experiences were those in which the teacher acted as a facilitator, paying careful attention to students and guiding 
them through critical stages of their projects" (p. 7). Owston (1997) states that the role of teachers in web-based instruction, "Has shifted from deliverers of instruction to academic guides and creators of learning experiences for students" (p. 30). Holmes (1999) demonstrates this in addressing differences in communicative strategies between teacher and student. In a research project involving 100 Japanese freshman students using the Internet as a learning tool for the first time, one student proclaimed,

When I was a third year student in my high school, I learned only grammar, no talking no communication. Teachers wrote words on the blackboard and students took notes. That was one-sided teaching. In those days, our English goals were to pass the university entrance examinations. That was not instructive for our English communication skills. But now, my English Communication Skills Course is very interesting. We use computers to make our homepages. We can ask questions and teacher responds in English. These many small communications could be the best class materials. A. S. (student initials)(1999, paragraph 14).

Another student in Holmes'(1999) study stated, “This English Communication Skills Course is not only student-teacher interaction, but also student-student interaction. Especially, the teaching style makes much communication and the class which use computer." M. N. (student initials)(1999, paragraph 15).These notions are a complete antithesis of how educators have been traditionally viewed in Japan, and a full paradigm shift in the relationship and behavior between teacher and student may be on the horizon. 
The second point of discussion is a comparison between the use of memorization in a Japanese teacher-centered environment versus the use of higher cognitive skills needed in student-centered web-based settings. In this regard, Reeves and Reeves (1997) discuss some basic pedagogical differences between web-based instruction and teacher-centered instruction, for example instructivist versus constructivist pedagogy. Basically, the former, which is practiced in a teacher-centered environment in Japan, is one where objectives are established and then sequenced into learning hierarchies. Reeves and Reeves (1997) state, "Learners are seen as passive recipients of instruction or treated as empty vessels to be filled with learning" (p. 60). In contrast, constructivists emphasize the importance of a combination of the learners' previous experience and current intentions mixed with a variety of learning resources in order to create a new learning experience. To be objective, for constructivists memorization does have its place, but in the context that it is chosen by the learner to be used as tool in constructing knowledge. The current methods of Japanese education do not support constructivist pedagogy nor the use of memorization to create knowledge but they do support instructivist pedagogy, with memorization of textbook facts being one of the most widely used teaching techniques in Japanese education. However, for web-based instruction, according to Relan and Gillani (1997), "The predominant source of content shifts from the textbook and the teacher to a more varied source of information." (p. 44). Reeves and Reeves concur and declare that higher cognitive skills are needed,

The learner should be responsible for recognizing and judging patterns of information, organizing data, constructing alternative perspectives, 
and representing new knowledge in meaningful ways.... When the World Wide Web is used by learners as a cognitive tool, the teacher is a coach or even a collaborator in the knowledge construction process (p. 62).

In utilizing web-based instruction, memorization is not an option, in fact, because of the changing nature of website material, a learner may experience a daily variety of information and material with different layouts. And for many Japanese students who have been conditioned to learn facts by rote memory with books that do not change, constructivist designed web-based instruction could completely disorient their learning processes.

In addition, web-based instruction demands individuality on the part of the learner, certain aptitude for knowledge construction, and self-monitoring of progress. Information on the web is in the form of a hypertext format that allows the user to determine his/ her personal sequence of content. This type of action falls out of the severe socialization process that Japanese students have been conditioned to follow. In fact, Collis and Remmers (1997) caution about using a web-based hyperlinked environment for cultures [like Japan] that advocate a hierarchical structure. They state that, "A hyperlinked environment emphasizing user choice may not be consistent with a hierarchically oriented culture (p. 88). Supporting this idea Sinclair (1998) states, "The student will now be faced with a multiplicity of choices as regards courses...this assumes that the student is well informed enough to make appropriate choices and impose a meaningful structure on his education" (p. 298).

Because the nationalized education system in Japan emphasizes passing entrance exams, Japanese students have very limited choices of elective subjects 
and even fewer textbooks to choose from. But with web-based instruction, students have a variety of choices consisting of content, time, feedback scenarios, as well as different forms of multimedia for expressing their understanding of the material. In fact, Hedberg, Brown, and Arrighi (1997) see multimedia aspects of web-based instruction inevitably acting as tools for complete individualization of the education process - one carried out both individually and in groups (p. 57). The person plays both a learner and knowledge constructor role with the eventual meshing of roles. Hedberg et al. (1997) believe,

The distinction between user and producer blurs with the ability on the Web to use applets to manipulate and re-present dynamic information. Essentially the user can create a personalized framework to access and manipulate Web information - potentially the Web becomes tailored as his or her own personal information system (p. 57).

In Japan, however, personalized education has not been advocated. In observing possible Japanese educational changes resulting from an on-line environment, McCarty states that, "On-line education requires a selfmotivated approach that is not demanded in the Japanese educational system where the teacher usually motivates through pressure on the students, who work together to support each other" (1999, paragraph 5). Considering the above discussion, two points emerge that could impact traditional Japanese learning methods. These points are self-directed learning through individualized instruction in a web-based course, and motivation factors that could influence students' performance in such a course. In order to better understand how these two issues relate to the current study, the third point 
for discussion is a review of motivation theory followed by self-directed learning theory.

\section{Motivation and Self-directed Learning Theory}

The overall goal of basic research on motivation is to understand human action. According to Atkinson (1978), scientific interest in motivation received its first major impetus late in the nineteenth century by Freud's pioneering investigations into human behavior. Contemporaries of Freud, William James (1890), William McDougall (1908) and Kurt Lewin (1925) all sought to determine behavioral or biological reasons for human motivations and actions.

Conventional wisdom viewed human consciousness as a receptacle possessing an unlimited number of reasons one may choose from in determining individual actions. Later theorists namely, Clark L. Hull (1943) and Edward Tolman (1950), while agreeing to the basics of behaviorism theory, felt there were other elements of behavior motivation besides that found in stimulus-response behaviorism. Regardless of how the behaviorist view was tweaked by various researchers, the traditional conceptions of motivation considered behavior in terms of discrete behavioral episodes that could be conceived in terms of a three-step process: a stimulus situation followed by an intervening organism followed by a reaction to the stimulated situation. In other words, behavior was episodic with the immediate environmental stimulus being the cause of the response.

In contrast to the traditional view, according to John Atkinson and David Birch (1978), the contemporary view of motivation was thrust into the mainstream by a study of persistence in problem solving conducted by Norman T. Feather (1960). As a result of this and other researchers, Atkinson stated that contemporary theorists see behavior as continuous instead of episodic, therefore, 
the content of the immediate environment influences an unending stream of behavior. Consequently, motivation is seen not as a separate stimulus creating some kind of response, but a chain of events that continues as a spiral with feedback loops motivating further behavior. To wit, the current view of motivation is not one of isolation, but a holistic view that affects a continuous course of human behavior.

Research conducted by Atkinson and Birch (1978) examined motivation and action within continuous streams of behavior which, in turn, provided further impetus to discover exactly and under what conditions an individual would be inclined to engage in some kind of activity. As a result, the study of achievement motivation provided, according to Atkinson and Birch (1978), ...a useful way of thinking about how characteristics of persons (personality) and features of the immediate situation (environment) interact to determine the nature and magnitude of instigating and inhibitory forces that influence the motivational tendencies expressed in the stream of behavior (p. 73).

They further stated that, "Achievement motivation is an important determinant of aspiration, effort, and persistence when an individual expects that performance will be evaluated in relation to some standard of excellence. Such behavior is commonly called achievement-oriented behavior" (Atkinson and Birch, 1978, p. 75). Basically, the theory of achievement motivation presumes that each person has both a motive to achieve success and to avoid failure. It is true that achievement motivation plays a major role in Japanese classrooms. Unfortunately, it appears to come from an external rather than internal source. For example, the main motive for achievement is seen in the intense competition 
for passing entrance exams as students perceive their futures will be determined according to the passage or failure of the exam.

Supporting Atkinson and Birch's theory, another theory of achievement motivation was formulated by J. O. Raynor (as cited in Atkinson and Birch, 1978). Raynor posited that, as perceived by an individual, within a continuous stream of behavior, not only the immediate, but a future opportunity and its consequences should intensify the achievement-motivation of a person within the current environment. In other words, perceiving that some future opportunity is contingent upon success in a present activity, the achievement motivation of a person should increase during the present activity. Like Atkinson and Birch (1978), Raynor's theory (as cited in Atkinson and Birch, 1978) is also related to the present study as Japanese students from pre-school to university level know future opportunities depend upon entrance exam scores at each stage of their education. The caveat, however, is that how future opportunity is perceived requires the employment of cognitive elements of logic and decision theory - elements that, in addition to being in different stages of development for different people, are not usually taught in a Japanese educational environment.

In his chapter on motivated cognitions, Covington (as cited in Paris, Olson, \& Stevenson, 1983) put forth a cognitive attribution theory of achievement behavior that dovetails with Raynor's theory (as cited in Atkinson and Birch, 1978). Covington asserted that rational human processes are used in creating a picture of one's world - a picture based on personal preferences and to some extent, control over one's fate. In this type of constructivist schema, motivation gives a sense of purposefulness and guidance to human activity. Therefore, human cognitions provide the motivational thrust with emotions playing a 
secondary role as causal determinants of achievement motivation. In essence, he states, "This model asserts that need for achievement [achievement motivation] is mediated by perceptions of causality [cognitions] that in turn influence affective reactions to failure, expectancy of future success, [emotions] and subsequent test performance" (as cited in Paris, Olson, \& Stevenson, 1983, p. 144). As a result, Covington asserted that people have distinct reasons for their successes and failures; reasons related to both cognitive and emotional attributes, for example, an individual's self-perceived ability level, effort, task difficulty, and luck. In Japan, this can also be seen in Japanese education as students who do not pass an exam often say they lacked ability, the test was too difficult, or they were just unlucky. Consequently, failure to pass an exam results in a negative stigma being attached to the student with opportunity to enter the school of their choice virtually eliminated.

Related to motivated cognition but taking a somewhat different tack is the examination of motivational factors that affect student approaches to learning. Entwistle (1988) described the Approaches-to-Study Inventory, developed over a five-year period, which evaluated organized study methods and active learning process together with a series of motivational components. According to Entwistle (1988), this inventory showed that there are distinctive forms of motivation, which affect both quantitative and qualitative learning outcomes. Regarding the latter, educational orientation was the motivational concept of greatest generality to emerge. This concept describes the set of values and attitudes connected to education that the student holds at the time of instruction. Within this concept there are four categories: vocational, academic, personal, and social. Regarding quantitative analyses, three motivational orientations to 
studying were accepted: meaning orientation, reproducing orientation, and achieving orientation. Meaning orientation contains elements of intrinsic motivation (cognitions) while reproducing orientation contains external influences that impose standards to be attained. Achieving orientation contains more mixed forms of motivation: a strategic approach linked to competitive achievement motivation and a combination approach which is motivated by careful planning, systematic study methods, and a positive attitude.

It seems that Entwistle's distinctive forms of motivation, which affect both quantitative and qualitative learning outcomes, can be observed in traditional Japanese classrooms. For example, in the qualitative area, educational orientation can be observed as Japanese students utilize elements of Confucianism into the classroom. To illustrate, students bring with them to the class expectations about behaviors between teachers and students, methods of learning, and use of exams. Regarding the quantitative area, reproducing orientation, which imposes standards to be attained, is also common in a traditional Japanese class with rote memory techniques used to determine students' knowledge. Finally achieving orientation which contains both qualitative and quantitative aspects of motivation is practiced, not only by students, but by Japanese parents, indeed, all Japanese society which reinforces the current system of competition. In summary, an examination of certain elements of motivation theory provides insight into current Japanese educational practices. Next to consider is how the previsous discussion of motivation theory together with self-directed learning theory as researched by Hofer, Yu, and Pintrich (1988), Schunk (1998), Winne and Stockley (1998), Winne and Hadwin (1998), compliments individualized learning found in web-based environments. 
According to Hofer, Yu, and Pintrich (1988), there are various of models of self-directed learning all of which have the same premise: through various processes such as regulating cognition, motivation, and behavior, students can perform better thus achieve their goals. In their model, the authors' state that there are two general organizing constructs, (1) knowledge/ beliefs, and (2) strategies used for regulation. In addition there are two general domains, cognitive and motivational with the latter having special importance to the current study. According to the authors, motivational knowledge has two sides: mastery or learning goals, and performance or extrinsic goals. Regarding the adoption of mastery goals, Hofer, Yu, and Pintrich (1988) state, "In general the research suggests that adopting a mastery goal orientation has a positive relation to both motivational and cognitive outcomes as well as overall performance" (p. 72). Performance or extrinsic goals are best seen as students seeking rewards in the way of getting good grades and/or besting others. Hofer, Yu, and Pintrich also support attribution theory as a motivational strategy for achieving performance goals. In addition, they highlight the importance of self-knowledge - students becoming aware of their own strategies for learning and motivation so as to make adjustments in learning and appropriate changes in their learning strategies.

The idea of self-knowledge as a motivational factor within a self-directed learning activity is also supported by Schunk (1998) who stated that, “Effective self-regulation depends on feeling self-efficacious for using skills to achieve mastery. As students work on a task, they compare their performances to their goals. Self-evaluations of progress enhance self-efficacy and maintain motivation" (p. 141). Schunk (1998) further states that students participating in a 
self-directed learning activity who feel self-efficacious are also likely to use effective learning strategies such as concentration, time management, and performance monitoring techniques.

Other views of self-regulated learning are given by Winne and Stockley (1998), and Winne and Hadwin (as cited in Winne and Stockley, 1998). Regarding the former, they state that self-directed learning can be measured by students' impressions of previously learned activities, and like other aptitudes, varies within individuals over time, and within individuals across tasks. Winne and Hadwin (as cited in Winne and Stockley, 1998) describe self-regulated learning as an event involving three necessary phases: perceiving the task, setting goals, and enacting tactics to approach goals, plus an optional fourth phase of adapting tactics. Transforming and constructing information within each phase provides the potential for metacognitive monitoring and control. Interestingly, once this type of learning has begun, it is recursive and loosely sequenced; events may skip or repeat phases as deemed necessary by the learner. It is obvious that the previous elements of self-regulated learning such as effective self-regulation, awareness of different learning strategies, and metacognitive monitoring and control do not compliment traditional Japanese educational practices, however, those same elements do compliment web-based instruction.

In essence, some elements of motivation theory can be seen in Japanese education. For example, achievement motivation which presumes that each person has both a motive to achieve success and to avoid failure is found in Japanese classrooms. In addition, meaning orientation and achieving orientation are also evident as is the idea of mastery of learning goals widely accepted. 
However, elements of self-directed learning which rely on the learner to make self-regulating observations about their progress, are difficult to locate in a Japanese classroom. For example, self-knowledge about personal learning strategies is not usually adovcated in such a class. In fact, students may not be aware there are different kinds of learning strategies. In addition, methods of monitoring cognitions are not taught in Japanese classrooms. As a result, utilization of web-based instruction could fuse together elements of motivation theory with self-directed learning, and provide Japanese students with a more holistic view of education motivated by intrinsic rather than extrinisic needs.

The fourth point of discussion is between Japanese education and webbased instruction is the perceived racial and cultural homogeneity among Japanese with strict rules of communication versus a diverse population of learners taking courses via web-based instruction using multimedia means of communication and interaction. For Japanese students, the current educational system with mainly Japanese participants somewhat levels the playing field. Japanese students, for example, know who and what and the competition is and how to prepare for "battle", mainly of passing entrance exams. Because of this perceived homogeneity in the Japanese psyche, a foreigner entering the scene often causes distress for the Japanese because the group dynamics have changed. Beauchamp (1992) confirms this in his statement, "In Japan...there is a traditional aversion to minorities, which is reflected in the Japanese word for foreigner, gaijin, or outsider" (p. 11). With web-based instruction, however, and the possibility of Japanese learners interacting with students from all parts of the globe, Japanese group dynamics could experience a paradigm shift in attitudes toward foreigners. Going beyond attitude changes, McCarthy states, "The 
interdisciplines of computer-mediated communication and intercultural communication need to be brought together and applied to world issues (1999, paragraph 12). Collis and Remmers (1997) agree that intercultural communication has opened new dimensions for web-based learners and state, "The World Wide Web has profoundly expanded the opportunities for crosscultural communication and interaction through its remarkable trans-border range and acceptance" (p. 87).

In addition to group dynamic changes that Japanese students would face, web-based learners display a cornucopia of communication techniques. Collis and Remmers (1997) caution, "We must be alert to the fact that there are substantial cross-cultural differences in interaction and communication beyond the actual words being said" (p. 88). This points to the issue of nonverbal communication and how that will/will not be utilized in web-based instruction. It is true that most cultures have both verbal and nonverbal communication patterns that are essential for communication. According to Goldman (1998), "Nonverbal communication comprises about $65 \%$ of all human communication" (p. 67). Research shows that there is considerable discourse on the differences between American and Japanese communication patterns especially with respect to nonverbal communication (e.g. Barlund, 1989; Goldman, 1988; Neustupny, 1989, McDaniel, 1993; Rinnert, 1994; Yang, 1993; California State Department of Education, 1987; Potoker, 1993; Reischauer, 1988). For Japanese, nonverbal communication plays such an important role that it may be difficult to enact in a web-based environment. While discussing Japanese culture and on-line education, McCarty states that, "The big question is how to reach [Japanese] users in terms of their own language and values, which are reflected in a 
communication style that prefers the diminutive to the demonstrative" (1999, paragraph 3). This type of communication has an entrenched history. In fact according to Potoker (1993), "Historical precedent for distrust of words by the Japanese is said to date back to the 7th or 8th centuries" (p. 6). Indeed, in contemporary times Japanese prefer silence over speaking is seen in the following Japanese proverbs:

To say nothing is a flower

Silence surpasses speech

McDaniel (1993), in researching Japanese nonverbal communication, observes that, "The hierarchical nature of Japanese society, and an unrelenting sensitivity toward social harmony $(w a)$, increases the reliance on nonverbal behavior, while concomitantly discouraging verbal interlocution" (p. 6). Saksaki (1996) agrees. In a study on teacher preferences of student behavior, she states that, "Japanese schools cultivate intuition, respect, and avoidance of words or acts that might bother others" (p. 231). Edwin O. Reischauer (1988), noted Japanologist, concurs and states that,

Japanese have always seemed to lean more toward intuition rather than toward reason, to subtlety and sensitivity in expression rather than to clarity of analysis, to pragmatism rather than to theory, and to organizational skills rather than to great intellectual concepts. They have never set much store by clarity of verbal analysis and originality of thought. They put great trust in nonverbal understanding and look on oral or written skills and on sharp and clever reasoning as essentially shallow and possibly misleading. They prefer complexity 
and indirection as coming closer to the truth than apparently simple verities as defined by fallible men (p. 201).

Nonverbal communication plays a much more significant role in Japanese culture than in Western culture. But the effect of social evolution, which all cultures participate in, may modify this behavior. Web-based instruction will definitely have an impact as using nonverbal communication through that medium may be seen as nonparticipation possibly resulting in exclusion from the learning process. On the other hand, increased intercultural discourse through a web-based community of learners may well alter some traditional Japanese nonverbal behaviors and introduce new ones. In commenting on Japanese culture meeting on-line education, McCarty (1999) states that, "The new [Internet] media run afoul of many taken-for-granted assumptions about human relations [in Japan], including proper introductions, in an elaborate face-to-face social system" (1999, paragraph 5). Only time will tell if Japanese social norms become transformed to fit the Internet or if the Internet adapts to the norms.

It is obvious that Japanese educators and government officials may face many difficulties in adapting traditional Japanese education methods with cultural and social behaviors entrenched in Confucianism, to the new web-based technologies. As has been seen throughout Japanese history, borrowing technology and ideology from both China and the West has met with ambivalence and at times, downright censure. With the directives from the Japanese government, in an attempt to wrestle out of the current recession, Japanese educators and officials must make some tough decisions - ones that will ultimately bring about changes in both the way Japanese view themselves as well as the outside world. 
In summary, there are distinct cultural influences in traditional Japanese education based on the elements of Confucianism that conflict with current and possible future features and pedagogy of web-based instruction. As web-based instruction becomes more common in Japanese education, these differences must be carefully studied and resolved. Only until these issues are clearly researched will educators understand the most effective ways to use web-based instruction as a competent and practical teaching method for Japanese learners. This dissertation addreses only a small aspect of the many concerns educators have in Japan who are attempting to utilize web-based instruction for Japanese learners. The next chapter will approach the specific aspects of the study to be investigated. 


\section{Chapter 3}

\section{Introduction}

This chapter describes the purpose of the study, research questions and design, site and sample selection, interview format, as well as data collection, analysis procedures, and limitations.

The purposes of this study were to investigate Japanese female college students' perceptions of learning in a web-based environment, and to measure performance between students in a traditional teacher-centered Pre-TOEFL preparation course and a similar course taught via web-based instruction. The following research questions were posed:

1. What cultural factors related to Confucianism enhance and/or inhibit female Japanese college students attitudes and/or perceptions of learning in a web-based environment?

2. Are there significant differences between the mean pre and posttest scores on the Pre-TOEFL Test of those Japanese female junior college students taking a TOEFL preparation course via web-based instruction and the mean pre and post-test scores of another group of Japanese female junior college students taking a similar course in a teacher-centered class?

The null hypothesis stated there was no significant difference between the mean pre and post-test scores on the Pre-TOEFL Test between one group of Japanese female junior college students taking a course taught by the traditional teacher-centered method and another group of Japanese female junior college students take the same course by web-based instruction. 


\section{Research Design}

As a result of the research questions, this study used a mixedmethodology research plan that consisted of both qualitative and quantitative designs. According to Creswell (1994), "This approach adds complexity to a design and uses the advantages of both the qualitative and quantitative paradigms" (p. 178). Utilizing a mixed-methodology design allowed for triangulation of results. Schumacher and McMillan (1993) described triangulation as, "A cross-validation among data sources, data collection strategies, time periods, and theoretical schemes. To find regularities in the data, the researcher compares different sources, situations, and methods to see if the same pattern keeps recurring" (p. 498). Guba and Lincoln (1981) stated that, "Triangulation is useful for verifying information on the same event from different actors and also for producing more confidence in data generated by different methodologies" (p. 257). Creswell (1994) stressed that in a mixedmethodological design study, the author collects both qualitative and quantitative data through an integrated use of mixed methods. This may have several purposes according to Green (cited in Creswell, 1994) such as “triangulating or converging findings, elaborating on results, using one method to inform another, discovering paradox or contradiction, and extending the breadth of the inquiry" (p. 185). Supporting the theory of triangulation, the first research question utilized a qualitative structured interview methodology while the second research question was addressed through a quasi-experimental design.

The goal of qualitative analysis is the understanding of human behavior and functioning. According to Straus and Corbin (1990), “Qualitative methods 
can be used to uncover and understand what lies behind any phenomenon about which little is yet known. Also, qualitative methods can give the intricate details of phenomena that are difficult to convey with quantitative methods." (p. 19). Merriam (1998), asserted that there are six assumptions of qualitative investigation: (a) the process is more important than outcome, (b) the meaning of how people make sense of their lives is essential, (c) data is mediated through the researcher who is the main instrument for data collection and analysis, (d) on site fieldwork is required of the researcher, (e) the research is descriptive, and, (f) the process is inductive rather than deductive. For the qualitative research question, structured interview methods were used as a theoretical framework for gathering, analyzing, and reporting subjective experiences of Japanese female students' perceptions of learning toward web-based instruction.

For the quantitative research question, a quasi-experimental method was employed. This method approximated the true experimental method and emphasized objectivity of phenomena through design, statistics, and experimenter control. According to Creswell (1994), "In quasi-experimental designs, control and experimental groups are used in the study, but subjects are not randomly assigned to the groups" (p. 130). As a result, quasi-experimental design is useful in educational situations where groups are already predetermined with no allowance for randomization. Schumacher and McMillan (1993) stated that, "A common situation for implementing quasi-experimental designs involves several classes or schools that can be used to determine the effect of curricular materials or teaching methods. The classes are 'intact', already organized for an instructional purpose" (p. 33). Therefore, for the purpose of this study, a quasi-experimental layout consisting of a nonequivalent pre/ posttest 
control group design was employed. A diagram of this type of study is given below.

$$
\begin{array}{lll}
\text { Group A. } & 0 \quad \times \quad 0 \\
\text { Group B. } & 0 \quad 0
\end{array}
$$

Both the Treatment Group A and the Control Group B consisted of 30 students each who were assigned to each group according to their last name by the school administration. Consequently, no further randomization was completed by the researcher. Both groups took a pre and posttest, but only Group A received the treatment - web-based instruction.

\section{$\underline{\text { Site Selection }}$}

Data were collected at Toyoko Gakuen Women's College (TGWC) in Setagaya-ku, Tokyo, Japan. The site was selected because the researcher was a full-time faculty member and Coordinator of the Intensive English Studies (I.E.S.) program at TGWC, and had access to the sample population. In order to better understand junior college education in Japan, data related to enrollment as well as the type of curriculum for junior colleges in Japan have been described below.

TGWC, a two-year private women's junior college located in Tokyo, Japan, was originally founded as Toyoko Commercial School for Girls in April, 1939 by Keita Goto, then president of Tokyo Kyuko Railway Service Co. Ltd., Japan. The college currently functions under the umbrella of the Goto Scholarship Society. According to the late college president, Masao Takatori (1995), "The objective of [the] college is to contribute to society by fostering the education of women, enabling them to live vital, righteous, and beautiful lives" (p. 5). He further stated that the school attached great importance 
to the liberal arts which enhanced a deeper understanding of students' culture and other world cultures as well as developing analytical skills and sound judgement. President Takatori acknowledged that unlike men who enter the workforce usually in their $20^{\circ} \mathrm{s}$ and continue to work until retirement, most women in Japan faced different problems from their early twenties through early thirties. Thus TGWC attempted to offer a different kind of liberal arts curriculum paying close attention to the special characteristics of women's lifestyle in Japanese society. (See Appendix A for curriculum guide).

TGWC enrolls approximately 500 new female students per year aged 1819 divided into two departments: the Department of Human Ecology and the Department of Language, Culture, and Communication. Regarding the former, the department is divided into two major sections: Social Sciences and Human Behavior, and Natural Sciences such as environmental studies. The Department of Language, Culture, and Communication is divided into two main sections: Japanese cultural studies and English language studies. It is within the English language studies that the Intensive English Studies program is located. Takatori (1995) stated, "Participation in Intensive English courses proves useful when applying for jobs or further educational endeavors (p. 11). Japanese female high school students are motivated to enter junior colleges for various reasons. According to Takatori (1995),

Many high school students, being unable to make up their minds yet about their future, enter a junior college. While cultivating themselves and fostering their resolute character, they work their way into coping with a wider range of choices. This time of constructive self reflection is indeed one of the characteristics of a junior college. Toyoko Gakuen Women's 
College pays close attention to the ever-changing needs of society and aims at fostering capable women who can make sensible judgments at difficult times and live a happy, fulfilled life (p. 5).

Possible reasons for entering TGWC could be the opportunity to transfer credits to a four-year college, specialized course offerings such as the Intensive English Studies program, test preparation for the Test of English in International Communication (TOEIC), a Study Abroad Program, Librarian Course, and the option of taking courses and getting credits from a nearby business college. Takatori (1995) reported, "10\% of graduates find their way into four year universities, professional schools, or language institutes abroad. Therefore our school has established a wide range of academic offerings, especially in the area of English education and literacy in new technologies" (p. 17). In addition to a strong academic program, TGWC also has an excellent college job placement record. For example, of the 1998 graduating students, $88.2 \%$ were placed in jobs through the school's job placement office. TGWC graduates secure jobs in areas such as finance, manufacturing, and government. Takatori (1995) declared, "The positive atmosphere of the school is the ideal setting for fostering responsible women who are liked and respected in their place of work" (p. 17). Sample Selection

Toyoko Gakuen Women's College.promotes an Intensive English Studies (I.E.S.) program that is open to all students from both departments. Since only 60 students are accepted to the I.E.S. program per year, students must submit an essay and petition to interview for a position. Interviews are conducted by the five-member I.E.S. faculty. If students pass the interview, they are accepted to the I.E.S. program for the duration of their two-year college career. The method of 
instruction is English and all additional communications with the I.E.S. faculty both in and outside of class are in English. After 60 students have been selected for the program by the I.E.S. faculty at the beginning of the school year, the names are given to the school administration. Students are then pre-assigned by the school administration according to last names into the two groups of 30 ; Group $A$ and Group B. In addition, the school administration determines student class schedules. For the purpose of the current study Group A, the Treatment group, was assigned to the researcher in the computer room every Monday morning from 9:00-10:30 while Group B, the Control group, was assigned to the researcher in a regular classroom every Tuesday morning from 9:00-10:30. Both groups, which consisted of all 60 students in the I.E.S. program, were used in this study. This type of sampling is considered convenience sampling and according to Creswell (1994),

“Although random selection enables a researcher to generalize results to a population, one may need to settle for a convenience sample because an entire group of individuals (e.g., a classroom, an organization, a family unit) is available to participate in the study" (p. 127).

Before the study began, the researcher collected data in class from both groups regarding students' current knowledge and use of computers, availability of computers at home, and use of the Internet. Next, the researcher randomly divided Group $A$ into five-member focus groups and had the students discuss their ideas, feelings, and experiences about web-based instruction in the classroom setting. The following questions were used in the focus group discussions and were written on the board for students to discuss: (a) What is your image (idea in your mind) of learning by web-based instruction? (b) How 
would learning by this method be different from what you are used to? (c) How would this method of learning be similar to what you are used to? (d) What are some difficulties using web-based instruction? (e) What are some advantages using this method? ( $f$ ) How do you feel about learning and/or taking a class by web-based instruction? (g) Do you think you will be somewhat different after learning by web-based instruction? If so, how? If not, why not? In addition to discussing the questions in the focus groups, students wrote their answers on paper and submitted them to the researcher at the end of the class. During the discussions in class, the researcher circulated among the groups, facilitated the discussions, and answered questions. After the class the researcher recorded data from the focus groups.

\section{Quantitative Data Collection}

The null hypothesis was tested in answering research question two. Data collection consisted of pre and post-test scores from the Pre-TOEFL Test, an internationally recognized standardized test acknowledged to be a valid and reliable testing instrument. Reliability coefficients of the Pre-TOEFL Test for section one, two, and three are $.82, .73$, and .83 , respectively. The Pre-TOEFL Test is used at Toyoko Gakuen Women's College for measuring the English ability of nonnative speakers at the low and intermediate proficiency levels. According to the Council on International Educational Exchange (1999), “Pre-TOEFL measures the same language skills as the TOEFL test but is less difficult and requires less testing time. It is appropriate for students at the beginning and intermediate levels of study" (p. 4). In addition, the Council stated that, "Content is written and statistical equating procedures are employed to ensure that scores on one edition can be compared to scores on any other test edition" (p. 6). 
The Pre-TOEFL Test consists of three sections: (a) listening comprehension, (b) structure and written expression, and (c) reading comprehension. It was administered during class to all 60 I.E.S. first-year students together on April 27, 1999. After completion, the answer sheets were sent to the official TOEFL Testing Center in Tokyo, Japan for scoring and then returned to the researcher who documented the scores. For this part of the study, the dependent variable was the pre and post-test score on the Pre-TOEFL Test for both Group $A$ and $B$, and the independent variable was web-based instruction for Group A.

Beginning the week of May 24, 1999, an eight-week web-based TOEFL preparation practice course was given to both groups once a week, facilitated by the researcher. The main objective for the TOEFL preparation practice course for both groups was to provide students an opportunity to practice Section Two and Three of the Pre-TOEFL test using practice test materials.

\section{Group A}

Group A, the Treatment group, met every Monday morning, first period, for 90 minutes in the computer lab. The main purpose was to use web-based TOEFL practice questions as the content for course. It must be noted that Section One, Listening Comprehension was not included in the practice sessions due to technology limitations of the school computers. Only Section Two, Structure and Written Expression and Section Three, Reading Comprehension, were practiced. In order to facilitate students locating TOEFL practice websites easily, the researcher announced to the students the following websites to be used each week. For week one and two http://www.TOEFL.org/swe-pq.html, and http://www.toeflcenter.com/practice.html. were used. Students practiced 
questions from http://www.toefl.org/rc-pq.html for week three, four, and five.

For week six, if students were absent any of the previous weeks, they worked on questions from the website http://www.toefl.org/cbtutprq.html. If they had not been absent, and had completed all the questions from the website, they were to review questions from http://www.toeflcenter.com/practice.html and http://www.toefl.org/rc-pq.html. For week seven, students completed one section of practice questions downloaded from http://www.netsales.net/pk/wcgi/ets00003/prod/1228577-1. For week eight students completed a practice English placement test that had similar TOEFL questions from http://www.peakenglish.com.

While students were working on the web-based TOEFL practice questions, the researcher circulated throughout the computer room and assisted students only when they had either technical problems with the computer or questions about the Internet and/or the practice website(s). Students were required to complete weekly log entries (See Appendix B for logsheets) designed by the researcher who inquired about the students' impressions of the practice sites and web-based instruction. These weekly logsheets were turned into the researcher at the end of each weekly class session and kept in the researcher's school office.

Group B

Group B, the Control group, participated in a TOEFL preparation practice course via a teacher-centered method in a regular school classroom every Tuesday morning, first period, from 9:00-10:30. As with Group A, this group practiced questions related to Section Two, Structure and Written Expression and Section Three, Reading Comprehension. Practice materials used for Group B 
came from a traditional TOEFL practice textbook: 5-Minute Quizzes For TOEFL: Structure and Written Expression and Reading Comprehension (1998). This book was chosen because it was previously purchased by the administration at Toyoko Gakuen Women's College specifically for TOEFL practice materials. One lesson was given each week for a total of eight weeks. Each lesson consisted of separate worksheets for structure, written expression, and reading comprehension. In an attempt to control for the different practice questions for each method of instruction, every effort was made to have the Control and Treatment groups practice questions related to the same section of the PreTOEFL Test. For example, for week two all students from both groups practiced questions related to the Structure and Written Expression section. During week three students from both groups practiced questions for the Reading Comprehension section.

At the end of week eight, all 60 students were given a posttest version of the Pre-TOEFL test together during a regular class period. Answer sheets were sent to the official TOEFL Testing Center in Tokyo, Japan for scoring, and then returned to the researcher who recorded the scores.

\section{Qualitative Data Collection}

Because the purpose of the qualitative section was to determine what cultural factors related to Confucian elements in Japanese education enhanced and inhibited female Japanese college students perceptions of learning in a webbased environment, the need to conduct structured interviews was essential. Merriam (1988) stated that, "Interviewing is necessary when we cannot observe behavior, feelings, or how people interpret the world around them." (p. 78) Thus the structured interview approach was an appropriate method for examining 
subjective experiences, and immersed the researcher and participants in face-toface interviews. The structured interview process that included open-ended questions encouraging free association, helped the researcher to comprehend and understand the meanings of the experiences and feelings expressed by the participants.

\section{Interview Procedures}

The purpose of data gathering in qualitative research is to produce clear descriptions of the meaning of human experience. According to Patton (1990), qualitative inquiry often focuses on relatively small samples selected purposefully to answer the research question. The rationale behind purposeful sampling lies in selecting information-rich cases or participants for in-depth study with no attempt made at randomization. Qualitative researchers typically follow a general format beginning with the researcher "bracketing" biases; preconceived ideas, and assumptions about the phenomenon to be studied. According to Valle (1989), bracketing is referred to as "phenomenological reduction" which allows the researcher to make assumptions and biases explicit before studying the phenomenon.

For the purposes of this study, six students were selected and interviewed. Selection was based on students' Pre-TOEFL scores returned to the researcher from the official TOEFL Testing Center. In order to get an objective sample to be interviewed, the researcher arranged the scores from highest to lowest and selected the two students with the highest scores, two students at the median, and two who scored the lowest. An informed consent form (See Appendix C) to participate in the interview process was signed by each interviewee, the researcher, and a witness. 
The researcher engaged in one-to-one in-depth interviews with the same six individual students described above regarding their perceptions of learning in a web-based environment. A total of 18 interviews were held in the researcher's office at Toyoko Gakuen Women's College in Tokyo, Japan during the normal school day. Interviews were conducted at three different times: one week after they had been selected and before the treatment began, once in the middle of the treatment, and within one week after the treatment finished. Each interview lasted between $30-45$ minutes, was tape recorded, and transcribed by the researcher. According to Merriam, "this practice insures that everything said is preserved for analysis" (p. 81). Through the interview process, students were queried using open-ended questions to describe their experiences, feelings, and perceptions of learning in a web-based environment. According to Guba and Lincoln (1981),

The distinguishing characteristic of open-ended questions is that they raise an issue but do not provide or suggest any structure for the respondent's reply; the respondent is given the opportunity to answer in his own terms and to respond from or create his own frame of reference. Such questions are called for when the issue is complex, the relevant dimensions are not known, or the interest of the research lies in the description of a process, or the individual's formulation of an issue (p. 177-178).

The sequence of questioning followed a funnel pattern where questions moved from general to specific. "When a comprehensive view of a respondent's experiences or feelings is desired, asking the most general questions first may eliminate the need to ask a large number of specific questions" (Guba and 
Lincoln, p. 180). In order to further the reply from participants responding to open-ended questions, both silent and directed probes were used. Guba and Lincoln (1981) asserted that probes are questions that allow the respondent to explore a given topic and reply to the question based on associative and elaborative responses. Silent probes indicate that the interviewer needs more information and/or is willing to wait until the respondent is thoroughly finished and satisfied with her own answer. This is especially useful in Japanese culture where silence has a distinctive place in daily communication. Directed probes included such questions that asked for clarification, justification, amplification, causal relationships, or an in-depth look at the respondent's feelings. A copy of each interview question guide is given in Appendix D.

\section{Qualitative Data Analysis}

Creswell (1994) stated that, "Data analysis requires the researcher be comfortable with developing categories and making comparisons and contrasts" (p. 153). During the analysis process, the researcher utilized simultaneous activities such as collecting information, sorting information into categories, formatting the information into a presentation, and writing the qualitative narrative. As a result, data analysis was an ongoing effort during each interview.

One goal of qualitative data analysis is to find common themes within the interview data. Because collection and analysis of data can occur simultaneously in qualitative studies, while collecting data during the structured interview process the researcher analyzed the information and searched for central themes, concepts, ideas, values, concerns, and issues as proposed by Guba and Lincoln (1989). 
Coding commenced after collection of all data and transcription of tapes was complete. Because this study utilized an unstructured elite interview style characterized by a fluid format, a variation of Tesch's eight steps (cited in Creswell, 1994) for analysis of data was used. "These eight steps engage a researcher in a systematic process of analyzing textual data. Certain variations exist in this process" (p. 155). For this study the steps included: (a) reading through all transcriptions to get a sense of the whole, (b) extracting phrases or sentences that directly related to student perceptions of web-based instruction (c) transforming these phrases or sentences into units of meaning such as clusters or themes, (d) listing all themes and/or clusters, (e) grouping themes into categories common to all of the interviews, (f) determining descriptive statements about female Japanese student perceptions of web-based learning, and ( $g$ ) constructing a descriptive narrative based on a synthesis of knowledge on female Japanese attitudes toward web-based learning.

Quantitative Data Analysis

For the quantitative section of the study, inferential statistics were used. According to Schumacher and McMillan (1993), "Inferential statistics are used to make inferences or predictions about the similarity of a sample to the population from which the sample is drawn" $(p, 192)$. For this project, a paired samples t-test was used to test the hypothesis, and to determine the level of significance of the mean pre and posttest scores within each group. Schumacher and McMillan (1993) explained that this type of statistical analysis is used when the same group of subjects are tested twice, as in a pretest-posttest study. In addition, an independent samples t-test was used to determine the level of significance 
between the gain scores for each group. A statistical software package, SPSS Version 9.0, was utilized for calculating levels of significance.

\section{Delimitation and Limitations of the Study}

The overriding delimitation of this study was it being the first of its kind to focus exclusively on how Japanese culture related to Confucianism may or may not have effected Japanese female college students' perceptions of learning in a web-based environment. Consequently, research for the study focused on the effect of Confucianism on Japanese culture, especially Japanese education, as well as studies, articles, and reports on using computers and the Internet in Japanese educational settings. Contrary to the one main delimination, however, this study had several limitations.

First, a small sample size of 60 participants and a population comprised of Japanese freshman junior college women, limited generalizing the results to groups other than the sample population. In addition, while every effort was made to identify possible biases of the non-Japanese researcher, a distinct cultural difference in social and educational background between the researcher and participants was noted. For example, in looking at Confucianism from the researcher's foreign perspective, the researcher determined which elements of Confucianism most influenced Japanese education and used those elements as a basis for designing interview questions. Furthermore, Confucian elements used by the researcher were neither supported nor refuted by native Japanese educators. In addition, while there were questions on the weekly logsheets that related to the five elements of Confucianism, overall logsheet design was not standardized to coincide with those elements but was designed as an informal way for students to comment each week on their experience with web-based 
design. Another limitation was that the researcher was also the instructor for both the Treatment and Control groups and also conducted the individual interviews; therefore, the potential for a positive or negative impact on both groups, but especially the six interview subjects, was considered. Furthermore, all interview communication between the researcher and participants was in the researcher's native language and not the participants'. This could have influenced the participants' responses to interview questions. A further limitation is that the language used for the weekly logsheets was in English however, beginning with the third week, a few students responded to the questions in Japanese. Other limitations were related to the Pre-TOEFL test and computer technology available at the school. While the Pre-TOEFL test determines students' abilities in three areas - listening, reading comprehension, grammar and written structure, students in both the Control group and Treatment group only had practice sessions for the latter two areas. This was due to technology limitations of the school computers which did not have listening capability; therefore, only reading comprehension and grammar and written structure were practiced. In addition, with the exception of the interviewees, participation by both groups was not voluntary as administration of the Pre-TOEFL test and practice course were part of the regular class curriculum. Finally, in coding the qualitative data, the researcher did not use such techniques as member checking, peer debriefing, or multiple researchers for data analysis. 


\section{Chapter 4}

\section{Introduction}

In this chapter, results from the two research questions investigated in this study are discussed. First, the procedure for pre-treatment data gathering including general questions asked of the entire sample population regarding computer use, the Internet, and web-based instructional experience have been described. Second, focus group questions and responses from Group $A$, the Treatment group, have been given. Next, the quantitative section including a sample description and discussion of the results of the statistical procedure have been presented. Following that, the qualitative question, sample selection, interview format, data collection, and results have been reported.

\section{Pre-treatment data gathering procedures}

The sample for pre-treatment data gathering consisted of the entire population of 60 first-year Japanese female college students enrolled in the 19992000 Intensive English Studies (IES) Program at Toyoko Gakuen Women's College in Tokyo, Japan. Ages for the students ranged between 18 and 19. All students came to Toyoko Gakuen Women's College from Japanese high schools and had therefore followed the Monbusho prescribed curriculum for high school education in Japan. At the beginning of the school year, IES students were assigned by the school administration into two groups of 30 students each according to their last name. Group A consisted of the Treatment group, and Group B was the Control group. Classes for the IES Program began on April 12, 1999, and students attended classes Monday through Friday from 9:00-10:30 a.m. 
Before the treatment commenced, information was obtained regarding the students' experiences with computers, the Internet, and web-based instruction. On April 26, 1999 all 60 students from both Group A and Group B responded to six statements created by the researcher. Students were asked to stand if they responded to the statement in the affirmative, and remain seated if in the negative. All students actively participated and there was no hesitancy to either stand or stay seated in response to the researcher's questions. The statements and results have been shown in Table 1. 
Table 1

Pretreatment questions regarding computer, Internet, and web-based experience.

\begin{tabular}{llll}
\hline $\mathrm{N}=60$ & $\begin{array}{l}\text { Group A } \\
\text { Treatment }\end{array}$ & $\begin{array}{l}\text { Group B } \\
\text { Control }\end{array}$ & Total \\
\hline Yes No & Yes No
\end{tabular}

1. Stand up if you have used a computer before this class.

27

3

21

9

60

2. Stand up if you have used the Internet before this class.

25

4

26

60

3. Stand up if you have a computer at home.

4. Stand up if you have a computer at home that you can use.

5. Stand up if this is the first time you have used the Internet in English.

6. Stand up if you have learned by web-based instruction before.

$0 \quad 30$

0

30

60

From Table 1, it is evident that many students from both groups had previous experience using computers; however, only four students from the Control group and five students from the Treatment group had Internet experience. The data show that while many students from both groups had 
computers at home, only a few were allowed to use them. When asked about using the Internet in English for the first time as well as their previous experiences with web-based instruction, all students responded in the affirmative to the former and negative to the latter which confirmed that this experience was their first encounter with web-based instruction. From the data, it is clear that there was very little difference in computer experience and Internet use between the Control and the Treatment group.

The next day, April 27, 1999, fifteen days after the beginning of the academic year, the Pre-TOEFL Test was administered to all 60 students together in the same room during the regular class time. The Pre-TOEFL test is an internationally recognized standardized test acknowledged to be a valid and reliable testing instrument. It has been used at Toyoko Gakuen Women's College for measuring the English ability of nonnative speakers at the low and intermediate proficiency levels. Upon completion of the test, answer sheets were sent to the official TOEFL testing center in Tokyo, Japan, and were marked and returned to the researcher who recorded the scores.

\section{Focus group questions and responses}

On May 10, 1999, a series of focus group discussions were held in the regular classroom for Group A, the Treatment group. The purpose was to allow students to discuss their ideas, feelings, and experiences about web-based instruction before the treatment began. In addition, the exercise provided the researcher with insight into student attitudes toward web-based instruction before they actually experienced it. The researcher randomly divided the Treatment group into six five-member groups and had the students discuss their ideas, feelings, and experiences about web-based instruction. The following 
questions were used in the discussions and were written on the board: (a) What is your image (idea in your mind) of learning by web-based instruction? (b) How would learning by this method be different from what you are used to? (c) How would this method of learning be similar to what you are used to? (d) What are some difficulties using web-based instruction? (e) What are some advantages using this method? (f) How do you feel about learning and/or taking a class by web-based instruction? (g) Do you think you will be somewhat different after learning by web-based instruction? If so, how? If not, why not? In addition to discussing the questions, students wrote their answers on paper and submitted them to the researcher at the end of the class. During the focus group discussions, the researcher circulated among the groups, facilitated the discussions, and answered the students' questions. It was observed that some groups were able to discuss all questions while other groups had time for only two or three. Results for the focus group questions are described below.

The first question attempted to gain insight into the students' perceptions of learning using the Internet. Responses were divided into three groups: positive, negative, and mixed. Of the 23 students, 15 responded in a favorable manner, and made statements such as, "I think difficult but little interesting," "I think that enjoy and a useful piece of information," "I think that exciting things," "I think it is very good study because we learn not English but also computer." The negative responses included four statements regarding the difficulty of using the computer. Three students stated, "We think very difficult machine," while the fourth said, "I think that it is difficult to use computer." Mixed reactions were from four students with two who stated, "Tnteresting but difficult," and three who gave a variety of answers which included, "Interesting, 
exciting, difficult," "Interesting, wonderful, difficult, high tech," and "T image its difficult, but I'm so exciting and interesting to learn on the Internet."

The second question asked students to consider how learning via the Internet would be different or similar to their regular classes. Twenty answers were reported and divided into two groups: different and don't know. For the first group, fifteen students provided a variety of answers and stated the class would be different from the regular class. Responses included, "It is good for the change and it is useful in more ways than one," "We don't need to write," "We don't need communication with other people," "Not using a textbook and not learning with classmates," "I will have tired eyes," "Usual class is happy for me. To learn Internet is very difficult for me and I must study alone," "I will have very little chance to speak to teachers," etc. Five students reported that they did not know how the class would be similar or different because they had never used the Internet.

Question three centered on the difficulties and good points of using the Internet for learning. 26 responses were recorded and divided into two groups: good points and difficulties for using the Internet. Of the good points there were 14 answers that included the following examples, "Good point is get information," "We can get new information soon and I will become accustomed to English," "Search many things simply," "I can understand many things," and "It is possible to access someone at any time." Examples of the 12 difficulties included, "Difficult to operate," "We can't understand foreign country's word," and "English is difficult." Five students specifically stated, "Difficulties is how to use computers." 
The fourth question asked students for their feelings about learning using the Internet. The 14 responses were divided into two groups: positive and negative. Of the 12 positive answers, two students said, "I think it's a good idea," while another two commented, "It's wonderful." Examples of the other statements included, "I feel that to get information about many countries without going there is the latest technology," "I feel the Internet can investigate more than dictionary," and "Tt's good, interesting, and difficult."

The final question attempted to get students to think about if and how they might be changed after experiencing web-based instruction. Twelve students responded and stated, "My interest will extend," "I will have good knowledge," "I think I will change after studying in the Internet," and "Yes, I do. I think that will be useful in the future." Two students commented, "I will understand how to use the Internet," while another three said, "f think I will get used to the computer."

In summary, according to the responses, there were mixed perceptions about web-based instruction. These included an overall positive feeling or image toward using the Internet because they could get a lot of information, but also anxiety over using the computer and not understanding the language, specifically, English.

\section{Quantitative results}

The quantitative question investigated in this study was as follows: Are there significant differences between the mean pre and post-test outcome scores on the Pre-TOEFL Test of those female Japanese college students taking a PreTOEFL course via web-based instruction compared to students in a teachercentered class? The null hypothesis assumed there was no significant difference 
between the mean pre and post-test outcome scores on the Pre-TOEFL Test between one group of Japanese female college students taking a course taught by the traditional teacher-centered method and another group of Japanese female college students taking the same course by web-based instruction. For this study, the dependent variable was the Pre-TOEFL Score for both groups while the independent variable was the web-based instruction for the Treatment group.

Beginning May 24, 1999 an eight-week TOEFL practice course was provided for all 60 students divided into Group A, the Treatment group, and Group B, the Control group. For Group A, a series of TOEFL practice websites selected by the researcher were used for the practice sessions. For Group B, TOEFL practice classes were taught by the researcher in a teacher-centered classroom using TOEFL practice texts previously purchased by the college. After eight weeks, on July 16, 1999 the Pre-TOEFL Test was administered again to all 60 students together in the same classroom during the regular class. Employing inferential statistics using the SPSS 9.0 software program, the null hypothesis was tested using a paired samples t-test to determine the level of significance of the mean pre and posttest scores within each group, and is displayed in Table 2. Because one participant from the Treatment group was absent from the posttest, $\underline{N}=29$. 
Table 2

Level of significance of pre and posttest mean scores within each group

\begin{tabular}{|c|c|c|c|c|c|c|}
\hline & $\underline{\mathbf{N}}$ & $\begin{array}{c}\text { Pretest } \\
\underline{M}\end{array}$ & $\begin{array}{c}\text { Posttest } \\
\underline{\mathbf{M}}\end{array}$ & $\begin{array}{l}\text { Gain } \\
\text { score } \\
\underline{\mathrm{M}}\end{array}$ & $\underline{t}$ & $\begin{array}{l}\text { Significance } \\
p<.05\end{array}$ \\
\hline Control & 30 & 360.20 & 379.10 & 18 & 5.203 & .000 \\
\hline Treatment & 29 & 353.20 & 366.20 & 13 & 2.641 & .013 \\
\hline
\end{tabular}

Results indicated that within each group there were significant differences of the pre and posttest mean scores at the .05 level. Upon further evaluation, however; using an independent samples t-test, the difference in the gain score between each group was not found to be statistically significant at the .05 level as shown in Table 3.

Table 3

Level of significance of mean gain scores between each group

\begin{tabular}{llcll}
\hline & $\underline{\mathbf{N}}$ & $\begin{array}{c}\text { Gain } \\
\text { Score } \\
\underline{\mathrm{M}}\end{array}$ & $\underline{\mathbf{t}}$ & $\begin{array}{c}\text { Significance } \\
\mathbf{p}<.05\end{array}$ \\
\hline Control & 30 & 18 & .969 & .337 \\
Treatment & 29 & 13 & .964 & .339 \\
\hline
\end{tabular}

In Table 3, since no significant differences were found between the two groups in term of the gain score, as such, we can conclude that while both groups improved their scores over the course of the semester, neither group performed better than the other, suggesting no real differences between the treatment and control groups. 


\section{Qualitative results}

The qualitative research question was as follows: What cultural factors related to Confucianism enhance and/or inhibit female Japanese college students' attitudes and/ or perceptions of learning in a web-based environment? The researcher attempted to tap into the interviewees' attitudes and perceptions of web-based instruction through the five tenets of Confucianism that, according to the researcher, are found in traditional Japanese education. These tenets included: (a) expected behavioral differences between teachers and students, (b) reward over effort, (c) memorization as a major learning technique, (d) reliance on textbooks, and (e) use of exams.

\section{Sample Selection}

As discussed in Chapter 3, the sample consisted of six students from the Treatment group who were selected on the basis of their Pre-TOEFL pre-test scores. In order to get an objective sample from the Treatment group, the researcher arranged the scores from highest to lowest and selected the two students with the top two scores, two students at the median, and two who scored the lowest. (See Appendix E for test scores).

\section{Format for Reporting Results}

As mentioned in Chapter 3, three sets of interviews for a total of 18 were completed. The following format was utilized in reporting the results from the interviews. First, a general description of the interviewees' demeanor was discussed. Second, a brief description of the researcher's purpose for the question and the Confucian tenet(s) that relate to the question were given. Next, the question was provided in italics followed by quotes from the respondents. Lastly, a discussion related to the Confucian tenet(s) and the respondents' quotes 
were elucidated. At the end of each set of interviews, a general synopsis of the interview process was provided, and a final summation of all three interviews has been given at the end of the chapter. Note that the native language of all interviewees was Japanese and reported data from the interviews were written in the interviewees' own words. No attempt was made to correct grammatical or usage errors of English.

In order to protect the anonymity of the interviewees, the following codes were used in all interviews for reporting responses: $1 \mathrm{H}$ and $2 \mathrm{H}$ represented the two highest scoring Pre-TOEFL test students, 3M and $4 \mathrm{M}$ depicted the two median scoring students, and $5 \mathrm{~L}$ and $6 \mathrm{~L}$ were the two lowest scoring students. In addition, when appropriate, pre and posttest scores have been provided in parentheses in the narrative and in the tables as an attempt to connect student responses with test scores. The interviews were reported in a descriptive narrative and when relevant, accompanied by tables that aided the researcher in understanding student responses. Also, responses from the interviewees were written with nonverbal cues incorporated into the narrative. Finally, triangulation between the interviewees' answers and weekly logsheet questions was reported when there was a clear link between the two.

\section{Pre-treatment Interview Results}

The purpose of the pretreatment interview was to gain insight into the students' attitudes and expectations regarding the web-based course they would subsequently experience the following eight weeks. All six students were interviewed during the week of May 17 1999, in the researcher's office during regular school hours. Interviews were successfully recorded for students $1 \mathrm{H}$ (427/397), 3M (357/347), 4M (350/373), 5L (310/343), and 6L(237/347) using the 
school equipment. However, due to a technology malfunction, recorded responses from student $2 \mathrm{H}$ were obtained only for question six. The original plan of talking to students for one hour turned out to be too optimistic for the pretreatment interview. Only 30 minutes were needed and during much of the time students thought about the questions for a couple of minutes before they answered.

After the students arrived at the researcher's office, general pleasantries were exchanged, the student was offered a seat, and a few minutes were spent in casual conversation. During this interchange, all six interviewees maintained good eye contact and told the researcher this was the first time a teacher had asked for their opinion about a teaching or learning matter. This in itself revealed that this type of behavior between teachers and students was not common in traditional Japanese education. Consequently, during the interviews, $1 \mathrm{H}$ $(427 / 397)$ and $4 \mathrm{M}(350 / 373)$ were somewhat relaxed but $2 \mathrm{H}(400 / 397), 3 \mathrm{M}$ (357/347), 5L (310/343), and 6L (237/347) showed signs of agitation as the interview progressed. In fact, during questioning, eye contact with the researcher decreased and students reverted to nonverbal communication methods that were similar among all interviewees. For example, techniques of speaking softly, looking down at the floor when thinking about an answer, twirling hair, looking around the researcher's office, looking in a dictionary, and nodding "yes" instead of speaking were nonverbal cues used by all the students. These behaviors, especially avoiding eye contact and looking down at the floor, are indicative of the type of behaviors Japanese students use when communicating to someone higher in rank, for example, a teacher, administrator, or parent. In addition, when there was a problem understanding the question, two of the students 
moved to the edge of the chair which was interpreted as a request to repeat the question. Even though the students were told there was no time limit for answering questions and they could just relax, they still appeared nervous. One student, 3M, became especially nervous and almost gave up on the interview. She relied heavily on gestures for her answers and the researcher used various directed probing questions to elicit the student's opinions and feelings about her attitude and perceptions of web-based instruction. It was noted by the researcher that the tape recorder had a negative effect on all interviewees but especially $3 \mathrm{M}$ and $6 \mathrm{~L}$. Both students requested that the tape recorder be turned off several times while they thought about their answers. While the following explanation is not conclusive regarding the source of the students' anxiety during the actual interview, it is fair to say that the combination of the tape recorder and the newness of this kind of interaction between a teacher and a student contributed to their anxiety.

The first question related to the Confucian tenet of expected behavioral differences between teachers and students. The researcher attempted to gain insight into the subjects' attitudes and perceptions about their prospective relationship with the teacher in the upcoming web-based course.

1. How do you think your relationship with your teacher will be affected by studying using web-based instruction? Do you expect it to be the same or different from a regular classroom? What behavior or actions do you expect of your teacher while you're using web-based instruction?

During both the interview and coding process, it was found that responses fell into two main categories with students being divided in their 
expectations of the relationship between the student and teacher as shown in Table 4.

Table 4

Responses to expectations of relationship between teacher and student.

$\begin{array}{llllll}\text { Interviewees } & 1 \mathrm{H} & 3 \mathrm{M} & \mathbf{4 M} & 5 \mathrm{~L} & 6 \mathrm{~L} \\ \text { Pre-test score } & 427 & 357 & 350 & 310 & 237 \\ \text { Post-test score } & 397 & 347 & 373 & \mathbf{3 4 3} & \mathbf{3 4 7}\end{array}$

Expects the relationship

with the teacher in the

Internet class to be the same as in the regular class.

$\mathrm{X} \quad \mathrm{X}$

Expects the relationship

with the teacher in the

Internet class to be

different from the

regular class.

$\mathrm{X}$

In analyzing the responses, three of the five students expected the relationship to be the same as in the regular classroom. Both $5 \mathrm{~L}$ and $6 \mathrm{~L}$ stated simply, "[The] relationship with the teacher is the same," while $3 \mathrm{M}$ provided more insight and said, "Teacher has to teach all the students....regular class and the Internet class - teacher's the same." Interestingly, these students were the middle and lower scoring students on the Pre-TOEFL pre-test suggesting a possible connection between lower scoring students and their preference for a traditional teacher/student relationship. Of the two students who anticipated the relationship to be different, $1 \mathrm{H}$, the highest scoring Pre-TOEFL test student, used words such as "We learn myself," which suggests she expected more freedom in this type of class as opposed to the regular class, therefore, the teacher/student relationship would be different. In comparison, 4M, a middle-scoring Pre-TOEFL 
test student also expected the relationship to be different. In expressing her ideas, $4 \mathrm{M}$ used words such as, "Personal study English...personal for me so teacher shouldn't teach. Internet teach for us". She further stated that, "Regular classroom we talking with teacher. Internet classroom we seldom talk with teacher. Relationship is different." Interestingly, during both the interviews and coding analysis, it was observed that expectations of the teacher's actions also fell into two categories as shown in Table 5.

Table 5

Student expectations of teacher actions

\begin{tabular}{llllll}
\hline Interviewees & $1 \mathrm{H}$ & $\mathbf{3 M}$ & $\mathbf{4 M}$ & $5 \mathrm{~L}$ & $6 \mathrm{~L}$ \\
Pre-test score & 427 & 357 & 350 & 310 & 237 \\
Post-test score & 397 & 347 & 373 & 343 & 347
\end{tabular}

1. Expects the actions by the teacher in the Internet class to be the same as in the regular class. $\mathbf{X} \quad \mathrm{X}$

2. Expects the actions by the teacher in the Internet class to be the different from the regular class. $\quad X \quad X$

Student $1 \mathrm{H}$, in keeping with her expectations about the student/teacher relationship being different in the web-based class, also expected the teacher's actions to be different and said, "I think the teacher has to think a different way to teach [between] text and computer." She further stated, "In the [regular] class if we have something we can't understand, we cannot say to the teacher but I think in the computer class we can...(pause) we can ask the teacher more than in other class." On the other hand, even though $3 \mathrm{M}$ expected the same relationship between the teacher and student, she expected different actions. She clearly declared, "Internet class...teacher no speaking...regular class...speaking." 
Conversely, though student $4 \mathrm{M}$ expected the relationship to be different, she expected the actions of the teacher in the Internet class to be the same as in the regular class, in other words teaching to the whole group as in the regular class. She stated, "I want the teacher to teach how to use the Internet and the language." This may seem like a contradiction with her previous statement about expecting the relationship to be different but it also suggested that in keeping with Confucian tradition, she expected the teacher to be the dispenser of knowledge even if the traditional student/teacher relationship was different. Student $5 \mathrm{~L}$ and $6 \mathrm{~L}$ also agreed that the teacher's actions should be the same as in the regular classroom. When queried student 5L simply stated, "Yes, same," while student 6L said very softly while looking down, "Very easy tell me...teach to me because I don't understand." In summary, from the responses, it appeared students had neither a clear idea nor consensus of how their relationship with the teacher would be affected or what actions they could expect of the teacher in the web-based class. However, considering that none of the interviewees had been exposed to web-based instruction prior to the interview, the responses seemed quite normal.

The second pretreatment question focused on the Confucian tenet of reward over effort. The researcher attempted to query students' attitudes toward working individually versus in a group environment, which is a common practice in traditional Japanese education.

2. In our class you will be working individually at a computer using websites for TOEFL practice. How do you think this type of individual and not group environment will affect your learning? How might it affect your classmates learning? 
All students responded affirmatively about working individually. Student $1 \mathrm{H}(427 / 397)$ clearly explained that learning at her own speed was better than studying together in the regular class. With a smile on her face and speaking very confidently, she stated, "I think that we can learn with own speed. [In the regular class] because we have to study each together...so we can't study at own speed so have to do together. I think using the computer is better." Student 3M (357/347) also felt that working by herself would help her correct previous problems she had in reading English texts and stated a bit nervously, "I had trouble in high school reading English text so I think the Internet will change this. Working by myself at the computer will help me." Other interviewees concurred. Student $4 \mathrm{M}(350 / 373)$ declared that, "Being individual is not a problem," while 5L (310/343) admitted, “Working by myself is a good thing. Classmates have the same idea." Student 6L (237/347) felt that working by herself was just as interesting as working with others in the traditional classroom. As a result of the above responses, it appeared the Confucian tenet of reward over effort was supported in this learning environment but in a different way than in the traditional classroom. Typically this tenet was found operational in a group environment as found in a traditional classroom, but the responses indicated that the students were ready to learn in a more individual environment which suggested a movement away from traditional Japanese educational practices with less competition and more self-fulfilling educational endeavors.

The next question attempted to elicit answers that were related to all five Confucian tenets, namely, expected behavioral differences between teachers and students, reward over effort, use of memorization as a major learning technique, reliance on textbooks, and use of exams. The researcher asked an open-ended 
question that sought to gain insight into the main advantage students could get from web-based instruction.

3. Describe the biggest advantage you hope to gain by web-based instruction.

This was a difficult question for the students and it was observed they all thought seriously about their response. Because none of the students had any previous experience with web-based instruction, answers to this question varied. For example, student $1 \mathrm{H}(427 / 397)$ continued to advocate the individuality of the learner in the new environment. She stated, "It's different so we can learn new way...it is individual so I think that's good." Students 3M (357/347), 5L (310/343), and $6 \mathrm{~L}(237 / 347)$ responded with simple but specific advantages. For instance, student $3 \mathrm{M}$ related her answer to a more practical view and said, "I need computer in working world...(pause) this point is my big point." Student $5 \mathrm{~L}$ stated that the advantage was that it would be a challenging experience for her while $6 \mathrm{~L}$ quietly confided in the researcher and said, "I expect to understand English and foreign country home page." Unlike the other interviewees, after rephrasing the question twice and asking several probing questions, student $4 \mathrm{M}$ (350/373) finally stated that she didn't know what the biggest advantage would be. In analyzing the relationship between the students' responses and the five Confucian tenets mentioned above, on the surface it seemed that no direct connection was made between the two; however, there may have been underlying or secondary connections between some responses and some tenets. For example, in examining 3M's answer, being adept at using a computer in the working world suggested learning a skill that would give her an advantage, i.e., reward over effort. Student 6L's response indicated that she was getting away from a dependence on a textbook for learning English and getting information 
about other countries. Student $1 \mathrm{H}$ continued to advocate her feelings about individualized education that could be seen as a clear sign of breaking away from traditional behaviors and expectations of contemporary Japanese educational practices.

In summary, similar to the responses from question number one, there was no consensus among the students regarding the biggest advantage for webbased instruction. However, the Confucian tenet of reward over effort gained support from one student, yet other responses indicated that the Confucian tenets of textbooks as a major source of knowledge and expected behavioral differences between teachers and students had been challenged.

The next question targeted the Confucian tenet of using exams as a means to measure knowledge. The following questions were posed to the students to determine their attitude and/or feeling about using exams in the web-based class.

4. Do you expect to have exams while learning by web-based instruction? If so, what kind of eoaluation or exams are you anticipating?

Similar to questions one and two, two main categories surfaced during the coding process as shown in Table 6.

Table 6

Exam expectations of interviewees during treatment

\begin{tabular}{llllll}
\hline Interviewees & $1 \mathrm{H}$ & $3 \mathrm{M}$ & $\mathbf{4 M}$ & $5 \mathrm{~L}$ & $6 \mathrm{~L}$ \\
Pre-test score & 427 & 357 & 350 & 310 & 237 \\
Post-test score & 397 & 347 & 373 & 343 & 347 \\
\hline Expects an exam & $\mathbf{X}$ & $\mathbf{X}$ & $\mathbf{X}$ & $\mathbf{X}$ & \\
\begin{tabular}{l} 
Does not expect an exam \\
\hline
\end{tabular} & & & & & $\mathbf{X}$ \\
\hline
\end{tabular}


For the most part, student responses to this question were short and to the point. Only student $6 \mathrm{~L}$ said she did not expect to have a test. In fact, she was emphatic about it and stated in a strong voice, "Test?......no!" Students $4 \mathrm{M}$ and $5 \mathrm{M}$ appeared nervous about the question and shyly stated they expected to have a test; however, when further queried by the researcher, looked down at the floor and did not give any further information. On the other hand, student $3 \mathrm{M}$ displayed a completely different demeanor and went so far as to specify what the test should be and declared, "It should be at the beginning of week five of the program." Student $1 \mathrm{H}$ was the most vocal and examined both sides of the situation. She stated,

I think we have to do [take a test]...every week if we do a short test. But if we do a long test, one time in the middle. If we have no test, I think that's good, too. But having a test makes us work hard.

In conclusion, it is apparent that use of exams continued to influence what students expected in a learning situation. Even though all the students had no web-based learning experience, the idea of having a test to determine what a student knows, regardless of the medium of instruction, was still a part of their psyche.

Question five attempted to get student attitudes about use of textbooks in the web-based class and was related to the Confucian tenet of reliance on textbooks for knowledge acquisition.

5. For our purposes you will not be using a traditional textbook but will use the TOEFL practice websites as textbooks. What is your feeling about this?

Table 7 shows a comparison of the interviewees' expectation of needing a text for instruction. 
Table 7

Interviewees' expectations of needing a text for instruction

\begin{tabular}{llllll}
\hline Interviewees & $1 \mathrm{H}$ & $\mathbf{3 M}$ & $\mathbf{4 M}$ & $5 \mathrm{~L}$ & $6 \mathrm{~L}$ \\
Pre-test score & 427 & 357 & 350 & 310 & 237 \\
Post-test score & 397 & 347 & 373 & 343 & 347
\end{tabular}

Needs a text

Does not need a text

Sometimes needs a text

$\mathbf{X}$

$x \quad x \quad x$

From Table 7, it is clear that there were mixed reactions to this question. Only student 3M (357/347) said she needed a textbook because she could not access the websites at home due to her family not having a computer. She stated, "I think I need textbook. Only website is...return my home...no studying TOEFL [because of no computer] but I want to study TOEFL." Contrary to this answer, student $1 \mathrm{H}(427 / 347)$ gave a good reason for not needing a textbook. Her eagerness to learn a new way was demonstrated in her response. Smiling, she declared, "I think it's a different way to study than the textbook so it's good." Student 6L (237/347) gave an answer in an opposite manner from her strong response to the previous question. Softly she said, "Enough understand Internet, no textbook." Student 5L (310/343) contemplated the pros and cons before answering and acknowledged that she would sometimes like to use a textbook. Finally, student $4 \mathrm{M}(350 / 373)$ responded with a purely practical reason that was strikingly different from the other interviewees'. When she realized that she would not need a textbook, her face lit up and she said, “Oh, I'm happy because not be textbook...my bag is lighter!" It is important to note that this response is not unusual for Japanese students as many travel long distances daily to and from school. In the case of student $\mathbf{4 M}$, she said it took an hour and a half to get 
to school and she had to stand on the train the entire time. In summary, from the responses three students were willing to entertain the idea of not using a textbook and rely solely on the Internet websites for their course work which is in direct conflict with the Confucian tenet of reliance on textbooks for knowledge acquisition. Only one student definitely wanted to use a textbook while another student wanted the option of using it or not using it.

The final pre-treatment interview question was related to the Confucian tenet of using memorization as a major learning technique. The interviewer attempted to get students to explain their plan for remembering how to navigate through the websites. For this question, responses were received from all six students.

6. While studying over the web, you will not be memorizing facts but you will have to remember how to navigate through several websites. How do you plan to remember this? Will you take notes, use pictures, ask your classmates? How will you remember what to do?

Most of the students had a strategy they planned to use for remembering how to navigate through the websites. For example, students $1 \mathrm{H}(427 / 397), 2 \mathrm{H}$ (400/397), 5L (310/343), and 6L (237/347) all stated they would take notes. In addition, students $2 \mathrm{H}, 5 \mathrm{~L}$, and $6 \mathrm{~L}$ specified they would then ask their friends to help them remember, while student $1 \mathrm{H}$ said she would ask the teacher. Student 5L even had a further plan of asking her e-mail friends for help. In a different vein, contrary to her experience in the regular class, student $3 \mathrm{M}$ (357/347) stated she would not use notes in the web-based class but remember how to use the websites from week to week declaring, "Because I have a memory, Internet class no notes - it's practice. Regular class note I have." Only student 4 M (350/373) 
stated that she had no plan for remembering how to navigate the websites. Her response, although short and to the point, was seen as the most insightful of the answers. Because none of the students had experienced web-based instruction before, having a memory strategy already determined could have been a result of their previous experience with memory methods for example, taking notes, asking friends for confirmation of the information, etc. In the case of $4 \mathrm{M}$, because she had no previous experience, she also had no idea what technique she would use, which appeared to be the most logical answer of all. A summary of all responses showed that five students clearly had decided on some kind of memory strategy while one student had yet to determine what the best method for remembering how to navigate the websites would be. This suggested that students intended for memory methods they used before in the traditional classroom to be transferred to the web-based instructional environment.

To summarize the first set of interview results, the pretreatment interview questions attempted to understand students' attitudes about web-based instruction using questions that were related to the five tenets of Confucianism that, according to the researcher, are observed in traditional Japanese education. From the data, there was unanimous agreement on the acceptance of working individually; however, consensus was not achieved for the other responses. A synopsis of the answers revealed that regarding the expected relationship between teachers and students in the web-based class, three of the respondents, $3 \mathrm{M}(357 / 347), 5 \mathrm{~L}(310 / 343)$, and $6 \mathrm{~L}(237 / 347)$, anticipated the same kind of relationship with the teacher in the web-based class as in the traditional classroom, while two respondents, $1 \mathrm{H}(427 / 397)$ and $4 \mathrm{M}(350 / 373)$ predicted a different kind of relationship. Similarly, three of the students $(4 \mathrm{M}, 5 \mathrm{~L}$, and $6 \mathrm{~L})$ 
expected the teacher's actions to be the same in the web-based class as in the regular class while two students ( $1 \mathrm{H}$ and $3 \mathrm{M}$ ) held opposing views. In examining the Confucian tenet of reward over effort, as previously mentioned students unanimously agreed that working individually was good, and learning by webbased instruction definitely had some advantages. With respect to the Confucian tenet of using exams for measurement of knowledge, four out of five students $(1 \mathrm{H}, 3 \mathrm{M}, 4 \mathrm{M}$, and $5 \mathrm{~L})$ said they expected an exam, which suggested that at this time, this tenet was still alive and well in the students' expectations of instructional techniques. Students were divided on the need for using a textbook as three students $(1 \mathrm{H}, 4 \mathrm{M}$, and $6 \mathrm{~L})$ stated they did not need a text while one student (3M) advocated the need for a text and another (5L) stated she sometimes needed a text. There was no division of opinion, however, on supporting the Confucian tenet of memorization as a major learning technique. Five out of six students $(1 \mathrm{H}, 2 \mathrm{H}, 3 \mathrm{M}, 5 \mathrm{~L}$, and $6 \mathrm{~L})$ clearly had a memory strategy already decided while only one student $(4 \mathrm{M})$ had not yet determined how she would navigate through the websites. This implied that students intended for memory methods that had already been established in the traditional classroom to be transferred to the web-based environment.

Interview \#2 Results

The main objective of the second interview was to acquire further understanding regarding the interviewees' attitudes and perceptions of webbased instruction after four weeks of study. Arranging the second set of interviews was very difficult. At first all students made appointments to be interviewed at the end of the fourth week; however, all students cancelled for various reasons, for example, dental and doctor appointments. Luckily, all 
interviews were carried out during the fifth week from June 21-25, 1999. In addition, responses from all six interviewees were successfully recorded. As in the first set of interviews, notes were taken on students' nonverbal language. Before reporting individual responses, a summary of the students' overall behavior during the interviews has been discussed.

Regarding the students' nonverbal communication patterns, the top three scoring Pre-TOEFL students, namely $1 \mathrm{H}(427 / 397), 2 \mathrm{H}(400 / 397)$, and $3 \mathrm{M}$ (357/347) were noticeably calmer and more relaxed than in the first interview. All interviewees had much better eye contact but still adhered to traditional nonverbal communication techniques such as looking down at the floor when they did not understand a question or when they needed time to think. Student 4M (350/373), a middle-scoring student, changed her appointment three times and had a very indifferent attitude during the interview. In fact, she appeared to be uninterested in the interview and seemed to want it to be over as soon as possible. She gave short curt responses while sitting on the edge of the chair and jumped up to leave as soon as the interview was over. Interestingly, both lower scoring Pre-TOEFL students, 5L (310/343) and 6L (237/347), appeared more at ease but were still not completely relaxed throughout the interview. During the interview it was necessary to ask several times for clarification of 5L's comments and opinions. Students $5 \mathrm{~L}$ and $6 \mathrm{~L}$ smiled more and maintained better eye contact during the second interview, however, both were still wary of the tape recorder. In fact, student $6 \mathrm{~L}$ used hand signals which was a sign for the researcher to turn off the tape recorder when $6 \mathrm{~L}$ had to think about an answer.

Consistent with the first interview, the second set of interview questions were related to the five tenets of Confucianism that, according to the researcher, 
are found in traditional Japanese education. Queries progressed from four general to eight specific questions and were reported in that order. The first three general questions were related to the Confucian tenet of expected behavioral differences between teachers and students while the fourth general question related to the Confucian tenet of reward over effort. In the first general question, the researcher attempted to understand how the students' behavior in the class had changed over the past four weeks from the beginning of the course.

1. Describe how your behavior and actions are different in this class since you started studying by web-based instruction.

The students did not give specific answers about their actions upon entering the computer room, but five out of six students stated their behavior had been positively affected. Students $1 \mathrm{H}(427 / 397), 3 \mathrm{M}(357 / 347)$, and $5 \mathrm{~L}$ (310/343) all used words such as "more active", and "more positive" than in the beginning of the class. For student $1 \mathrm{H}$, it was because she could remember how to use the website. Student $5 \mathrm{~L}(310 / 343)$ gave as her reason her use of the computer at home while 3M (357/347) did not give a specific reason for her positive attitude. Student $2 \mathrm{H}(400 / 397)$ gave a response that related her web experience to her English ability and stated, "My behavior towards English had quite changed because of IES class. I became the person who considered seriously about English because I could notice that my English ability was weak but now it's a little better." For student 6L (237/347), it was the individual learning that she liked. Only student $4 \mathrm{M}(350 / 373)$ had a negative answer. She categorically replied, "My behavior and actions have not changed since I started studying web-based instruction." In summary, the majority of students $(1 \mathrm{H}, 2 \mathrm{H}$, $3 \mathrm{M}, 5 \mathrm{~L}$, and $6 \mathrm{~L}$ ) stated their behaviors were more positive and active than in the 
beginning of the course. Only one student (4M) stated she had not been affected and her actions were the same. Generally speaking, this suggested that most students were becoming aware of the differences in behaviors one can experience while learning via web-based instruction compared to a traditional classroom environment.

Further probing the same Confucian tenet of expected behavioral differences between teachers and students, the second question attempted to get students' perceptions toward the teacher's behavior in both the traditional class and the web-based class.

2. You've been in this class for four weeks. Describe how the teacher's behavior and actions in your web-based class are different from your other teachers' actions and behaviors who have been teaching you in the traditional way during the last four weeks.

Four out of six students saw a distinct difference between the actions of the web-based teacher and the regular class teacher. Both $1 \mathrm{H}(427 / 397)$ and $6 \mathrm{~L}$ (237/347) stated that the teacher, "Teaches each student individually," and the "Teacher talk and teach us one to one." Student $2 \mathrm{H}(400 / 397)$ and 5L (310/343) used the word "active" to describe their perceptions about the difference between the teachers. $2 \mathrm{H}$ declared, "In the regular class, the teacher writes on the board and I sit quietly and listen to what she says so I am not active but in Internet class I am very active and I must do by myself. $5 \mathrm{~L}$ concurred and replied, "The difference is in the regular class. The teacher is passive but in the Internet class the teacher is active."

The two middle scoring Pre-TOEFL students, 3M (357/347), and 4M (350/373) had completely different responses. Student 3M simply stated that she felt no difference while $4 \mathrm{M}$, in keeping with her indifferent attitude during the 
interview clearly explained, "Because the class situation between the regular class and Internet class is totally different I can't compare the teacher's actions or behavior. In brief, four out of six students $(1 \mathrm{H}, 2 \mathrm{H}, 5 \mathrm{~L}$, and $6 \mathrm{~L})$ felt there was a difference between the teacher's actions in the web-based class compared to the regular class.

In triangulating the interviewees' responses with answers from the entire Treatment group on the logsheet question, "What was the teacher doing while you were working on your practice questions?" similar responses occurred. Out of 19 answers, 15 centered on the teacher helping the students. Examples included, "Teacher was walking and helped student," "Give me lesson downloaded from the above website," The teacher helped study of student," "She walked around me. I became interested in doing more and more," "The teacher was teaching students and used the computer," and "My teacher advised to me."

To summarize, in comparing the interviewees' responses with the entire Treatment group's logsheet answers, the overall theme for this question was "active teacher actions" versus "passive teacher actions" suggesting students" perceived the teacher's actions in the web-based class to be more active than the teacher's actions in the traditional class. This implied the Confucian tenet of expected behavioral differences between teachers and students, as documented in Japanese classrooms, was challenged in this web-based learning environment.

In an attempt to understand how the participants behavior with their classmates had changed, the third general question attempted to draw out the interviewees' perceptions about how they communicated with their classmates during the web-based class. 
3. Tell me about how you interact or communicate with your classmates during web-based instruction.

The responses were evenly divided for this question. Three students stated they spoke very little or did not talk to their classmates while working on the computer. Student 5L (310/343) stated simply, “I do not talk to my classmate. I work by myself," however, $2 \mathrm{H}(400 / 397)$ provided more of a reason why she did not talk to her friends. She explained, "I seldom communicate with other. I'm active with the computer but quiet with friends." Student $4 \mathrm{M}(350 / 373)$ exclaimed, "In the Internet class, I work by myself so I talk to my classmate a little." The remaining three students stated they communicated with their classmates quite often during the class. For student $6 \mathrm{~L}(237 / 347)$ and $1 \mathrm{H}$ (427/397) it was important to communicate with classmates about how many right answers they got while working on the TOEFL practice sites. $1 \mathrm{H}$ declared, "I communicate with my classmates about how many answers I got correct. Every time." $6 \mathrm{~L}$ hesitantly informed the researcher and said, "I ask my classmate how to operate the Internet. We talk about how many right answers we have." In the same meek way, student 3M (357/347) quietly stated, "I look at my friend's screen and my friends look at my screen. We help each other. Every time." She defended this position and further articulated, "T feel the communication with my classmate in the Internet class is the same as the regular class." It is clear that $50 \%$ of the interviewees felt comfortable communicating with other students during the course while the other half preferred to work alone.

Triangulation was achieved between the interviewees' answers and the week five logsheet responses from the Treatment group. According to the latter, $84 \%$ reported they worked independently which was a much higher number 
than the $50 \%$ reported by the interviewees. Furthermore, only $10 \%$ of the students stated they communicated with their classmates when they had a problem. This was far less than the $50 \%$ reported by the interviewees.

The final general question related to the Confucian tenet of reward over effort. Building upon a similar question that was asked in the pre-treatment interview, the following question attempted to grasp the students' perceptions about the advantages and disadvantages of learning by way of web-based instruction.

4. At this time, what advantages and disadoantages can you see from learning through web-based instruction?

After four weeks of treatment, the interviewees stated various positive advantages of web-based instruction. To illustrate, student $1 \mathrm{H}(427 / 397)$ continued to support the idea of individual learning. Looking at the researcher directly she clearly stated, "The advantages is we can study at our own pace and I have no disadvantages." Student 3M's (357/347) statement supported her classmate's. She replied, "I can study at my own pace." Other answers were mixed with student $2 \mathrm{H}(400 / 397)$ who stated, "I think if there is no this kind of class, I have no chance to use a computer, therefore, I think this class is a very good opportunity for me to be familiar with computer." Student $4 \mathrm{M}(350 / 373)$ continued her praise of not needing a textbook, and Student 5L (310/343) stated that the TOEFL test practice is good. Student 6L (237/347) followed simply with, "I can concentrate."

Contrary to the pretreatment interview question about the biggest advantage of web-based instruction, question four also inquired about the students' perceived disadvantages of web-based instruction. Student $1 \mathrm{H}$ 
(427/397) claimed she had no disadvantages while student $2 \mathrm{H}(400 / 397)$ complained specifically about a website. She revealed, "I have a complain about the website process which didn't have explanation, explanation time for the answers. Usually there were just answers but no explanation. I always wanted to know why my answer was not correct." Student 4M (350/373) also targeted her disadvantage to the website and said, "Disadvantage is when I find a new word from TOEFL practice passage, I look up the word in my dictionary but I can't write the word meaning into computer." Both 5L (310/343) and 6L (237/347) stated the disadvantage was they did not practice at home while $3 \mathrm{M}(357 / 347)$ revealed that she had trouble solving problems while working. Quietly she stated, "If I have a problem it is hard to keep going because it take [time] to solve the problem. To sum up, the disadvantages were related to the websites and not the method of instruction.

Returning to the advantages, in the second interview the comments were more specific than in the first interview, and supported the tenet of reward over effort in this type of learning environment. Key concepts were "individual learning," "our own pace," and "T can concentrate" which continue to appear in the respondents' answers. These answers added further support to the fact that, regardless of the disadvantages, as the treatment progressed, the interviewees' became more attuned to the advantages of individualized instruction via a webbased course. Consequently, this one theme, acceptance of individualized instruction, could ultimately undermine all five Confucian tenets investigated in this study.

The next part of the second interview consisted of asking eight specific questions all of which were related to the five tenets of Confucianism as 
previously mentioned. The first question related to the expected behavioral differences between teachers and students.

1. Tell me the process you follow when learning via web-based instruction, for example, what kinds of actions do you take when you enter the computer room? What do you do first, second, etc. How is this compared with a class you would take in a regular classroom?

Student $1 \mathrm{H}(427 / 397)$ reported that her actions were the same but the method of instruction was different, for example, "In regular class I open the textbooks to the page the teacher told to us but in this class I input the home address from my log paper." Student 4M (350/373) had the same idea and explained, "Regular class is not use the computer." 5L (310/343) did not see any difference and declared, "My action in the Internet class is the same regular class." A small difference was expressed by student $6 \mathrm{~L}(237 / 347)$ who said, "The regular class is the same but in the computer class I take any vacant seat. The regular class I have the same seat." Only student 3M (357/347) saw a distinct difference in her actions and declared, "In the Internet class I must be more independent. I use my dictionary more in the Internet class than regular class." Responses to this question ranged from no difference to a distinct difference in actions which suggested students were mixed in their attitudes about their actions in the web-based class being different from actions performed in a traditional class.

During the second question, the researcher attempted to understand what methods students used to remember their websites and how to navigate through them. This question related specifically to the Confucian tenet of use of memorization as a major learning technique. 
2. What techniques are you using to remember your websites and how to narigate through them?

Two answers were connected to using paper as a method of remembering. Student $1 \mathrm{H}(427 / 397)$ reported she used the logsheet and $3 \mathrm{M}(357 / 347)$ stated that she copied the directions on a paper. $2 \mathrm{H}(400 / 397)$ and $5 \mathrm{~L}(310 / 343)$ said they relied on "Yahoo" to remember while 4M (350/373) declared, "I use the bookmarks and the toolbar for Netscape and Yahoo." 6L (237/347) stated that she did the same thing every Monday and that helped her to remember. Clearly, students had different ways of remembering how to use the websites with no one method taking priority over another.

Question number three delved into the student's attitude about not using a textbook and attempted to see if there was a change in their attitude from the pretreatment interview. The Confucian tenet of reliance on textbooks was the impetus for the question.

3. During the first interview, I mentioned that you would not be using a textbook but the websites would take the place of a textbook. Now that you've been learning this way for four weeks, describe your impression or feeling about not using a textbook. Is it the same or different from our first interview?

Although they had different reasons, student $1 \mathrm{H}(427 / 397), 2 \mathrm{H}(400 / 397)$, and $4 \mathrm{M}(350 / 373)$, advocated not using a textbook. Student $1 \mathrm{H}$ stated, "It is the same with first interview. I feel good about not using textbook because we can study at our own pace," while student $4 \mathrm{M}$ continued with her practical reason. "I have the same opinion as the first interview. I don't have to carry heavy books to school." Student $2 \mathrm{H}$ related the experience of not using a textbook to increasing her knowledge of using the computer and declared, "I like the no textbook way 
because I can learn how to use computer more and more at the same time." On the other hand, student $3 \mathrm{M}(357 / 347)$ continued with her need to have a text and stated, "I think I want to use a textbook because I forget the website information each week. So I ask my friend but my friend forget, too. So we need a textbook." Student $5 \mathrm{~L}(310 / 343)$ who was undecided in the pretreatment interview about needing a textbook, now stated that she wanted to use a textbook so she could practice at home. Contrary to her pretreatment response, "Enough understand Internet, no textbook," Student 6L (237/347) now ad vocated using a text. She elaborately stated,

I think using a textbook because I can review at home. I write in textbook for Japanese translation and I can mark an important sentence for TOEFL. practice. I think it is better to write the answers on paper so I can remember and easy to review. We should have a textbook in this class. In summary, for this question students $1 \mathrm{H}$ and $4 \mathrm{M}$ had the same perception as in the first interview regarding not needing a textbook. In addition, student $2 \mathrm{H}$ whose response was not recorded in the pre-treatment interview, agreed with $1 \mathrm{H}$ and $4 \mathrm{M}$ for a total of three students not needing a textbook. As in the pre-treatment interview, student $3 \mathrm{M}$ continued with her need for a textbook. Moving in that direction, student, $5 \mathrm{~L}$, who was undecided in the pre-treatment interview now claimed the need for a text while the Last student, 6L, who did not want to use a text in the first interview, had completely changed her mind. To put this into perspective, in the pre-treatment interview, only one student stated she definitely needed a text while in this interview, three students requested a textbook. These answers suggested that students were still not clear about how web-based instruction can be used successfully without a textbook. It was 
obvious, however, that more students were moving toward wanting a textbook in the web-based class.

The next question also followed up on a pretreatment interview question that was related to the Confucian tenet of expected behavioral differences between teachers and students. The researcher listened for differences in the interviewees' responses between their initial perceptions of expected behaviors between teachers and students and actual behaviors after four weeks of webbased instruction.

4. Describe what the teacher actually does while you are studying by web-based instruction? Do the teacher's actions follow what you expected when we discussed this in our first interview? If not, please describe how the teacher's actions are different from what you expected.

All students stated their expectations followed what they expected when we discussed this topic in the pretreatment interview. For example, in her pretreatment interview answer, student $1 \mathrm{H}(427 / 397)$ stated, "I think the teacher has to think a different way to teach [between] text and computer. In the [regular] class if we have something we can't understand, we cannot say to the teacher but I think in the computer class we can...(pause) we can ask the teacher more than in other class." However, responding to the second interview question, she stated, "Teacher is walking around the room. And the teacher should teach...(pause) I think the teacher should teach individually." Both of these statements support her initial response of teaching a different way. Students 3M (357/347), 4M (350/373), and 5L (310/343), all agreed with Student $1 \mathrm{H}$ that the teacher walked around the room, and all four stated this was what they expected. Even though there were technical difficulties recording $2 \mathrm{H}^{\prime} \mathrm{s}$ 
(400/397) pretreatment responses, for this question she clearly stated, "The teacher always took care of us but if I got some problem I could not ask it to my teacher because of my English problem. I didn't have enough skill to speak out what I want to say. The teachers actions are what I expected." Student 6L's (237/347) answer was directly related to her pretreatment response of, "Very easy tell me...teach to me because I don't understand." For the second interview question she said, "The teacher explains to me simply when I don't know what to do. This is what I expected." From the responses, it was clear the actions of the web-based teacher, although different from the regular classroom teacher, were what the students expected.

Question five investigated the students' methods for finding solutions to problems during web-based instruction. This question related to the Confucian tenets of expected behavioral differences between teachers and students, reward over effort, and reliance on textbooks.

5. What do you do if you do not understand something on the website? Do you ask a classmate, ask the teacher, or do nothing?

While exact problem-solving methods were different for each student, the contents appeared the same. Most answers included asking their classmates and then asking the teacher. For example, students $2 \mathrm{H}(400 / 397)$ and $6 \mathrm{~L}(237 / 347)$ stated they would first ask friends and then ask the teacher. Students $3 \mathrm{M}$ $(357 / 347)$ and $4 \mathrm{M}(350 / 373)$ said they would try to solve the problem first and them ask a classmate. However, $4 \mathrm{M}$ differentiated between website and computer difficulties and stated that if she had computer problems, she would ask the teacher. In keeping with her independent attitude, student $1 \mathrm{H}(427 / 397)$ declared that she would only ask her classmates while student $5 \mathrm{~L}(310 / 343)$ had 
a completely different attitude toward problem-solving and revealed that she would just ask the teacher. These responses showed that the higher Pre-TOEFL scoring students, namely $1 \mathrm{H}(427 / 397)$ and $2 \mathrm{H}(400 / 397)$, would first rely on their friends and then ask the teacher, while the middle scoring students would try to solve the problem themselves and then ask a classmate. Resembling the higher scoring students, $5 \mathrm{~L}(310 / 343)$ and $6 \mathrm{~L}(237 / 347)$ would also ask classmates as well as the teacher. In relating the responses to the Confucian tenets mentioned above, it appeared that there are indeed different behaviors practiced by the students for problem solving. Attesting to the fact that all students had some kind of strategy suggested that reward over effort played a role in motivating students to find a solution to their problem. However, reliance on textbooks does not enter the formula as none mentioned they would consult a textbook to find the answer to a problem.

The next question grappled with the Confucian tenets of expected behavioral differences between teachers and students.

6. How do you get the teacher's attention and speak to the teacher while you are working on a website? Is this the same or different compared to a regular classroom? If different, how is it different?

Similar to the previous question, five interviewees had the same components to their answer but different procedures for getting the teacher's attention. Three students, $1 \mathrm{H}$ (427/397), 6L (237/347), and3M (357/347) reported they raised their hand which was the same as in the regular class. For example, $1 \mathrm{H}$ proclaimed quite clearly, "It is the same as the regular classroom. I call my teacher. I raise my hand. Likewise, 6L explained, "I put my hand up and ask a question. Eye contact. [In the regular class] I hand up and ask a question." $3 \mathrm{M}$ 
declared her actions were also the same but the conditions were different and stated, "I raise my hand. It's the same but in the Internet class I feel more free to raise my hand than in the regular class. On the other hand, student $2 \mathrm{H}(400 / 397)$ and 5L (310/343) had completely different strategies for getting the teacher's attention. $2 \mathrm{H}$ stated, “I look at the teacher's eye when I wanted to speak something with her and I said, 'Excuse me.' In the regular class I don't have much chance to ask question because the teacher is always lecturing all the time." For 5L, "In the regular class I raise my hand but in the Internet class I wait till the teacher walks by my desk and speak to me." Only one student, $4 \mathrm{M}$ (350/373), had no strategy and quietly reported, "I usually don't speak to the teacher in the Internet class," which was in direct opposition to her previous answer where she conceded she asked the teacher when she had computer problems. From these responses, it was inferred that students' methods for getting the teacher's attention in the web-based class varied which again suggested that expected behaviors between students and teachers in the regular class versus the web-based class were somewhat different.

The next question examined students' attitudes toward working individually and their feelings related to their interactions with the teacher and classmates in the web-based classroom. The Confucian tenet studied was expected behavioral differences between teachers and students. 7. Because you have been working individually, interaction with your fellow students is different from that in a regular classroom. Describe your feelings about your interactions with your teacher and classmates while you are working on a web-based assignment. 
Student responses continued to strongly support working in an individualized environment. Key words in the responses were "working at my own pace" and "concentrating." For example, student 1H (427/397) stated, "I think it is good because everybody is working with their own pace and concentrating." Student $\mathbf{4 M}(350 / 373)$ concurred and stated in a succinct manner, "I can concentrate my attention on what I am studying." Student $2 \mathrm{H}(400 / 397)$ stated that at first she thought she would lose the opportunity to speak to her classmates and the teacher, however, now she needed an individualized class. $5 \mathrm{~L}$ (310/343) compared the web-based class to the regular class and announced, "In the regular class all student work together but in the Internet class I can work at my own pace." Student 6L (237/347) had similar comments, "I learn myself. I seldom contact the teacher or classmate. But that's good. I like learning by myself." Unfortunately, because of technical difficulties, a response from $3 \mathrm{M}$ $(357 / 347)$ was not recorded.

In summary, from the above responses, it appeared that the traditional expected behavioral differences between teachers and students that are found in the regular Japanese classroom are different from the expected behaviors in the web-based class as students voiced their approval of working in an individual versus group environment.

The final question related to a preinterview question regarding the Confucian tenet of use of exams. Through this question, the interviewer attempted to extract the students' attitudes toward exams being a part of the course thus allowing students to know their rank within the group.

8. You have already had exams in some of your traditional classes but in this class exams are not an important part of the course. Based upon your experience so far in this 
class, do you feel that exams should be a part of the course in order to know where you now rank with your other classmates?

Table 8 compares the preinterview responses with answers to the current question.

Table 8

Comparison of exam expectations between the preinterview and the second interview

\begin{tabular}{lllll}
\hline & \multicolumn{2}{l}{ Pre-Interview Responses } & \multicolumn{2}{l}{ Second Interview Responses } \\
\hline $\begin{array}{l}\text { Expects } \\
\text { an exam }\end{array}$ & $\begin{array}{l}\text { Does not } \\
\text { expect an } \\
\text { exam }\end{array}$ & $\begin{array}{l}\text { Needs } \\
\text { an exam }\end{array}$ & $\begin{array}{l}\text { Does not } \\
\text { need an } \\
\text { exam }\end{array}$ & Undecided \\
\hline $1 \mathrm{H}$ & $\mathrm{X}$ & & $\mathrm{X}$ & $\mathrm{X}$ \\
$2 \mathrm{H}$ & $\mathrm{X}$ & $\mathrm{X}$ & $\mathrm{X}$ & \\
$3 \mathrm{M}$ & $\mathrm{X}$ & & $\mathrm{X}$ & \\
$4 \mathrm{M}$ & $\mathrm{X}$ & & $\mathrm{X}$ & \\
$5 \mathrm{~L}$ & $\mathrm{X}$ & $\mathrm{X}$ & & \\
$6 \mathrm{~L}$ & & & & \\
\hline
\end{tabular}

Student responses to this question were different from their previous responses which suggested their attitudes had somewhat changed regarding the need for a test in the web-based class. In fact, in the pre-interview question, four out of five students stated they expected an exam while for this question only one student thought a test would be useful. To illustrate the attitude changes from the preinterview question, Student $1 \mathrm{H}(427 / 397)$ declared that if it was a short test she expected one each week but if it was a long test, then once in the middle. She further stated that having a test made the students work hard. However, for the current question she stated, "I feel we do not need a test because we will have a TOEFL test in July and we can know where we rank at that time after we get the test scores." Likewise, both 4M (350/373) and 5L 
(310/343) said in the pre-interview that they expected to have a test but after four weeks changed their minds. Student $4 \mathrm{M}$ specified, "I don't like test in the computer class but I'm interested in my rank," while 5M was vociferous in declaring, "In the computer class I think there is no need for a test. I don't care about my class rank." Contrarily, students 3M (357/347) and 6L (237/347) were consistent in their responses with $3 \mathrm{M}$ reporting in the pre-interview that she thought the test should be at the beginning of week five. For this question $3 \mathrm{M}$ remarked, "I think I should have a test so I know how much I understand about the Internet." $6 \mathrm{~L}$, in her short emphatic preinterview answer, "Test, no!" continued with the same idea albeit a bit more wordily, "I don't feel exams should be a part of the course." Because of technical difficulties, the preinterview response from student $2 \mathrm{H}(400 / 397)$ was not recorded; however, for this question she appeared to be undecided. She stated, "I think I don't need to take a test to know my order but I think that it is a good idea to take a test if it's just to know my ability of English whether or not it is improving."

Several points were considered in summing up the second interview. First, regarding nonverbal communication strategies, students were more comfortable during the second interview with better eye contact, but continued to utilize nonverbal cues when contemplating an answer. The tape recorder did not pose much of a threat for five of the students $(1 \mathrm{H}, 2 \mathrm{H}, 3 \mathrm{M}, 4 \mathrm{M}$, and $5 \mathrm{~L}$ ); however, one student (6L) continued to express extreme anxiety about the technology. Next, in attempting to further determine which Confucian tenets influenced the respondents' attitudes towards web-based instruction, two key points surfaced from the responses. First, regarding the expected behavioral differences between teachers and students, the responses indicated that students 
were more active in the web-based class compared to a traditional class possibly because of the individualized instruction in the web-based class versus group instruction in the traditional class. Second, students reported a difference in the expected actions of teachers in both types of classrooms, for example, lecturing and writing on the blackboard versus walking around. In fact, there was consensus that the teacher's actions in the web-based class were different from the actions of the teacher in the regular class. From these two points, it was inferred that for the interviewees, expected behavioral differences between teachers and students found in the traditional class were not supported in the web-based class.

Next, in assessing the Confucian tenet of reward over effort, from the responses it appeared that this tenet had a different kind of influence on students in the web-based class compared to the traditional class. For example, reward over effort in the web-based class appeared to be connected to the acceptance of individualized learning while in the traditional class it is connected to competition within a group learning environment. The next Confucian tenet of reliance on textbooks saw a change from the respondents' answers in the pretreatment interview moving from one student stating she needed a textbook to three students requesting a text. This suggested that this tenet still has merit for some students in this group when learning in a web-based environment.

Examining the Confucian tenet of memorization as a major learning technique revealed all students used traditional methods such as taking notes and using repetition in order to remember how to navigate through the websites. The last Confucian tenet of use of exams revealed that students who expected an exam during the pre-interview now discouraged the practice. In fact, only one 
student (3M) advocated giving an exam which suggested that after four weeks of web-based experience, students held negative perceptions about this tenet being employed in a web-based learning environment.

\section{Posttreatment Interview Results}

Interviews were held during the last week of classes beginning July 12, 1999, after the web-based course was finished. The main objective of the posttreatment interview was to acquire a greater understanding of students' attitudes and perceptions of the web-based course after eight weeks of instruction. An additional objective was the continued search for patterns in the interviewees' responses which would provide further insight into their attitudes and perceptions of web-based instruction. As in the pretreatment and second interviews, notes were taken on students' nonverbal communication techniques and are provided below.

The transformation of the students' interview behavior was impressive. From the onset, it was evident that all participants were much more relaxed and everyone was comfortable with the tape recorder. Students $1 \mathrm{H}(427 / 397), 2 \mathrm{H}$ (400/397), 3M (357/347), 5L (310/343), and 6L (27/347) all expressed more confidence in the interview process and participated in a more positive manner. Five out of six respondents displayed a variety of behaviors that seemed to be related to their happiness at being finished with the web-based course. For example, in addition to maintaining excellent eye contact, student $1 \mathrm{H}(427 / 397)$ also often smiled and chuckled. Even though she appeared somewhat selfassured in the first two interviews, during this interview she appeared to be a totally confident individual with a positive outlook on life. Student $2 \mathrm{H}(400 / 397)$ was excited about the third interview and gave her perceptions without any 
hesitation. She sat comfortably in the chair and looked directly at the researcher. She often smiled widely and appeared to listen intently to the interview questions. Unlike the other interviewees, at the end of the formal interview student $2 \mathrm{H}$ offered several suggestions for improvements to the course.

The next participant, student 3M (357/347), marched like a drill sergeant into the researcher's office at the exact time and sat down in the interview chair even before the usual courtesies were exchanged. She displayed an extremely confident and enthusiastic attitude during the interview in spite of the heat, humidity, and lack of air conditioning in the office. In addition, she maintained eye contact, smiled a lot, and gave short concise answers. Likewise, student 5L (310/343) appeared more confident and maintained good eye contact throughout the interview. Even though she spoke softly and was sometimes hard to hear, she answered the questions confidently and to the best of her ability. She often smiled and listened intently to the questions and was willing to clarify and expand her answer when further queried. The lowest-scoring member of the group, student 6L (237/347), was also prepared for the interview and arrived at the exact time. She was much more at ease than in the other interviews and, like the others, sat back in the chair and relaxed. In addition, she maintained extremely good eye contact throughout the interview and, contrary to the first and second interviews, never requested to turn off the tape recorder. Only student 4M (350/373) showed increased signs of distress and discomfort. She arrived on time but displayed a negative attitude about participating in the interview. In fact, the week before the interview she reported that she did not want to participate at all; however, she voluntarily changed her mind. During the interview her eye contact was very good but, unlike the other interviewees, 
4M never smiled. Furthermore, opposite to the others who sat back and relaxed in the chair, 4M sat on the edge of the chair, gave short curt answers, and attempted to make the interview as short as possible.

Consistent with the first and second interviews, the eleven posttreatment questions were related to the five tenets of Confucianism determined by the researcher to be evident in traditional Japanese education. Queries progressed from three general to eight specific questions and have been reported in the same order.

The three general questions were related to all five Confucian tenets: expected behavioral differences between teachers and students, reward over effort, use of memorization as a major learning technique, reliance on textbooks, and use of exams. The first question attempted to reveal the respondents' overall feeling about web-based instruction now that the course was completed. 1. Please describe your overall impression of learning by web-based instruction? All interviewees reported different but positive attitudes toward webbased instruction. In keeping with her previous responses about learning individually and not needing a textbook, $1 \mathrm{H}(427 / 397)$ stated, "I can concentrate more than using textbooks." This statement was in direct conflict with the Confucian tenet of reliance on textbooks. Related to reward over effort. $2 \mathrm{H}$ (400/397) stated in the second intervicw that if the class wasn't available, she could not learn how to use a computer. In the post-treatment interview she further elucidated, "What I learned from the class will work positively for rest of my life. I think that our society will be required to use computer more and more. So this kind of class will be more needed for students. That's why I like the class." Students 4M (350/373), 5L (310/343), and 6L (237/347) also gave 
responses that related to the tenet of reward over effort. In keeping with her quick answers, 4M simply stated, "I could know how to study a new way" while students $5 \mathrm{~L}$ and $6 \mathrm{~L}$ were more animated in their responses. $5 \mathrm{~L}$ exclaimed, "It was useful to me that I study TOEFL by computer," and 6L stated, "It is good to use Internet websites. I got used to TOEFL practice." On the other hand, student 3M's (357/347) impression of learning by web-based instruction was much more explicit and was related to the Confucian tenet of memorization as a major learning technique. She stated, “When I repeat same question, I can most understand the TOEFL question." In summary, the above answers suggested that the Confucian tenets of use of textbooks, reward over effort, and use of memorization as a major learning technique influenced the interviewees' outcome perceptions of the web-based course.

The next general question attempted to ascertain the participants' suggestions for students who would take the same web-based course for the first time in October, 1999. Note that the researcher looked for responses that related to any or all of the five Confucian tenets previously mentioned.

2. What recommendations would you make to students who are going to take this web-based course for the first time beginning in October of this year?

For the most part, the interviewees gave very practical suggestions to future students of the TOEFL practice web-based course. Relevant to the Confucian tenet of reliance on textbooks, student $2 \mathrm{H}(400 / 397)$ advised, "I think that students need to know the concerning words about the computer as preknowledge before they take the class. Next, they had better practice how to use the computer." Students 3M (357/347), 5L (310/343), and 6L (237/347) also gave pragmatic suggestions related to the above Confucian tenet as well as use of 
memorization as a learning technique. For example, 3M proposed, "I think it better to copy the question from the screen to the notebook," followed by $5 \mathrm{~L}$ who advocated, "I think they had better repeat many times the TOEFL website program." Finally, 6L disclosed, "I got used to the Internet websites by using the same Internet websites repeatedly. So I recommend this to students studying this for the first time." In sharp contrast to these practical suggestions, students $1 \mathrm{H}$ $(27 / 397)$ and $4 \mathrm{M}(350 / 373)$ had completely different responses. $1 \mathrm{H}$ gave a very general suggestion that was related to behavioral expectations between teachers and students. She stated, "You can study by yourself and ask the teacher when you have a question," while $4 \mathrm{M}$ had no recommendations and declared, "I would keep it the same." With the exception of $4 \mathrm{M}$, other responses indicated a connection between the Confucian tenets of reliance on textbooks, use of memorization as a major learning technique, and behavioral expectations between teachers and students and the interviewees' recommendations to future students of the TOEFL practice web-based course.

The final general question, simple and direct, aspired to seek specific suggestions for improvements in the TOEFL practice web-based course. As it was an open-ended question, all five tenets of Confucianism were challenged. 3. What suggestions can you make to improve the course?

Analysis of the responses revealed little connection to the five Confucian tenets found in traditional Japanese classrooms. However, one student, $2 \mathrm{H}$ (400/397), provided insight into the Confucian tenet of expected behaviors between teachers and students and disclosed, "Before teacher start the class, teacher needs to show some review question of TOEFL which are very important or quite difficult for students." With the exception of student $2 \mathrm{H}$, other answers 
were short and simple. To illustrate, student $1 \mathrm{H} \mathrm{(427/397)} \mathrm{concisely} \mathrm{stated,} \mathrm{"I}$ want to have listening practice," while 5L (310/343) hesitantly stated, "Mmmm...grouping work is good 50\% of the time." Interestingly, 4M (350/373) put the emphasis, not on the course improvement but on her own personal improvement and revealed, "I think I should study more new words." Only students 3M and 6L had no suggestions. 3M (357/347) said very cheerfully, “Nothing! Because I can handle the computer by myself and I enjoy working by myself. 6L (237/347) concurred but revealed in a softer manner, “Nothing. I would keep everything the same." While all of the above responses do not explore all five Confucian tenets, two respondents, namely $2 \mathrm{H}$ and $4 \mathrm{M}$, targeted the tenet of expected behavior between teachers and students and provided good suggestions for improving of the course.

Moving from the general to the specific, the next eight questions asked for more detailed answers from the respondents. The purpose was to have the students reflect upon their experience and thus provide the researcher with more understanding of their attitude and perceptions toward web-based instruction. All questions related to one or several of the following Confucian tenets: expected behavioral differences between teachers and students, reward over effort, use of memorization as a major learning technique, reliance on textbooks, and use of exams.

The first question queried the interviewees' feelings about how their image of web-based instruction had changed from the pre-interview to the postinterview. Because this was an open-ended question, all five Confucian tents listed above were related to the following question. 
1. Has your image about web-based instruction changed from the first interview and the beginning of the course? If so, how? If not, how has it remained the same as in the beginning of the course?

Only two students stated that their image was the same as the first interview. 1H (427/397) reported, "My image is the same as the first interview. I thought it's interesting and exciting for me." Student 5L (310/343) was of the same opinion and said, "The same impression; it is good for me to study in my pace." Respondents $2 \mathrm{H}(400 / 397), 3 \mathrm{M}$ (357/347), and 6L (237/347) all confessed they now had different ideas of web-based instruction from the first interview, and upon further inquiry, all divulged distinct reasons for their differing images. For instance, $2 \mathrm{H}$ revealed,

At first, I though a class was so difficult because I've never took that kind of class which use a computer during class. I, however, could change my feeling toward the class. The class was very interesting for me because I could get used to use a computer step by step.

In analyzing her response which suggested a connection to the Confucian tenet of expected behaviors between teachers and students, it is evident that she did not have experience with courses that use computer technology. This further suggested that, in addition to her lack of computer experience, she may have been anxious about other things, for example, the expected behaviors in the class, and what role the teacher would perform. To illustrate, in the second interview when asked how she got the teacher's attention, $2 \mathrm{H}$ stated, "I look at the teacher's eye when I wanted to speak something with her and I said, 'Excuse me.' In the regular class I don't have much chance to ask question because the teacher is always lecturing all the time." For this student, it is clear the behaviors 
were different in the web-based class and the traditional class. Luckily, she overcame the initial anxieties of the web-based course, including her lack of computer experience, and, according to her, enjoyed the class. In a similar vein related to experience with technology, student $6 \mathrm{~L}$ (237/347) related her anxiety specifically to using the websites and stated, "My first image about web-based instruction was it's difficult how to use Internet websites but now I have a good image because I enjoyed the Internet class." One student, 4M (350/373), provided a general answer that paralleled with her pre-interview responses about web-based instruction. She simply stated, “Generally speaking I like webbased instruction depending on the website. Some of the sites I didn't like."

In summary, from the above responses it is clear that the students' perception toward web-based instruction changed as the course progressed. This suggested that the Confucian tenets present in a traditional Japanese classroom had a lesser affect on the students' attitude toward web-based instruction.

The second question investigated students' perceptions of the differences between the web-based course and the traditional classroom. Confucian tenets of expected behavioral differences between teachers and students, reward over effort, use of memorization as a major learning technique, reliance on textbooks, and use of exams were connected to the following question.

2. Now that the course is over, tell me specifically how this course was different from learning in a traditional classroom setting?

Four out of six respondents stated a difference between learning individually versus learning in a group. To illustrate, student $1 \mathrm{H}(427 / 397)$ declared, "In the traditional classroom, I learn with my classmates, but in the Internet class I learn by myself. I like learning by myself." The researcher noted 
that this response was consistent with her attitude throughout the three interviews as she repeatedly stated she liked working alone or independently. Student $2 \mathrm{H} \mathrm{(400/397)}$ also liked working alone and stated, "The most important thing for the Internet class is that I have to do everything by myself. I've never gotten bored during the class. In addition, student $2 \mathrm{H}(400 / 397)$ provided further insight to the difference between the two classrooms, namely the difference between active and passive behaviors. For example $2 \mathrm{H}$ stated, In regular class the teacher would write down something on the blackboard and I would sit quietly and listen to what she said therefore I was tired of hearing compared with Internet class. I really enjoyed the Internet class because I would participate in the class. During the regular class I got bored.

Supporting her classmates, student 5L (310/343) explained, "At computer room, I was studying alone. In a traditional classroom I studied mainly conversation with other students in a group." $6 \mathrm{~L} \mathrm{(237/347)} \mathrm{agreed} \mathrm{and}$ proclaimed, "Traditional classroom is learned everybody together. Internet classroom is learned by myself. I like learning by myself."

Interestingly, an examination of the logsheet responses for week eight, revealed that $41 \%$ of the students stated the best part of the web-based course was studying at one's own pace. Taken together with the interviewees' answers, it appeared that contrary to popular belief about Japanese education and the emphasis on the group, these students reported that working individually was an acceptable mode of learning and actually had some merit over working in a group. It is clear that reward over effort continued to be positively influenced by the acceptance of individualized learning. 
The next question helped the researcher gain knowledge of students' perceptions of how the teacher's actions affected the students. In this question, the Confucian tenet of expected behavioral differences between teachers and students was further examined.

3. Describe how the teacher's actions helped or hindered your experience of learning by web-based instruction.

Only one student, 3M (357/347), said the teacher's actions did not affect her and stated, 'The teacher's actions did not affect me because I can operate the computer by myself." However, the other five students responded that the teacher helped when they had a question, when they did not understand a word, when they couldn't solve a problem, or when they didn't understand how to operate the computer. These responses challenged the Confucian tenet mentioned above and suggested the expected behavioral differences between teachers and students found in the traditional class do not influence students in the web-based class. For example, in the web-based class, instead of being the central figure controlling the learning experience, the teacher would, if requested, assist students only when they had a problem leaving time for the students to learn at their own pace.

In an attempt to further understand the respondents' feelings about completing the course without a textbook, the next two-part question, related to the Confucian tenets of reliance on textbooks and use of memorization as a major learning technique, revealed more interesting perceptions of web-based instruction. 


\section{You have completed the course completely without a textbook. Now that the} course is over, what is your impression of using the web as a textbook? Would you be willing to take other courses using the web as a textbook?

There were mixed reactions to both parts of the question. For the first part regarding using the web as a textbook student $3 \mathrm{M}(357 / 347)$ disclosed, "At the beginning I was nervous about not using a textbook but now I found I'm all right without textbook." In a different vein, in the first interview 6L (237/347) was definitive in her support of not needing a textbook while in the second interview she requested a text. In the last interview she reverted to her original opinion and stated, "This class OK without textbook." Student 5L (310/343) somewhat agreed but with a certain condition and explained, "T think satisfactory studying without textbook in instruction. If I have textbook go home and practice." Student $4 \mathrm{M}$ (350/373), however, was diametrically opposed and clearly proclaimed, "I don't like using the web as a textbook." Leaning toward a negative answer but relating it to a previous response, student $2 \mathrm{H}(400 / 397)$ stated, "Before I took the class I thought I don't need a textbook but now I think I need it because I couldn't review TOEFL practices when I want to."

In an attempt to triangulate the interviewees' responses with those of the Treatment group, the researcher posed a much more direct question on the students' logsheet for week eight. "From your experience using the Internet for TOEFL practice, is it necessary to use a textbook while studying via the Internet?" Out of 24 responses, 19 answered "yes" while five answered "no." Compared to the interviewees' answers which were clearly divided about the need for a textbook, the general feeling from the Treatment group was that a textbook is necessary, which suggested this tenet influenced the students' 
attitude toward web-based instruction. It was possible that some kind of text or guidebook would have been useful for students, especially those who had no web-based experience, but whether or not students actually needed a text for instructional or review purposes was not clear.

Regarding the second half of the question, only three students provided an insight about their willingness to take another web-based course with the web used as the textbook. True to form, student $1 \mathrm{H}(427 / 397)$ stated in an excited manner, "I had a good time. I want to take other Internet courses," while 3M (357/347) and 4M (350/373) had opposite opinions. 3M stated, "I enjoy various way of using TOEFL practices but I don't choose other courses because of my eyesight is bad." Stating directly with her usual confidence, 4M said, "I wouldn't take other courses using the web as a textbook."

Question five attempted to understand what initiative the students took to help themselves with this new method of instruction. The students had access to the computer room other than class time and the researcher wanted to ascertain if the students used the computer room or some other method to help them with web-based instruction. Indirectly related to the Confucian tenets of reward over effort, the researcher started with a general question followed by two specific questions.

5. As a student, what did you do to help your understanding of web-based instruction? For example, did you come to the computer room by yourself to practice the TOEFL questions using the websites? Did you work with a classmate on the TOEFL practice websites outside class time?

Four of the six students reported they did nothing outside of class. Smiling shyly and a little embarrassed, student $1 \mathrm{H}$ (427/397) said, “I didn't do 
anything. I only studied using the Internet in this class time." Students $3 \mathrm{M}$ (357/347) and 4M (350/373) had similar answers, and 3M volunteered, "I only did TOEFL practice during class." $4 \mathrm{M}$ stated in her usual short answer, "No I didn't (come to the computer room outside class). Student $6 \mathrm{~L}(237 / 347)$ was of the same attitude but more responsive in her answer, "Particularly I did nothing...(pause) but I studied English vocabulary a little." Only 2H (400/397) and $5 \mathrm{~L}(310 / 343)$ reported they studied outside the class but in different ways. $5 \mathrm{~L}$ revealed, "I studied TOEFL textbook in my house," while $2 \mathrm{H}$ had a two-part method and commented, "I sometimes went to computer room for study. I opened TOEFL practice site and I borrow TOEFL studying guide from my friend then I studied it twice a week." Based on the above answers, reward over effort was a stimulus for only two students. Even though this was the first time for these students to engage in this form of instruction, it was obvious that there was an overwhelming lack of initiative demonstrated by students to work outside class on the TOEFL sites. This suggested that, in the context of this question, reward over effort was not a motivating issue or students' felt the time spent in class was adequate for working through the websites. The next question focused on the Confucian tenet of use of memorization as a major learning technique and delved into students' methods for remembering how to use the websites.

6. What learning technique did you use to remember how to use the websites and would you recommend this technique to other students who were going to take this course for the first time?

For the first time in the interview process, there were six completely unique answers. Student $1 \mathrm{H}$ (427/397) offered, "I used the logsheet and input the address and open the website," while $2 \mathrm{H}(400 / 397)$ stated, "I always "Yahoo" to 
find out homepage sites. I would recommend this." 3M (357/347) revealed, "I took ah...some ... note. I recommend taking note." $4 M(350 / 373)$ flatly stated, "I typed the URL address from the logsheet. I have no recommendations." $5 \mathrm{~L}$ (310/343) smiled and said, "I ask the teacher. I recommend to ask the teacher." Only $6 \mathrm{~L}(237 / 347)$ gave the answer that was most expected but surprisingly not received from the others. She specified, "I repeated the same thing. It is important to use the same Internet websites again and again." The above answers revealed that all students had their own technique for remembering what to do and how to use the websites. While it was not exactly clear what the best method was for remembering the procedures for learning via web-based instruction, it was clear that rote memorization as practiced in the traditional class did not influence students in the web-based class.

Question \#7 researched students' attitudes toward working in a group versus working individually and explored the Confucian tenets of expected behavioral differences between teachers and students, and reward over effort. 7. In this web-based course you had to work by yourself and not as a part of a group. How do you feel about working alone and not in a group?

Only one student, $4 \mathrm{M}(350 / 373)$, stated she preferred to work in a group rather than by herself. Responses from the other five students were strikingly similar in particular the use of the words "concentrate" and "at my own pace." To illustrate, student $1 \mathrm{H}(427 / 397)$ stated, "I can work at my own pace and I can more concentrate," while 5L (310/343) revealed, "I can work at my own pace," and 6L (237/347) agreed and disclosed, "It's good. I learned TOEFL practice at my own pace." Student $2 \mathrm{H}(400 / 397)$ gave a detailed response, 
I have no complain about I take the class by myself and not as a part of a group because I feel that I can more concentrate and also if there were some problem I could ask those my friends and my teacher. I like working by myself.

In a similar vein, student 3M (357/347) said, "I don't bother to other student, so I can calm down to study." Once again, the theme of working individualiy came to the front with positive responses from five out of six interviewees. Triangulating the interviewees' responses with those from the logsheets from the last week of treatment revealed further interesting data. The logsheet question was as follows: "Do you prefer working in a group or by yourself while studying via the Internet?" From the 24 Treatment group students who responded, ten students stated they preferred to work in a group of two, one student revealed she preferred a group of three, while 13 students reported they preferred to work alone. Combining the latter responses with the positive remarks from the interviewees' clearly showed a preference for learning in an individual learning environment; a theme which repeatedly surfaced in all three interviews, and which was related to reward over effort. From the above, it was possible that this group of Japanese female college students entertained the idea of the benefits of an individual learning paradigm versus the traditional group learning method which could affect all five Confucian tenets under discussion throughout this study.

The final question in the post-treatment interview challenged the Confucian tenets of expected behavioral differences between teachers and students, reward over effort, and use of exams. A question about the use of 
exams was also asked in the pre-treatment and second interviews. A comparison of the responses for the three interviews has been given below.

8. How do you feel about exams not being a major part of the course? Did this bother you or was it a relief? What recommendations could you make about using exams in the course?

A comparison of responses from the three interviews revealed the following data. In the pre-interview question, four out of five students $(1 \mathrm{H}, 3 \mathrm{M}$, $4 M, 5 L)$ stated they expected an exam while in the second interview only one student (3M) thought a test would be useful. In the final interview, all six students stated they felt it was good not to have a test during the course. In analyzing the responses, four out of six students used the word "relieved" to describe their feeling about not having a test. For example, student $1 \mathrm{H}(427 / 397)$ described her feelings about not having a test and when a test should be given, "I am relieved. At the beginning of the course I thought we should have test, but now I think we should have at the last class." Students 4M (350/373), 5L (310/343), and 6L (237/347) also stated they felt relieved about not having an exam. 5L further stated that if there were a test, it should be the Pre-TOEFL test that would replace a regular test. On a slightly different note, student $3 \mathrm{M}$ (357/347) revealed, "It is good for me not to worry about a test. I would like to enjoy using Internet for learning and not worry about a test." Only student $2 \mathrm{H}$ (400/397) was a bit bland in her reaction. She opined, "T feel nothing about it but actually I feel better when I heard that exams not being a major part of the course." She stated that if there was a test it should be the Pre-TOEFL test which would take the place of a regular test. Next, a synopsis is presented of all three interviews followed by major and minor themes that emerged. 


\section{Summary}

To reiterate, all three interviews attempted to answer the second research question: What cultural factors related to elements of Confucianism influence Japanese female college students attitudes and/or perceptions of learning in a web-based environment? The researcher attempted to tap into the interviewees' attitudes and perceptions of web-based instruction through the five tenets of Confucianism that, according to the researcher, are found in traditional Japanese education. Those tenets are: (a) expected behavior between teachers and students, (b) competition with rank, (c) reliance on textbooks as a main source of knowledge, (d) use of memorization as a major learning technique, and (e) use of exams. As was previously mentioned, all interviewees graduated from Japanese high schools and therefore had been educated using traditional methods. Fortuitously for this study, none of the interviewees had experienced web-based instruction before the study commenced. In addition to weekly web-based learning activities for the entire Treatment group, six students from that group were interviewed three times: before, during, and after the treatment.

After intense examination of the responses from all three interviews, major and minor themes appeared. Regarding the latter, minor themes were connected to all five tenets, for example, unresolved issues about the need for both a text and a test, as well as different methods for remembering how to use the websites. However, in examining major themes, the overriding factor that enhanced the interviewees' perceptions of web-based instruction was the acceptance of individualized learning, which is a transformational shift in thinking for Japanese students. 
The notion of individualized instruction challenged all five tenets of Confucianism as found in the traditional classroom. For example, expected behavioral differences between students and teachers that have been documented to take place in traditional Japanese classrooms are, according to the responses, much different in an individualized learning environment. Similarly, reward over effort found in a traditional classroom was also challenged as it appeared that students advocated working in an individual environment with little concern about the group. Use of traditional memorization techniques were also challenged as students moved from definite predetermined methods in the pretreatment interview to six different ways of remembering information in the post-treatment interview. Interviewees also moved away from expectations of an exam. On the other hand, use of text was advocated by only one student in the pretreatment interview, but was supported by three students in the posttreatment interview.

While reflecting on the results of data from all three interviews, the researcher concluded that in a web-based environment, students moved away from the influence of the five Confucian tenets as found in traditional Japanese classrooms. It appeared that, parallel to the paradigm shift in the Japanese economy, a paradigm shift in thinking was also taking place with the interviewees' attitudes toward education and the acceptance of individualization through web-based instruction. As a result, if adopted into Japanese classrooms, web-based instruction could have profound effects on Japanese education. First, web-based instruction could allow students to move from working in groups with a ranking system governing the placement of students, to a more democratic form of learning that emphasized self-fulfillment rather than 
competition within the group. In addition, individualization would also affect methods for learning material. For example, traditional rote memorization techniques used mainly for memorizing entrance exam questions would be discarded in favor of individual preferences for remembering information. This would further allow students to move toward experiential learning instead of learning by rote. Furthermore, individualization could also affect the entire entrance examination system that is endemic in Japanese education. The reliance on textbooks and use of exams found in traditional Japanese education would also be overhauled if individualized education is accepted into the mainstream. In short, this one factor, the acceptance of individualized instruction through web-based learning, could undo contemporary Japanese education methods influenced by Confucianism that have been in place since the Tokugawa era. 


\section{Chapter 5}

\section{Introduction}

This chapter provides a brief summary of material presented in the first three chapters and the findings from chapter four. Following that, a summary of the conclusions followed by elements of motivation theory and self-directed learning relative to the current study will be examined. Woven into that examination, a list of implications for designing web-based courses for Japanese female college students will be reported. The chapter concludes with recommendations for future studies followed by final comments by the researcher.

\section{Restatement of the Problem}

The Japanese Ministry of Education, Science, Sports and Culture [Monbusho] plans to implement several reforms in Japanese education in the 21st century namely, "The principle of putting emphasis on individuality, the transition to a lifelong learning system, and coping with various changes in society including internationalization and the spread of information media" (Monbusho, 1997, paragraph 2). As a result, Monbusho plans to have schools and colleges utilize technology, specifically computers and the Internet on a national scale. Within that setting, web-based instruction will become more common as schools try to accommodate Monbusho's initiatives as well as attract students from a dwindling population base. The problem, however, is that traditional educational practices in Japan have been influenced by 
elements of Confucianism that are not found in web-based instruction. Those elements include: (a) expected behavior between teachers and students, (b) reward over effort, (c) reliance on textbooks, (d) use of memorization as a major learning technique, (e) and use of exams. In the traditional Japanese classroom, these elements operate in an instructivist teacher-centered environment whereas web-based instruction advocates a constructivist learning environment with the teacher acting as facilitator. In addition, because traditional Japanese education advocates extensive use of testing, it is necessary to examine test scores from students learning in the traditional manner versus web-based instruction. Therefore, the challenge is for educators to determine exactly and to what extent elements of Confucianism affect Japanese learners in a web-based environment thereby allowing web instructional designers to incorporate that information in web-based courses.

\section{$\underline{\text { Research Questions }}$}

The research questions that guided the study are summarized below.

1. What cultural factors influence Japanese female college students' attitudes and/or perceptions of learning in a web-based environment?

2. Are there significant differences between the mean pre and posttest scores on the Pre-TOEFL Test of those Japanese female junior college students taking a TOEFL preparation course via web-based instruction and the mean pre and posttest scores of another group of Japanese female junior college students taking the same course in a teachercentered class? 
As a result of the above questions, this study added to the body of knowledge for Japanese education, specifically Japanese female college students, minority education, international education, educational diversity, and web-based design.

\section{Methodology and Procedures}

For this study, a mixed-methodology research plan consisting of both qualitative and quantitative designs was implemented. This added complexity to the design, incorporated the advantages of both methods of research, and allowed for triangulation of results. For the qualitative research question, a structured interview method was used as the theoretical framework for gathering, analyzing, and reporting subjective experiences of Japanese female junior college students' perceptions of learning toward webbased instruction. For the quantitative question, a quasi-experimental method was used. This method approximated the true experimental method and emphasized objectivity of phenomena through design, statistics, and experimenter control.

The study was conducted during the first semester of the Japanese academic year beginning April 1, 1999 and ending July 28, 1999. The sample population consisted of all 60 female junior college students enrolled in the Intensive English Studies Program at Toyoko Gakuen Women's College in Tokyo, Japan. Students were assigned by the school administration to two groups according to their last name. Consequently, Group A was the Treatment population and Group B was the Control group. Before the treatment began, the researcher queried all 60 students on their computer and 
Internet experience. It was found that the majority of students had some computer experience but none had experienced web-based instruction. As a result, this was the Treatment group's initial experience with this mode of learning.

In order to test the null hypotheses, a Pre-TOEFL Test was given to all students on April 27, 1999 in the same classroom during the regular school day. Beginning May 24, 1999 an eight-week TOEFL practice course was provided for all 60 students divided into Group A, the Treatment group, and Group B, the Control group. The former group took the practice course by web-based instruction while the latter group attended classes in a traditional teacher-centered class. After eight weeks, on July 16, 1999 the Pre-TOEFL Test was administered again to all 60 students together in the same classroom during the regular class. For this study, the dependent variable was the PreTOEFL score for both groups while the independent variable was the webbased instruction for the Treatment group.

For the qualitative question, structured interviews were conducted in order to determine what cultural factors influenced Japanese female junior college students' perceptions of learning in a web-based environment. From the treatment group, six students were selected and interviewed three times: before, during, and after the treatment. Selection of interviewees was based on students' Pre-TOEFL scores returned to the researcher from the official TOEFL Testing Center in Tokyo, Japan. Scores were arranged from highest to lowest and the researcher selected the two students with the two highest scores, two students at the median, and two who scored the lowest. The 
researcher engaged in three in-depth one-to-one interviews with the same six individual students described above. Open-ended interview questions followed by directed probes were used to record how certain tenets of Confucianism influenced the students' perceptions of learning in a contemporary web-based environment. A total of 18 interviews were held in the researcher's office at Toyoko Gakuen Women's College in Tokyo, Japan during the normal school day. Each interview lasted approximately one hour, was tape recorded, and transcribed by the researcher. It was reported in chapter four that, due to technical difficulties, in the pretreatment interview recorded data were obtained from five students for questions one through five and all six interviewees for question six. As a result, a total of 17 out of 18 interviews were successfully recorded and transcribed by the researcher. Discussion of the Findings

Employing inferential statistics, the null hypothesis was tested using a paired samples t-test to determine the level of significance of the mean pre and posttest scores within each group. Results indicated that within each group there were significant differences of the pre and posttest mean scores at the .05 level, therefore the null hypothesis was rejected. However, the difference in the gain score between each group was not found to be statistically significant at the .05 level. It was observed that there was some improvement for both groups, with a greater improvement being achieved by the Control group. However, it was not clear what caused the improvement for both groups as well as the greater improvement for the Control group. It was inferred that, other things being equal between the groups, the greater 
improvement by the Control group could have been due to learning in a traditional teacher-centered class whereas the Treatment group did not have as large an improvement due to learning via web-based instruction.

Regarding the qualitative part of the study, the findings were reported using the interviewees' own words. Upon evaluation of the data, it was discovered that as the treatment progressed, respondents changed their opinions about how influential the five Confucian tenets were on their attitudes toward web-based instruction. It was observed that as students moved through the web-based course, the influence of the five Confucian tenets dwindled. Below is a summary of how the respondents' opinions changed throughout the three interviews.

For the pretreatment interviews, responses indicated that students expected three out of five Confucian tenets found in the teacher-centered class to have an influence in the web-based class. For example, regarding the tenet of expected behaviors between teachers and students three out of five respondents anticipated the same kind of actions by the teacher and relationship with the teacher in the web-based class as in the regular classroom. Next, regarding the tenet of memorization as a major learning technique, five out of six students favored using a memory strategy they had already developed from their previous experiences in a traditional learning environment. Finally, with respect to the tenet of using exams for measurement of knowledge, four out of five stated they expected an exam. Contrary to the above, the two remaining Confucian tenets were found to have mixed responses from interviewees regarding their influence in a web- 
based class. First, regarding the tenet of reward over effort, all five interviewees agreed that working individually was good. This suggested that since the interviewees expressed positive attitudes toward the individualized nature of the course, competition within rank might not have as much influence in a web-based course compared to a course taught in a traditional class. Second, regarding the Confucian tenet of reliance on textbooks, students were also divided on the need for using a textbook. To illustrate, three students, 1H (427/397), 4M (350/373), and 6L (237/347), stated they did not need a text, 3M (357/347) advocated the need for a text, $5 \mathrm{~L}(310 / 343)$ was undecided, and the response for $2 \mathrm{H}(400 / 397)$ was unrecorded. To summarize, responses from the five interviewees during the pretreatment interviews revealed that even before the treatment began, students expected three out of five Confucian tenets found in traditional Japanese classrooms to have influenced their perceptions of learning in a web-based instructional environment. Those tenets are expected behaviors between teacher and students, use of memorization, and use of exams.

The second set of interviews was held in the researcher's office after four weeks of treatment with a clear recording obtained from all six interviewees. During the interview process, queries progressed from four general to eight specific questions further probing the influence of Confucianism on the interviewees' attitudes toward web-based instruction. Different from the pretreatment interview, the second interview results showed that after four weeks of web-based instruction the influence of Confucianism on students' attitudes toward web-based instruction appeared 
to be less as seen in a change in some of the interviewee's opinions. First, related to the Confucian tenet of expected behaviors between teacher and students, it was inferred that the expected behaviors found in a traditional Japanese class did not transfer to the web-based class. In fact, contrary to the pretreatment interview, interviewees reported a difference in the expected actions of teachers in both types of classrooms, for example, lecturing and writing on the blackboard in the traditional class versus walking around in the web-based class. There was consensus that the teacher's actions in the webbased class were more active than the teacher's actions in the traditional class. Supporting this idea, interviewees also indicated that they were more active in the web-based class compared to a traditional class. This could possibly be a result of the actions of the teacher and the method of individualized instruction in the web-based class versus group instruction in the traditional class. Next, the Confucian tenet of reliance on textbooks saw a change from the respondents' attitudes in the pretreatment interview shifting from only one student, 3M (357/347) who stated she definitely needed a textbook to three students, 3M (357/347), 5L (310/343), and $6 \mathrm{~L}(237 / 347)$, requesting a text. This suggested that this tenet still influenced students' perceptions of learning in a web-based environment. Third, the Confucian tenet of use of exams revealed that students who expected an exam during the pretreatment interview, $1 \mathrm{H}$ (427/397), 4M (350/373), and 5L (310/343) now discouraged the practice. In fact, only one student, 3M (357/347), continued to support giving an exam while $2 \mathrm{H}(400 / 397)$ was undecided. This suggested that after four weeks of web-based 
experience, the influence of incorporating this tenet into a web-based environment was dwindling.

On the opposite end of the spectrum, during the second interview, the interviewees also expressed opinions that, overall, remained the same as those of the first interview. These opinions were related to the Confucian tenets of reward over effort and use of memorization as a learning technique.

First, in assessing the Confucian tenet of reward over effort, as in the first interview the majority stated there were advantages of learning in a new way. Key responses were "individual learning," "our own pace," and "I can concentrate." Consequently, it can be inferred this tenet is still active although in a different manner in the web-based class. In fact, interviewees during the pretreatment and second interview unanimously accepted the concept of individualized learning with little regard for the group as a whole. Second, examining the Confucian tenet of memorization as a major learning technique, as in the first interview, students continued to advocate using traditional methods such as taking notes and using repetition in order to remember website information and how to navigate through the websites.

A post-treatment interview consisting of three general and eight specific questions was held during the last week of classes before summer vacation, with a recording obtained from all six respondents. Figure 1 compares the interviewees' responses from all three interviews. 


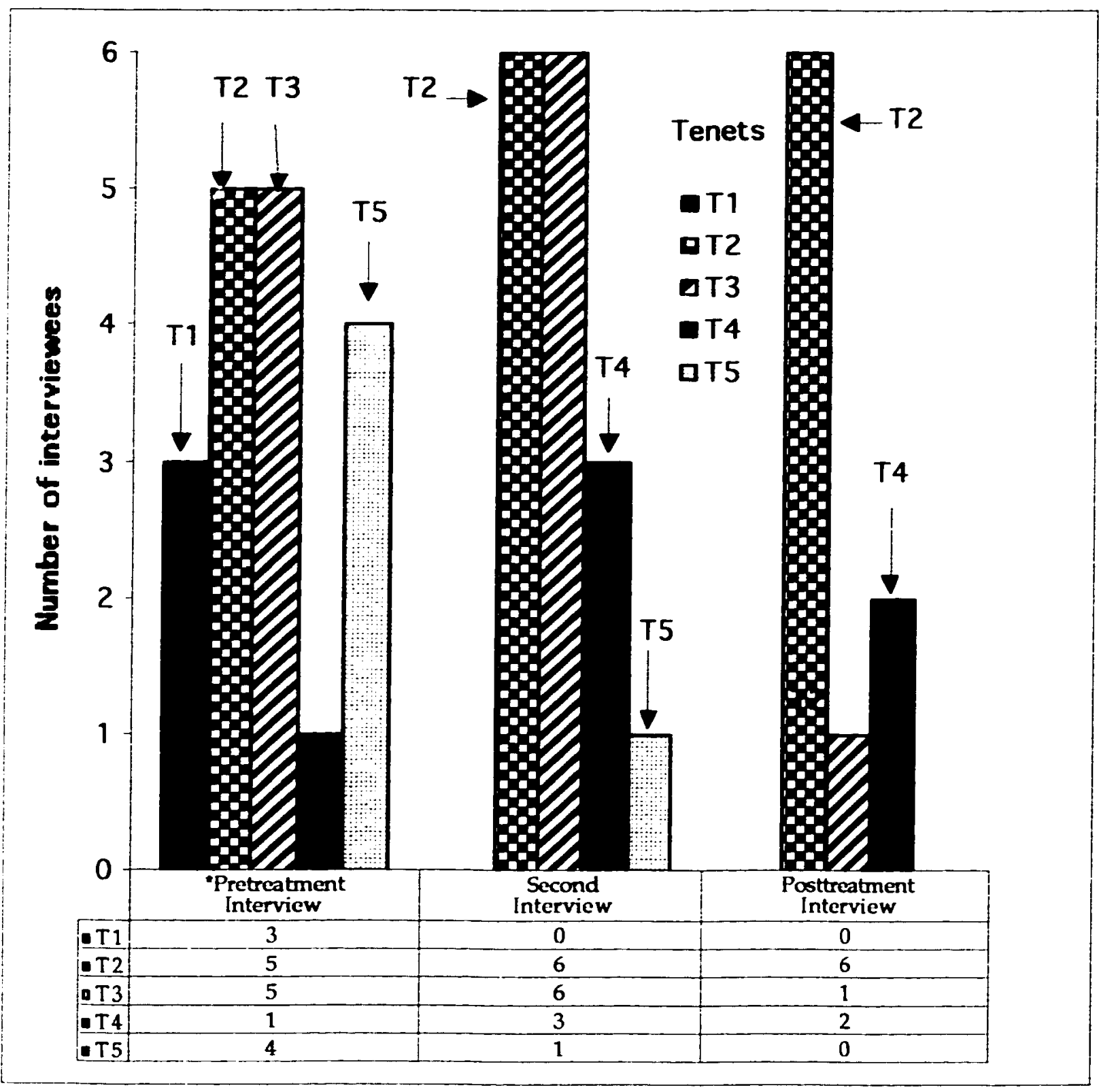

Figure 1. Comparative influence of tenets in all interviews.

*For the pretreatment interview there were a total of five recorded responses.

T1: Expected behaviors between teachers and students.

T2: Reward over effort.

T3: Memorization as a major learning technique.

T4: Reliance on textbooks. 
T5: Use of exams.

Responses indicated the interviewees' opinions in the second interview for tenets one and two were the same while there was a slight difference for tenets three and four. However, opinions changed regarding tenet three, use of memorization as a major learning technique. In fact, six completely different answers were reported by the students with a distinct movement away from use of traditional forms of memorization in order to remember the website material and how to navigate through the websites. It was reported that students used a variety of ways to remember the information from using the Yahoo Internet browser to asking the teacher. Only one student, $6 \mathrm{~L}(247 / 347)$, stated that she repeated the same thing, and that it was important to use the websites over and over again; therefore a value of one was assigned to this tenet in the posttreatment interview. As a summation, it was found that the influence of the five tenets of Confucianism on students' attitudes toward web-based instruction was higher during the pretreatment interviews and decreased as the web-based course progressed.

\section{Conclusions}

Conclusions will be discussed first from the quantitative aspect followed by the qualitative view. Regarding the quantitative area, several conclusions can be inferred. First, even though there was no significant difference between the gain scores of the Control and Treatment groups, there was a significant difference between the mean pre and posttest scores for each group. Therefore, it was possible that the difference was caused by the 
different mode of instruction. However, in addition to the mode of instruction, another possible factor that could have affected results was the different materials used for each group, for example, traditional paper/pencil materials used for the Control group contrasted with websites for the Treatment group. Since both the pre and posttests were of the paper variety, it could be concluded that the Control group had the greater improvement because the mode of instruction matched the mode of testing. Likewise it could also be concluded the greater improvement by the Control group was a result of a combination of the traditional method of teaching using traditional materials. Conversely, for the Treatment group, it could be concluded that their scores were not as high as the Control group because the web-based method of instruction did not match the testing materials.

Conclusions for the qualitative findings show that, in the pretreatment interview the tenets held more of an influence than in the second and posttreatment interviews. Regarding the first tenet, expected behaviors between teachers and students, pretreatment interview data show three students were influenced by this tenet, however, in the second and posttreatment interviews attitudes changed. In fact, students expressed a distinct difference of behaviors between the teacher and students in a webbased environment compared to those expected in a traditional environment. It was therefore inferred that by the end of the treatment this tenet held no influence on students' attitudes toward web-based instruction.

Data for the second tenet of reward over effort shows that during all interviews students revealed a definite advantage and acceptance of 
individualized instructional methods via web-based instruction, with little concern about competition among the students in the group. Therefore, with the exception of the pretreatment interview where there were only five recorded answers, it was concluded that all interviewees were influenced by this tenet as it operated in a web-based environment.

The third tenet, use of memorization as a major leaning technique also saw a shift of influence throughout the interview process. During the first two interviews, for example, students expressed their willingness to incorporate predetermined methods to remember information and how to use the websites. In the posttreatment interview, however, six completely different suggestions were made for remembering the information and only one student, $6 \mathrm{~L}$ (247/347), advocated repeating the same websites, therefore a value of one was given to this tenet in the posttreatment interview.

The fourth tenet of reliance on textbooks saw an interesting shift of responses from the first interview where only one student was influenced by stating she needed a text. Three students advocated the need for a text in the second and two students expressed a need in the third interview. The fifth tenet, use of exams, also saw a shift in influence where four students expected an exam in the pretreatment interview to one student expressing a need for a text in the second interview, and no students expressing that same need in the posttreatment interview.

Finally, in addition to the shift of influence of Confucian tenets on the students' perception of web-based instruction, a major theme was derived from the interviews which is reported below. 


\section{Acceptance of Individualized Learning}

It was concluded that the concept of greatest generality to emerge from all three interviews was the acceptance of individualized learning. It was further concluded that this one factor, if incorporated into Japanese classrooms through web-based instruction, would challenge and possibly eliminate the influence of all five tenets of Confucianism in a web-based environment. For example, according to the interviewees' responses, expected behavioral differences between students and teachers that have been documented to take place in traditional Japanese classrooms will be considerably different in an individualized web-based environment. Similarly, reward over effort in a traditional classroom with students learning in a group would also be challenged as students operating in an individualized web-based environment are less concerned with the group rank and/or personal rank within the group. Consequently, an individualized learning environment would allow students to move from working entirely in groups with a ranking system governing the placement of students, to a more democratic form of learning that emphasizes selffulfillment rather than competition.

In addition, individualization would also affect traditional rote memorization techniques used mainly for memorizing entrance exam questions, now discarded in favor of individual preferences for remembering information. In fact, individualization could transform the entire entrance examination system that is endemic in Japanese education thus further 
affecting the Confucian tenets of reliance on textbooks and use of exams found in traditional Japanese education.

In short, parallel to the overhaul of the Japanese economy caused by the explosion of the 1992 bubble economy and subsequent recession, this one factor, the acceptance of individualized instruction through web-based learning could propel Japanese education into a new era - one that advocates creativity and personal choice thereby changing the structure of Japanese education, providing opportunities for students to make individual and personal decisions about their future.

To culminate, for the quantitative section the null hypothesis was rejected as there was found a significant difference between the pre and posttest mean scores of the Control and Treatment groups, however, there was no significant difference between the gain scores for each group. In essence, both groups showed an improvement in scores but there was no concrete evidence as to what caused the increase. Consequently, several conclusions were provided that speculated on the results. Regarding the qualitative section, findings revealed that, as the treatment progressed, there appeared to be a movement away from the five tenets of Confucianism influencing the students' attitudes toward web-based instruction, but there was no clear reason why this occurred. What remains is that for both the quantitative and qualitative sections of this study, many questions linger as to why the current set of results was produced. However, returning to motivation and self-directed learning theory as previously discussed in chapter two, provides insight for explaining the results of the current study. 
Therefore, the next section discusses the connection between the findings of both sections of the study, first with elements of motivation theory followed by self-directed learning.

\section{Conclusions related to motivation and self-directed learning theory}

As mentioned in chapter two, the current view of motivation is not one of isolation but a holistic view that affects a continuous stream of human behavior. For the purpose of this study, Raynor's theory of achievement motivation was revisited for further understanding why the Control group had a higher mean gain score than the Treatment group. To review, Raynor (as cited in Atkinson and Birch, 1978) posited that, as perceived by an individual, within a continuous stream of behavior, not only the immediate but a future opportunity and its consequences should intensify the achievement-motivation of a person within the current environment. In other words, perceiving that some future opportunity is contingent upon success in a present activity, the achievement motivation of a person should increase during the present activity. The caveat, however, is that how future opportunity is perceived requires the employment of cognitive elements of logic and decision theory - elements that may be in different stages of development for different people including the subjects of the current study. Relating this to the quantitative results of the study, it can be assumed that the Treatment group, as a whole, did not envision practicing TOEFL preparation techniques through web-based instruction influencing a future opportunity as much as did the Control group practicing TOEFL preparation techniques through the traditional way. Therefore, it is speculated that the 
present web-based activity did not increase achievement motivation for the Treatment group (Posttest $\underline{M}=366$ ) as much as the traditional method did for the Control group (Posttest $\underline{M}=379$ ). Another speculative assumption is that the Control group saw the content of the traditional class as having more of an impact on future opportunity thus increasing achievement motivation with the opposite being true for the Treatment group. A final assumption is that the overall cognitive development of the Control group was higher than the Treatment group thus enabling the Control group to see a more of a logical connection between present activity and future opportunity.

Relating Raynor's ideas about achievement motivation can also be connected to the qualitative section of the study. Assuming elements of cognition were employed by interviewees to show a future opportunity based on a present activity, there should have been a positive correlation between interviewees' comments about the advantages of web-based instruction and their pre and posttest scores. In other words, interviewees who said there were advantages to learning via web-based instruction should have had higher posttest scores, however, this was the case for only three out of five of the interviewees who were recorded. To illustrate this, following are examples reported in chapter four of student responses to a pretreatment interview question that inquired about perceived advantages of web-based instruction with students' pre and posttest scores in parentheses.

Student $1 \mathrm{H}(427 / 397)$ stated, "It's different so we can learn new way...it is individual so I think that's good." Student 3M (357/347) related her answer to a more practical view and said, "I need computer in working 
world... (pause) this point is my big point." Student 5L (310/343) stated that the advantage was that it would be a challenging experience for her while $6 \mathrm{~L}(237 / 347)$ quietly confided in the researcher and said, "I expect to understand English and foreign country home page." Student 4M(350/373) stated that she didn't know what the biggest advantage would be. While student $2 H^{\prime}$ s $(400 / 397)$ response was not recorded in the pretreatment interview because of technical difficulties, it is evident that, like students $3 \mathrm{M}$ and $1 \mathrm{H}$, her posttest score was lower.

Interestingly, the three lowest scoring pretest students, $4 \mathrm{M}, 5 \mathrm{~L}$, and $6 \mathrm{~L}$ raised their posttest scores while the three highest pretest students, $1 \mathrm{H}, 2 \mathrm{H}$, and 3M lowered their posttest scores. It seems possible that cognitive elements may have helped students $4 \mathrm{M}, 5 \mathrm{~L}$, and $6 \mathrm{~L}$ reflect on the advantages of such instruction, but did this reflection act as an incentive for motivating performance? Similarly, what cognitive elements, if any, were lacking for students $1 \mathrm{H}, 2 \mathrm{H}$, and $3 \mathrm{M}$ to get lower posttest scores? It is possible that there were other advantages not mentioned by the interviewees to the researcher that motivated $4 \mathrm{M}, 5 \mathrm{~L}$, and $6 \mathrm{~L}$ to get higher scores. Likewise, what advantages were missing for $1 \mathrm{H}, 2 \mathrm{H}$, and $3 \mathrm{M}$ ? In addition to motivation, maturation could have been a factor. It is possible that even though students were the same chronological age, the maturation process was somewhat different causing a difference in their cognitive abilities thus affecting their analytical decision-making processes which could inhibit some from possessing the full ability to see a future opportunity from a present activity. Furthermore, it is also possible that emotional factors related to the students' ability or inability 
to use the computer affected their future vision as well. Next to be discussed is how Covington's theory of motivated cognitions, as discussed in chapter two, provides additional possibilities for the differences in results between the Treatment and Control groups.

In brief, Covington (as cited in Paris, Olson, and Stevenson, 1983) put forth a cognitive attribution theory of achievement behavior that compliments Raynor's theory (as cited in Atkinson and Birch, 1978). Covington asserted that rational human processes are used in creating a picture of one's world - a picture based on personal preferences and to some extent, control over one's fate. In this type of constructive schema, motivation gives a sense of purposefulness and guidance to human activity. Therefore human cognitions provide the motivational thrust with emotions playing a secondary role as causal determinants of achievement motivation.

To illustrate this, in the present study cognitive and emotional attributes of achievement motivation were related to both the qualitative and quantitative areas of the study. For example, in the qualitative area, cognitive and emotional attributes related to cultural influences of Confucianism and the students' perception of web-based instruction were considered. For example, regarding the emotional attributes of achievement motivation, by the end of the treatment students felt a difference in expected behaviors with the web-based instructor as compared to a traditional class. Regarding the cognitive attributes of achievement motivation, at the beginning of the study, the majority of the interviewees did not see a need for a textbook, but by the 
end of the study five out of six felt they needed a text. This was also supported by $79 \%$ of the Treatment group as reported on their final logsheets.

On the other hand, from the quantitative view, Covington's attribution theory of achievement behavior (as cited in Paris, Olson, \& Stevenson, 1983) provides food for thought concerning the basic assumptions of achievement behavior that students bring with them to a course of study. In a word, what attributes of achievement motivation caused 26 out of 30 students in the Control group and 18 out of 29 students in the Treatment group to improve their test scores? Contrarily, what attributes caused the remaining students from both groups not to improve their test scores? Covington's theory provides more fuel when considering what cognitive and/or emotional attributes motivated students to produce a difference in gain scores.

Returning to Entwistle's (1988) Approaches-to-Study Inventory provides further clues for interpreting the results of both parts of the study. As discussed in chapter two, according to Entwistle (1988), his inventory showed that there are distinctive forms of motivation, which affect both quantitative and qualitative learning outcomes. Regarding the latter, educational orientation was the motivational concept of greatest generality to emerge. This concept describes the set of values and attitudes connected to education that the student holds at the time of instruction.

Within this concept there are four categories: vocational, academic, personal, and social. Upon a re-examination of the interview questions, it was found that several interview questions incorporated some of the categories 
listed above. For example, asking about the advantages of web-based instruction fell into both vocational and personal categories. Similarly, questions related to competition with rank, use of textbooks, and exams fall into the academic category. It seems that Entwistle's idea of educational orientation could have been a factor in the interviewees' motivational orientations to studying thereby possibly affecting interview responses and test scores.

Regarding quantitative analyses, as discussed in chapter two, three motivational orientations to studying were accepted: meaning orientation, reproducing orientation, and achieving orientation. It seems that all three of these motivational orientations could be found in the traditional Japanese classrooms, and specifically in the Control group classroom of this study. For example, elements of meaning motivation could be seen as students in the Control group used traditional learning techniques to help improve their scores on the Pre-TOEFL test. In addition, reproducing orientation, which imposes standards to be attained, is common in a traditional Japanese class with rote memory techniques used to determine students' knowledge. Finally achieving orientation complements reproducing orientation as students in the Control group could have used previously learned study methods to better learn the TOEFL material. Consequently, because the Control group in the present study had overall higher posttest scores, it could be inferred that they had stronger motivational orientations to studying in the traditional class. 
Entwistle further proposed that there are three approaches to learning: surface, deep, and strategic, all of which contain different motivational factors. Moreover, he also suggested that students might change their motivational approaches to learning depending on the academic discipline with which they are engaged. Therefore, Entwistle's ideas about motivational factors that affect student approaches to learning could be adapted to examine Japanese students' motivational approaches to learning and test taking by web-based instruction for different content areas and types of instruction.

From the previous discussion, it is evident that elements of motivation theory provide insight into the results of the study. The next section discusses a connection between the findings of the study and selfdirected learning as previously discussed in chapter two.

To review, Hofer, Yu, and Pintrich (1988) developed a self-regulated learning conceptual framework based on a general social-cognitive model of motivation and cognition, and applied the model to teaching college students to be self-regulated learners. Like Covington who supported attributions of achievement motivation, Hofer, $\mathrm{Yu}$, and Pintrich also supported attribution theory as a motivational strategy for achieving performance goals. Schunk (1998), as described in chapter two also supported the idea of self-knowledge as a motivational factor within a self-directed learning activity. Schunk (1998) stated that students participating in a self-directed learning activity who feel self-efficacious were more likely to use effective learning strategies such as concentration, time management, and performance monitoring techniques. 
A connection can be seen between the above author's ideas related to self-directed learning and the findings of the current study. First, related to students comparing performance to goals, at the end of the treatment program, the usual weekly logsheet was administered to all students in the Treatment group. Several students commented that when a student got a wrong answer on the TOEFL practice website, the reason why the answer was incorrect was not given. As a result, it is possible that the lack of the ability for students in the Treatment group to check their performance could have negatively influenced their self-efficacy therefore decreasing motivation. This in turn, could have been a factor in the Treatment group having a lower posttest mean score than the Control group. Second, throughout the treatment program the majority of the interviewees stated that they liked web-based instruction because they could concentrate more and work in their own way. This specifically supports Schunk's ideas as mentioned above, that as students work on a task, they compare their performances to their goals. Therefore, in an individualized learning environment such as a web-based course, checking performance should be done as needed thus enabling each student to monitor their own progress.

The last discussion will briefly compare the results of the study with aspects of self-directed learning as researched by Winne and Stockley (1998). To reiterate from chapter two, the authors describe this type of learning as an event involving three necessary phases, for example, perceiving the task, setting goals, and enacting tactics to approach goals, plus an optional fourth phase of adapting tactics. Transforming and constructing information within 
each phase provides the potential for metacognitive monitoring and control. Interestingly, once this type of learning has begun, it is recursive and loosely sequenced; events may skip or repeat phases as deemed necessary by the learner. According to Winne and Stockley (1998), this model of self-regulated learning can be supported through the use of computing technologies.

In the present study, all interviewees from the Treatment group stated that they liked web-based instruction because it was individualized and they could work at their own pace. This in itself suggests that they were capable of cognitive self-monitoring even if they had no training in that process before the course began. In fact, upon reflection of their experience with web-based instruction, the interviewees gave suggestions for improvement of the course, which included the need for self-evaluation of their progress as well as the need for a textbook for additional practice when a computer was not available. Therefore, Winne and Stockley's (1998) four phase archetype of selfdirected learning mentioned above, could provide a theoretical base for designing web-based courses for those Japanese female college students in the current study who have repeatedly expressed support of working individually.

In summary, in an attempt to further understand the results from both sections of the current study, motivation theory and self-directed learning theory were revisited. As a result, that information together with the qualitative and quantitative results of the study suggests several implications for instructional designers of courses for Japanese female college students. Implications for instructional designers 
This study was conducted on a limited population of Japanese female college students. As a result, the following implications speak specifically to instructional designers of web-based courses for Japanese female college students.

- First, it is necessary to understand the basic assumptions, from both a cognitive and emotional level, about achievement behavior that students bring with them to a course of study. This can be determined by questioning large samples of a target population during the planning stages of the web-based course either quantitatively or qualitatively. In the current study, for example, this was attempted through an examination of six interviewees' opinions of what elements of Confucianism influenced their perceptions of learning in a web-based environment.

- Second, motivational factors must be determined as to what kind of web-based courses Japanese female college students would take and what they expect to get from such a course. In other words, what future opportunities, if any, would motivate students to take a web-based course?

- Third, cognitive levels of the students must be determined in order to design web-based content to fit their analytical abilities.

- Fourth, web-based course materials for this population should include some kind of textbook.

- Fifth, web designers should consider creating web pages that are selfexplanatory complete with explanations for correct and incorrect 
answers. Furthermore, proper feedback about the student's overall progress should be built into the course at various stages.

- Lastly, courses should be designed to be completed individually at one's own pace within a specified time frame.

What follows are suggestions for future research based on all the data previously provided.

\section{Recommendations for future research}

As a result of the limited population used for the current study, results cannot be extrapolated to a larger Japanese population. Consequently, research at all grade levels needs to explore a variety of factors that affect both male and female Japanese students' relationship with technology in education, specifically web-based instruction. The following recommendations speak to educational researchers who are considering investigating these phenomena in both the qualitative and quantitative areas.

\section{Qualitative recommendations for research}

- Investigate the impact of the transition from a group-oriented educational system to one that emphasizes the expression of creativity and individual choice.

- Examine ways to incorporate self-regulated learning methods for both male and female Japanese students within a web-based environment at all grade levels.

- Research into the taxonomy of different tasks required of Japanese students utilizing web-based courses in a variety of disciplines at various grade levels. 
- Analyze and/or compare the learning styles of those Japanese students who prefer to learn in a web-based manner compared to those who prefer a teacher-centered class.

- Duplicate the current study among several layers of Japanese society thereby providing more insight into the results reflecting the influence of culture on Japanese educational practices.

\section{Quantitative recommendations for research}

- Examine the relationship between teaching method and test scores, for example, web-based instruction and testing versus traditional teaching and paper test scores.

- Measure the mean scores for students taking a web-based course with the teacher present in the room versus another group taking the same course without the teacher present.

- Compare the effectiveness of web-based courses for various content areas among different groups within the overall Japanese population.

\section{Limitations/Delimitations}

The following is a review of the delimitations and limitations as previously mentioned in chapter three. The overriding delimitation of this study was it being the first of its kind to focus exclusively on how Japanese culture related to Confucianism may or may not have effected Japanese female college students' perceptions of learning in a web-based environment. As a result of the limited population used in the study, the results cannot be extrapolated to the larger Japanese population. 
There were several limitations to the study. First, a small sample size of 60 participants and a population comprised of Japanese freshman, junior college women limited generalizing the findings to groups other than the sample population. Next, there was a distinct cultural difference in social and educational background between the researcher and participants.

Furthermore, Confucian elements used by the researcher were neither supported nor refuted by native Japanese educators. In addition, while there were questions on the weekly logsheets that related to the five elements of Confucianism, overall logsheet design was not standardized to coincide with those elements but was designed as an informal way for students to comment each week on their experience with web-based design. Another limitation was the researcher was also the instructor for both the Treatment and Control groups, and also conducted the individual interviews; therefore, the potential for a positive or negative impact on both groups, but especially the six interview subjects, was considered. Furthermore, all interview communication between the researcher and members of both the Treatment and Control group was in the researcher's native language and not the participants'.

Other limitations were related to the Pre-TOEFL test and computer technology available at the school. While the Pre-TOEFL test determines students' abilities in three areas - listening, reading comprehension, grammar and written structure, students in both the Control group and Treatment group only had practice sessions for the latter two areas. This was due to technology limitations of the school computers, which did not have listening 
capability; therefore, only reading comprehension and grammar and written structure were practiced. Additionally, with the exception of the interviewees, participation by both groups was not voluntary as administration of the PreTOEFL test and practice course were part of the regular class curriculum. Finally, in coding the data, the researcher did not use techniques such as member checking, peer debriefing, or multiple researchers for data analysis. Summary

This study attempted to see what cultural elements related to Confucianism influenced Japanese female college students' attitudes toward web-based instruction, and to determine if there was a significant difference in test scores between two groups of students: one taking a course in the traditional manner and another via web-based instruction. In the quantitative section, the null hypotheses was rejected as a significant difference was found between the pre and posttest scores within each group. In the qualitative section, results showed that the influence of the five tenets of Confucianism decreased as the treatment progressed with the unanimous acceptance of individualized instruction being the main theme that surfaced. However, it was apparent there was no clear evidence as to explain the results from either section of the study. Therefore, the researcher conducted an investigation into motivation theory in an attempt to shed light on both sets of data. As a result, elements of motivation theory helped to explain the findings from the quantitative and qualitative sections. Because the study was limited to a small subgroup within the Japanese population, the results can be 
applied only to that particular population; therefore, several recommendations for future research were listed.

In essence, the study scratched the surface on a topic that is important, not only for the future of web-based education in Japan, but for other countries attempting to introduce this method of instruction. Considering that all human beings view life through some kind of cultural lens, discovering how those lenses affect learners' attitudes toward new educational technologies can provide instructional designers with valuable information in creating programs tailored to fit students belonging to a specific ethnic group. Because the Internet and web-based instruction will become more accessible to a larger global population, it is imperative that further research seeking the myriad ways culture affects individuals must be conducted in order to design both web-based content and evaluation methods for particular nationalities ensuring a positive learning experience for all. 


\section{References}

Academic american encyclopedia. (Vol. C). (1981). Princeton, New Jersey: AretÊ Publishing Company, Inc.

Anderson, F. E. (1993). The enigma of the college classroom: Nails that don't stick up. A handbook for teaching English at lapanese colleges and universities. Oxford: Oxford University Press.

Antonoplos, D. P. (1986). Student characteristics, learning, and curriculum in Japan. United Stated Department of Education: Office of Educational Research and Improvement. (ERIC Document Reproduction Service No. Ed 271 378)

Beauchamp, E. R. (1991). The development of Japanese educational policy, 1945-1985. In E. R. Beauchamp (Ed.), Windows on Japanese education. (pp. 28-49). New York: Greenwood Press.

Beauchamp, E. R. (1992). Japanese and U.S. education compared. Bloomington, Indiana: Phi Delta Kappa Educational Foundation.

Bellah, R. N. (1957). Tokugawa religion: The cultural roots of modern Lapan. New York: Macmillan, Inc.

Bielema, C. L. (1996). Factors affecting implementation of interactive, computer-mediated instructional techniques for instructors and learners at a distance. (Doctoral dissertation, University of Ilinois at Urbana-Champaign, 1996). (University Microfilms No. 9712201) 
Bodgan, R., \& Taylor, S. J. (1975). Introduction to qualitative research methods: A phenomenological approach to the social sciences. New York: Wiley \& Sons.

Bremmer, B. (1996, September 6). Japan's banks. Business Week, Asian Edition. 20-23.

Bremmer, B., Thornton, E., Kunii, I. M, \& Tanikawa, M. (1999, October 25). A new Japan? Business Week, Asian Edition. 55-61.

Bremmer, B. (1998, November 30). Japan. Wanted: a new economic model. Special Report. Business Week, Asian Edition. 45-48.

California State Department of Education, Sacramento. (1987). Handbook for teaching Japanese-speaking students. Washington, DC: Department of Education. (ERIC Document Reproduction Service No. ED 287 316).

Creswell, J. W. (1994). Qualitative \& quantitative approaches. Thousand Oaks: Sage Publications.

Collis, B., \& Remmers, E. (1997). The world wide web in education: Issues related to cross-cultural communication and interaction. In B. H. Khan (Ed.), Web-based instruction (pp. 85-92). Englewood Cliffs, NJ: Educational Technology Publications, Inc.

Confucianism [Homepage of Ohio State], [Online]. Available: http:/ / deall.ohio-state.edu/jin.3/c231/refs/confism.htm [1999, October 31]. Council on International Educational Exchange TOEFL Division/ ITP. (1999). TOEFL test of English as a Foreign Language institutional testing program 1999-2000. [Brochure]. Tokyo: ETS. 
Covington, M.V. (1983). Motivated cognitions. In S. G. Paris, G.M.

Olson, \& H.W. Stevenson (Eds.), Learning and motivation in the classroom (pp. 139-164). New Jersey: Lawrence Erlbaum Associates, Inc.

Dore, R. P. (1984). Education in Tokugawa Japan. London: the Athlone Press.

Foreign Press Center Japan. (1991). Japanese women: Yesterday and today. Tokyo, Japan: Foreign Press Center Japan.

Foreign Press Center Japan. (1995). Education in Japan. Tokyo, Japan: Foreign Press Center Japan.

Greene, D. \& Hunter, L. (1993). The acculturation of oral language learners and instructors in EFL. The Language Teacher, 17(11), 9-15; 47.

Goldman, A. (1988). For Japanese only: Intercultural communication with Americans. Tokyo, Japan: The Japan Times, Ltd.

Gorsuch, G. (1999). Monbusho approved textbooks in Japanese high school EFL classes: An aid or a hindrance to educational policy innovations? The Language Teacher, 23(10), 5-15.

Goto Scholarships Society. (1995). Toyoko Gakuen Women's College as it stands today. Tokyo, Japan: Masao Takatori.

Guba, E. G. \& Lincoln, Y. S. (1981). Effective evaluation. San Francisco, CA: Jossey-Bass Inc. Publishers.

Guba, E., \& Lincoln, Y. S. (1989). Fourth generation evaluation. Newbury Park: Sage.

Halsey, W. (Ed.). (1977). Collier's encyclopedia. (Vols. 1-24). New York: Macmillan Educational Corporation. 
Hashizuze, D. (1999, October 4). Bold proposals for educational reform. The Daily Yomiuri, pp. A5.

Hasumi, N. (1998). Internet is a treasury of teaching materials. Education and Information, 1 (478), 40-43.

Headcount.com. (1998). Who's Online by Country. Japan. [Homepage of International Communications Headcount.Com], [Online]. Available: http://www.headcount.com/count/datafind.htm?id=234\&choice=country / [1999, October 21].

Headcount.com. (1998). Who's Online by Country. The U.S. . [Homepage of Internationai Communications Headcount.Com], [Online]. Available: http: //headcount.com/count/datafind.htm?choice $=$ country\&choicev\%5B\%5 $\mathrm{D}=$ The+US\&submit=Submit/ [1999, October 21].

Hedberg, J., Brown, C., \& Arrighi, M. (1997) Interactive multimedia and web-based learning: Similarities and differences. In B. H. Khan (Ed.), Web-based instruction (pp. 47-58). Englewood Cliffs, NJ: Educational Technology Publications, Inc.

Hiraga, M. (1998). Japanese metaphors for learning. In E. Berendt (Ed), Learning: East and West (pp. 7-22). San Antonio, TX: International Association for Intercultural Communication Studies.

Hoke, M. E. (1984). Research report on the Japanese school system, computer-aided instruction in Japan and the Japanese home computer market. Boston, MA: Houghton Mifflin Co. (ERIC Document Reproduction Service No. Ed 249 645)

Holmes, B. (1998). Cross-cultural differences of use of information technology in education: A comparative study of the use of computers in Japanese and 
British classrooms. (Doctoral dissertation, University of Cambridge, Cambridge, England), [Online]. Available:

http: / byrnholmes.com/research/thesis/ Tin Japan.html [1999, October 31].

Holmes, B. (1998). From black ships to microchips: The arrival of ITC in Japan. In P. Lewis (Ed.), Teachers, learners and computers: Exploring relationships in CALL (pp. 181-187). Nagoya, Japan: The Japan Association for Language Teaching Computer-Assisted Language Learning National Special Interest Group.

Holmes, B. (1999). Initial perceptions of CALL by Japanese university students. [Online]. Available:

http:/ / byrnholmes.com/research/CALLJournal/index.html [1999, October 9].

Holmes, B., Mikhailova, S., \& Field, M. (1999). The other in the mirror: Student perception and identity in on-line Japan (Paper presented at CAL 99) [Online]. Available: http://byrnholmes.com/research/CAL.99/index.html [1999, October 9].

Holmes, B., Jussila, T., Arachi, M., \& Field, M. (1999).Virtual learning environments in Japan: The new floating world. [Online]. Available: http:/ byrnholmes.com/VLEs/research/lapanVLE.html [1999, October 12].

Hofstede, G. H. (1980). Culture's consequences - International differences in work-related values. Newbury Park, Ca.: Sage Publications, Inc.

Hofer, B. K., Yu, S. L., and Pintrich, P. R. (1998). Teaching college students to be self-regulated learners. In D. H. Schunk, \& B. J. Zimmerman (Eds.). Self-regulated learning: From teaching to self-reflective practice. (pp. 57-85). New York: The Guilford Press. 
Hoobler, T., \& Hoobler, D. (1993). Confucianism world religions. New York: Facts on File, Inc.

Husserl, E. (1969). Ideas: General introduction to pure phenomenology (W. R. Boyce Gibson, Trans.). London: Allen \& Unvin. (Original work published 1931).

Ishiguro, T., Hatanaka, Y., Essig, W., \& Saito, K. (1997). 10-Minute TOEFL practices. Tokyo: Kirihara Shoten.

Japanese Government National Institute for Educational Research (1990). Basic facts and figures about the educational system in Japan. (NIER Publication). Tokyo, Japan.

Japanese Government National Institute for Educational Research (1991). Towards formulating goals, aims and objectives of secondary education for the twenty-first century. (NIER Publication). Tokyo, Japan. Japan. Japanese Government Policies in Education, Science, and Culture. (1994). The shift to an Information-oriented Society: Implications for education, science, culture, and sports. Part II, Chapter 11, Section 3. Utilizing and developing new information media. [Online]. Available: http://www.monbu.go.jp/hakusyo/eng/2-c11.html\#2.11 [1999, October 30]. Japan. Japanese Ministry of Education, Science, Sports, and Culture. (1998). Kotogekko-yo kyokasho mokuroku. [Monbusho Approved Textbooks for 1999]. Tokyo, Japan: Japanese Ministry of Education, Science, Sports, and Culture.

Japan. Japanese Ministry of Education, Science, Sports, and Culture. (1996) 
Priorities and prospects for a lifelong learning society: Increasing diversification and sophistication. Chapter 1 [Online]. Available:

http://www.monbu.go.jp/hakusyo/1996eng.c1.html [1999, January 20].

Japan. Japanese Ministry of Education, Science, Sports, and Culture. (1997) Monbusho News. Program for educational reform. [Online]. Available: (http://www.monbu.go.jp/news-en/00000042/\#top) [1999, October 30].

Japan. Japanese Ministry of Education, Science, Sports, and Culture. (1997) Educational reform: Why is educational reform required now? [Online]. Available: http://www.monbu.go.jp/aramashi/1997eng/e201.html [1999, October 30].

Japan. Japanese Ministry of Education, Science, Sports, and Culture. (1997) The model for Japanese education in the perspective of the 21st century.

Chapter 1 [Online]. Available: http://www.monbu.go.jp/seriesen/00000012/ [1999, October 30].

Japan. Japanese Ministry of Education, Science, Sports, and Culture. (1997)

Responding to the information age [Online]. Available: http://www.mongu.go.jp/aramashi/1997eng/e242.html [1999, October 30]. Japan. Japanese Ministry of Education, Science, Sports, and Culture. (1997) Current main activities of Monbusho [Online]. Available: http:// www.monbu.go.jp/aramashi/1997eng/e101.html [1999, October 30].

Japan. Japanese Ministry of Education, Science, Sports, and Culture. (1998) Average Number of Installed Computer Units as of 1998. [Homepage of Japan Information Network Statistics], [Online]. Available: http://iin.jcic.or.jp/stat/stats/16EDU31.html/ [1999, October 21]. 
Japanese National Government. (1996) Computerized society and the younger generation (General Affairs Agency: Countermeasure Headquarters for the Younger Generation). Tokyo, Japan.

Khan, B. H. (1997). Web-based instruction (WBI): What is it and why is it? B. H. Khan (Ed.), Web-based instruction (pp. 59-66). Englewood Cliffs, NJ: Educational Technology Publications, Inc.

Kato, K., Takaura, K,. \& Ishizaka, K. (1989). An analysis of student learning outcomes. Tokyo, Japan: Research Bulletin of the National Institute for Educational Research.

Keene, D. (1982). The distinctiveness of the Japanese. Tokyo, Japan: Asahi Press.

Koshigiri, K., Shinkei, T., Hongo, S., Teraguchi, M., (1996) WWW Internet and educational support system for Japanese K-12 educational information. The Bulletin of Osaka University of Education, 45(1), 139-148.

Kunii, I. M. (1999, August 16). The behemoth of the Net? Business Week Asian Edition 21.

Kuroda, K. (1995, October). Effective School Research from Japanese Perspective. Paper presented at the Comparative and International Education Society North-East/ Mid-West Regional Conference, Buffalo, New York. (ERIC Document Reproduction Service No. ED 397 482)

Lamb, A., Smith, N., \& Johnson, L. (1997). Wondering, wiggling, and weaving: A new model for project-based and community-based learning on the web. Learning and Leading With Technology, 45 (7), 7-13.

Lehmann, J. (1982). The roots of modern Japan. New York: St. Martin's Press. 
Leestma, R. (1987). Iapanese Education Today. A report from the U.S. study of education Japan. Prepared by a special task force of the OERI Japan study team. Washington, D.C.: Office of Educational Research and Improvement. (ERIC Document Reproduction Service No. 275620)

Levenson, J. R., \& Shurmann, F. (1969). China: An interpretive history. University of California Press: Berkeley and Los Angeles.

Li, L. (1996). The China factor in modern Japanese thought: The case of Tachibana Shiraki, 1881-1945. Albany, New York: State University of New York.

Linc Media, Inc. (1998, May). New use grows in '97. Computing Japan. 35.

Linc Media, Inc. (1999, January). Wither Japan's Internet market: The outlook for 1999. Computing Japan 6, (1), pp. 22-23.

Lincicome, M. (1991). The historical context of Japanese education to 1945. E. R. Beauchamp (Ed.), Windows on Japanese education. (pp. 1-25). New York: Greenwood Press.

Long, R. W. III, \& Russell, G. (1999). Looking back: Student attitudinal change over an academic year. The Language Teacher, 23(10), 17-27.

Lord, L. J., Horn, M., and Lord, M. (1987, January 19). The brain battle. U.S. News \& World Report, 58-64.

Matsuda, K. (1989). The change in female students' attitude toward the computer during the development of lessons. Japanese Ministry of Education, Science, Sports, and Culture. Computer and Education, 7 (2), 1-10. 
McCarty, S. (1997). Educational Rigors Begin Early in East Asia [Online]. Available: http://www.kagawa-jc.ac.jp/--steve mc/East Asian edu.html [1999, October 11].

McCarty, S. (1999). Japanese Culture Meets Online Education [Online]. Available: http:// www.educause.edu/ir/library/html/erm993a.html [1999, October 12].

McDaniel, E. R. (1993, November). Lapanese Nonverbal Communication: A Review and Critique of Literature. Paper presented at the International and Intercultural Division of the Speech Communication Association, Miami Beach, FL.

McGreal, I. P. (Ed). (1995). Great thinkers of the eastern world. New York: HarperCollins Publishers.

Merriam, S. B. (1988). Case study research in education: A qualitative approach. San Francisco: Jossey-Bass.

Nakata, M. (1990) Computerized education in the computerized society: The attitudes of university and college students toward the computer. Iournal of the Liberal and General Education Society of Japan, 2, 63-68.

Nakata, M. (1993). The student's attitude toward the computer. Hiroshima Electrotechnological University and Hiroshima Automobile Industrial College, 26, 171-180.

Nakane, C. (1992). Japanese Society. Tokyo, Japan: Charles E. Tuttle, Company, Inc.

Oda, K. (1985). The attitudes of students from the Department of Education toward the introduction of computers to the school curriculum. Research Report of Educational Engineering Center, Mie University, 5, 1-11. 
Ohtsuka, S. (1998). Utilization of Internet information for class.

Computerized Education and Children, 9 (608), 48-51.

Owston, R. (1997). The world wide web: A technology to enhance teaching and learning? Educational Researcher (March), 27-33.

Passin, H. Society and education in Japan. Teachers College, Columbia University. 1965.

Patton, M. Q. (1990). Qualitative evaluation and $r$ research methods. Newbury Park, CA: Sage Publications.

Peak Online Interactive English. (1999). Welcome to Peak's placement test. [Online]. Available: http:// peak english.com/home/placement/ [1999, July 10].

Potoker, E. (1993, April). Management and Training across Cultures: Importance of Non-verbal Communication Strategies-A Case Study. Paper presented at the Annual Conference on Language and Communication for World Business and the Professions, Ypsilanti, MI.

Reischauer, E. O. (1988). The Japanese today. Cambridge, MA: The Belknap Press of Harvard University Press.

Reeves, T. C. and Reeves, P. M. (1997). Effective dimensions of the interactive learning on the world wide web. In B. H. Khan (Ed.), Web-based instruction (pp. 59-66). Englewood Cliffs, NJ: Educational Technology Publications, Inc.

Relan, A. and Gillani, B. (1997). Web-based instruction and the traditional classroom: Similarities and differences. In B. H. Khan (Ed.), Webbased instruction (pp. 41-46). Englewood Cliffs, NJ: Educational Technology Publications, Inc. 
Rinnert, C. (1994). Culturally influenced communication patterns: Overview, implications and applications. In K. Kitao (Ed.), Culture and communication (pp. 3-17).

Rockelman, J. (1991). Role expectations of Japanese EFL students. In K. Kitao (Ed.), Culture and communication (pp. 133-143). Kyoto: Yamaguchi Shoten.

Sasaki, C (1996). Teacher preferences of student behavior in Japan. IALT Journal, 18 (2), 229-239.

Schirokauer, C. (1993). A brief history of Japanese civilization. Orlando, Fl: Harcourt Brace Jovanovich.

School washes hands in Haruna case. (1999, November 29). Mainichi Daily News, p. C12.

Schoppa, L. (1991). Education reform in Japan: goals and results of recent reform campaign. In E. R. Beauchamp (Ed.), Windows on Japanese education. (pp. 51-75). New York: Greenwood Press.

Schotsberger, P. (1997). Emerging roles for instructors and learners in the web-based classroom. In B. H. Khan (Ed.), Web-based instruction (pp. 101-105). Englewrood Cliffs, NJ: Educational Technology Publications, Inc. Shibuya, T. (1998, November 19). New study courses stress creativity. The Japan Times, p. 3.

Shoji, K. (1990, September). Japan's education factory. Business Tokyo 20-25.

Schumacher, S. \& McMillan, J. (1993). Research in education: A conceptual introduction (3rd ed.). New York: HarperCollins College Publishers. 
Schunk, D. H. (1998). Teaching elementary students to self-regulate practice of mathematical skills with modeling. In D. H. Schunk, \& B. J. Zimmerman (Eds.). Self-regulated learning: From teaching to self-reflective practice. (pp. 137-159). New York: The Guilford Press.

Sinclair, J. (1998). Does the virtual classroom really exist or is it still out there. The Electronic Library, 16 (5), 297-299.

Slote, W. H. \& De Vos, G. A. (1998). Confucianism and the family. New York: State University of New York Press.

Statistics Bureau, Management and Coordination Agency. (1998).

Annual report on the labour force survey. [Online]. Available: http://iin.jcic.or.jp/stat/stats/O9LAB31.html [1999, October 30].

Stapleton, P. (1995). The role of Confucianism in Japanese education. The Iapan Association for Language Teaching, 19 (4), 13-16.

Strauss, A. \& Corbin, J. (1990). Basics of qualitative research. Newbury Park: Sage Publications.

Sugimoto, M. \& Swain, D. L. (1989). Science and culture in traditional Iapan. Tokyo: Charles E. Tuttle Company.

Sullivan, P.N., \& Zhong, G.Y.Q. (1995). Arco preparation for the TOEFL (7th ed.). New York: Macmillian USA.

Takayama, S. (1988). Learning \& computer. A study of attitudes toward the computerized education. The Bulletin of Education Department, Shimane University, 22(1), 53-60.

Tanaka, K. (1997). Project type synthetic learning using the Internet. Education and Information, 6 (471), 40-43. 
Tashiro, J., \& Lougheed, L. (1998). 5-Minute quizzes for TOEFL: Structure and written expression, reading comprehension. Tokyo: Macmillan Languagehouse Ltd.

Taylor, R. L. (1988). The Confucian way of contemplation: Okada Takehiko and the tradition of quiet-sitting. Columbia, South Carolina: University of South Carolina Press.

The Educational Testing Servive. (1999). ETS online ordering - Tutorial \& practice questions for the computer-based TOEFL Test. [Online]. Available: http://www.netsales.net/pk.wcgi/ets00003/prod/1228577-1 [1999, July 2]. Thornton, E. (1999, August 9). No room at the top. Business Week Asian Edition, 27.

Thornton, E. (1999, November 1). Will Japan Inc. copy Nissan's new model? Business Week Asian Edition, 20.

TOEFL Org. (1999). TOEFL - Practice questions section 3, reading comprehension. [Online]. Available: http://www.toell.org/rc-pq.html [1999, May 31].

TOEFL Org. (1999). TOEFL tutorials on the web. [Online]. Available: http://ww'w.toefl.org/cbtutprq.html [1999, June 12].

TOEFLcenter.com. (1999). The Practice page. Barron's how to prepare for the TOEFL. [Online]. Available: http://www.toeflcenter.com/practice.html [1999, May 30].

Totsuka, T (1998). Synthetic learning and the near-future Internet. Education and Information, 8, (485), 22-25. 
Valle, R. S. King, M., \& Halling, S. (1989). An introduction to existential-phenomenological thought in psychology. In R.S. Valle, \& S. Halling (Eds.). Existential-phenomenological perspectives in psychology: Exploring the breadth of human experience. (pp. 3-16). New York: Plenum Press.

Von Eckartsberg, R. (1986). Life-world experience: Existentialphenomenological research approaches in psychology. Washington, D. C.: Center for Advanced Research in Phenomenology and University Press of America.

Watanabe, R. (1990, April). The Use of Computers in Japanese Schools. Paper presented at the Annual Meeting of the American Educational Research Association, Boston, MA.

White, M. (1987, January 19). A society where students are No. 1. U.S. News \& World Report 65.

White, R. (1990). Laying it on the line. University of Reading, England: Centre for Applied Language Studies. (ERIC Document Reproduction Service No. Ed 319 233)

Winne. H. P., and Stockley, D. B. (1998). Computing technologies as sites for developing self-regulated learning. In D. H. Schunk, \& B. J. Zimmerman (Eds.). Self-regulated learning: From teaching to self-reflective practice. (pp. 106-136). New York: The Guilford Press.

Yang, H. J. (1993, November). Communication Patterns of Individualistic and Collective Cultures: A Value Based Comparison. Paper presented at the Annual Meeting of the Speech communication Association, Miami Beach, FL. 
Cultural Influences 208

Yoshimori, M. (1983). A social psychological study of person-computer relationships (1): An analysis of attitudes toward the computer. The Bulletin of the Department of Education, Hiroshima University, 1(32), 175-182. 
Appendix A

Toyoko Gakuen Women's College Curriculum Guide 


\begin{tabular}{|c|c|c|c|c|c|}
\hline \multicolumn{2}{|c|}{$\begin{array}{l}1999 \text { TGWC Department of } \\
\text { Language \& } \\
\text { Communication Curriculum }\end{array}$} & Ist yr - Ist semester & 1st yr - 2nd semester & 2nd yr - Ist semester & 2nd yr - 2nd semester \\
\hline \multicolumn{2}{|c|}{ Basic Required Subjects } & $\begin{array}{ll}\text { - Information \& } \\
\text { Society } \\
\text { - Language \& } \\
\text { Communication } \\
\end{array}$ & $\begin{array}{l}\text { - People \& Thought } \\
\text { - Women \& Society }\end{array}$ & $\begin{array}{ll}- & \text { Intercultural } \\
& \text { Communication }\end{array}$ & \\
\hline \multicolumn{2}{|c|}{ Basic Electives } & $\begin{array}{l}\text { Intro to Literature } \\
\text { - English Language \& } \\
\text { the Japanese } \\
\text { - Contemporary Media } \\
\text { Theory }\end{array}$ & $\begin{array}{l}\text { Man \& Languages } \\
\text { International } \\
\text { Community in } \\
\text { Japan } \\
\text { - Future Socicty \& } \\
\text { Information } \\
\end{array}$ & & $\begin{array}{l}\text { Culture \& Art } \\
\text { - Nonverbal } \\
\text { Communication } \\
\text { - Living in Harmony } \\
\text { with Other } \\
\text { Cultures }\end{array}$ \\
\hline \multirow{3}{*}{ 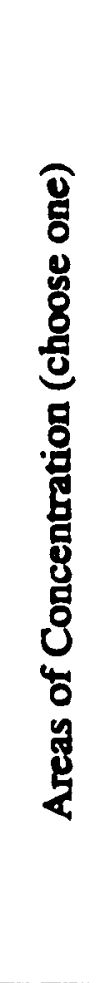 } & $\begin{array}{c}\text { Culture } \\
\text { Concentration }\end{array}$ & $\begin{array}{l}\text { - Japanese Culture } \\
\text { - Discovery of } \\
\text { Language }\end{array}$ & 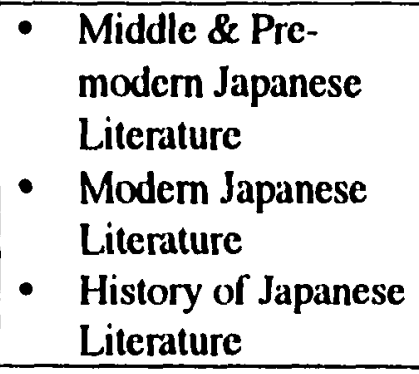 & $\begin{array}{l}\text { - Reading Japanese } \\
\text { Literature } \\
\text { - Religion \&Art } \\
\text { - Art Appreciation }\end{array}$ & $\begin{array}{l}\text { Ancient Japanese } \\
\text { Literature } \\
\text { Modem } \\
\text { Playwrights } \\
\text { The Culture of } \\
\text { Sound and Voice }\end{array}$ \\
\hline & $\begin{array}{l}\text { Lang. \& } \\
\text { Linguistics } \\
\text { Concentration }\end{array}$ & 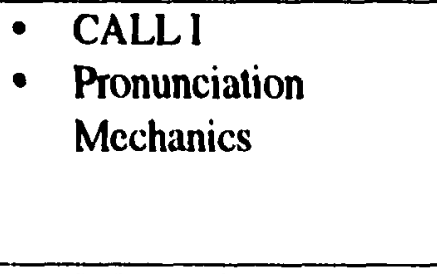 & $\begin{array}{ll}- & \text { CALL II } \\
\text { - } & \text { Reading Readiness } \\
\text { - } & \text { Reading } \\
& \text { Interpretation Skills }\end{array}$ & $\begin{array}{ll}\text { - Journalistic } \\
\text { English } \\
\text { - } \text { Oral } \\
\text { Communication I } \\
\text { - } \text { Reading I } \\
\end{array}$ & $\begin{array}{ll} & \text { Writing } \\
\text { - } & \text { Oral } \\
& \text { Communication II } \\
\text { - } & \text { Reading II }\end{array}$ \\
\hline & $\begin{array}{l}\text { Information \& } \\
\text { Society } \\
\text { Concentration }\end{array}$ & $\begin{array}{l}\text { - Information Literacy } \\
\text { - Data Processing I }\end{array}$ & $\begin{array}{ll} & \text { Database Mgmt } \\
\text { - } & \text { Data Processing Il }\end{array}$ & \begin{tabular}{|l|} 
Mass \\
Communication \\
Studies \\
- Office Automation \\
Studies \\
- Intro to the \\
Internet \\
\end{tabular} & 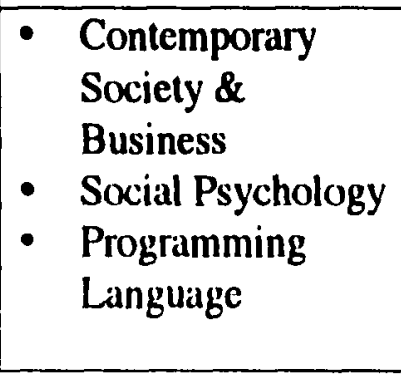 \\
\hline
\end{tabular}




\begin{tabular}{|c|c|c|c|c|c|}
\hline \multicolumn{2}{|c|}{$\begin{array}{l}1999 \text { TGWC Dept of } \\
\text { Language \& Comm. } \\
\text { Curriculum Condt. }\end{array}$} & Ist yr - Ist semester & Ist yr - 2nd semester & 2nd yr - Ist semester & 2nd yr - 2nd semester \\
\hline \multirow{4}{*}{ 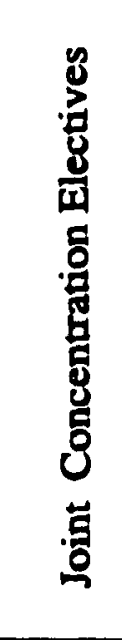 } & Seminars & & Seminar I & Seminar II & Seminar III \\
\hline & $\begin{array}{c}\text { Women's } \\
\text { Presence in } \\
\text { Modem Japan }\end{array}$ & $\begin{array}{l}\text { - Intro to Women's } \\
\text { Studies } \\
\text { - Women \& the Law }\end{array}$ & - History of Woinen & $\begin{array}{l}\text { Era of } \\
\text { Continuing } \\
\text { Education } \\
\end{array}$ & $\begin{array}{l}\text { - Women in Asia } \\
\text { - Women in } \\
\text { Japanese Culture } \\
\end{array}$ \\
\hline & $\begin{array}{l}\text { Japan \& the } \\
\text { Languages of } \\
\text { the World }\end{array}$ & $\begin{array}{l}\text { - Children's Litcrature } \\
\text { - Linguistic Expression I }\end{array}$ & $\begin{array}{l}\text { - Languages of the World } \\
\text { \& English } \\
\text { - Linguistic Expression II }\end{array}$ & $\begin{array}{ll}\text { - } & \text { History of } \\
\text { Language } \\
\text { - Japanese Lang. } \\
\text { Teaching Skills I }\end{array}$ & $\begin{array}{l}\text { Contemporary } \\
\text { Japanese Lang. } \\
\text { Japanese Lang. } \\
\text { Teaching Skills II }\end{array}$ \\
\hline & $\begin{array}{l}\text { Contemporary } \\
\text { Social Issues }\end{array}$ & $\begin{array}{l}\text { - Images of } \\
\text { Contemporary America } \\
\text { - New Perspectives on } \\
\text { Life }\end{array}$ & $\begin{array}{ll}- & \text { History } \\
- & \text { Life and the } \\
& \text { Environment }\end{array}$ & $\begin{array}{l}\text { - The World in } \\
\text { Upheaval }\end{array}$ & $\begin{array}{l}\text { - Contemporary } \\
\text { Law } \\
\text { - Social Survey } \\
\text { Taking }\end{array}$ \\
\hline \multicolumn{2}{|c|}{$\begin{array}{l}\text { Electives available for all } \\
\text { students }\end{array}$} & $\begin{array}{l}\text { - English I } \\
\text { - IES I } \\
\text { - English Testing I } \\
\text { - French I } \\
\text { - Voluntecrism } \\
\text { - Spanish I } \\
\text { - Contemporary Health } \\
\text { Issues } \\
\text { - Chinese I } \\
\text { - Secretarial Studies } \\
\text { - P.E. I }\end{array}$ & $\begin{array}{ll}\text { - } & \text { English II } \\
\text { - } & \text { IES II } \\
\text { - } & \text { English Testing II } \\
\text { - } & \text { French II } \\
\text { - } & \text { Modern Film Studies } \\
\text { - } & \text { Spanish II } \\
\text { - } & \text { Chinese II } \\
\text { - Overscas Study Tour } \\
\text { - Secretarial Practice I } \\
\text { - } \text { P.E. II } \\
\text { - Women \& Work }\end{array}$ & 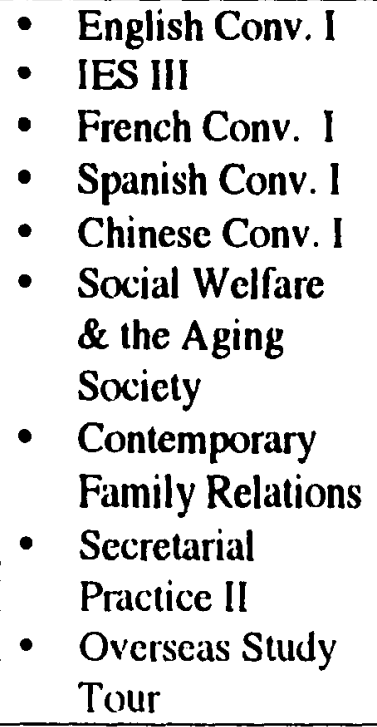 & $\begin{array}{l}\text { - English Conv. II } \\
\text { - IES IV } \\
\text { - } \text { French Conv. II } \\
\text { - Spanish Conv. II } \\
\text { - Chinese Conv. II }\end{array}$ \\
\hline
\end{tabular}




\section{Appendix B}

\section{Student Weekly Logsheets}


Name

Number

URL

Week \# 1 Date: 5-24-99

Please write a short answer for each question.

1. After this class, how do you feel about using the Internet for studying?

2. What was the best part about using the Internet in class today?

3. What was the worst part about using the Internet in class today?

4. Do you feel comfortable using only the Internet for studying?

5. When you used the Internet today, did you work by yourself or with another student?

6. How many times did you talk to your teacher today when using the Internet? 
Name Number

URL http:/ / www.toeflcenter.com/ practice.html

Week \#2 Date: 5-31-99

Please write a short answer for each question.

1. When you came into the class today, how did you remember to use the Internet? Did you follow some notes, ask someone, or just remembered from last week how to use the Internet?

2. How do you feel about not using a textbook for TOEFL practice? Circle one of the choices below.

For TOEFL practice:

I prefer to use only the Internet for studying.

I prefer to use the Internet and a textbook for studying.

I prefer to use only a textbook for studying.

3. Today you had a worksheet to use to help you with the website practice questions. Was the worksheet useful? Y/N

4. Please tell how this TOEFL practice website was better or worse from the TOEFL practice website you used last week.

5. Check one: Today I worked by myself with another student

6. I talked to my teacher today while using the Internet. $\mathrm{Y} / \mathrm{N}$

7. Please feel free to tell any other ideas or feelings you had while using the Internet today for studying. Use the back of this paper, if necessary. 
Name

URL http:/ / www.toefl.org/ rc-pq.html

Number

Week \#3 Date: 6-7-99

Directions: Answer all of the following questions. Use the back of this paper if necessary.

1. This is the third week of TOEFL practice on the Internet. Did you have any problems starting the computer and logging on to the website? $\mathrm{Y} / \mathrm{N}$

If you had a problem, how did you get the answer?

I solved the problem by myself.

I asked my classmate.

I asked my teacher.

I read my notes from a previous TOEFL Internet class.

I never solved my problem.

2. Today you worked on a TOEFL Reading Comprehension website. Do you think the website was useful for TOEFL Reading Comprehension Practice? Y/N

3. Check one: Today I worked

By myself

With another student

4. Do you prefer to work by yourself or with another student while using the Internet?

By myself

With another student

5. How has the Internet helped you learn about the TOEFL Test?

6. What was the teacher doing in the class while you were using the Internet for TOEFL practice?

7. Do you feel you are learning more or less about the TOEFL test from working on the Internet sites?

I am learning more.

I am learning less.

6. I talked to my teacher today while using the Internet. $\mathrm{Y} / \mathrm{N}$

7. Please feel free to tell any other ideas or feelings you had while using the Internet today for studying. Use the back of this paper, if necessary. 
8. Name

Number

URL http:/ / www.toefl.org/rc-pq.html (TOEFL practice questions

downloaded from this site)

Week \#4 Date: 6-14-99

Directions: Answer all of the following questions. Use the back of this paper if necessary.

1. This is the fourth week of TOEFL practice on the Internet. Did you have any problems starting the computer and beginning the TOEFL practice program? $\mathrm{Y} / \mathrm{N}$

If you had a problem, how did you get the answer?

I solved the problem by myself.

I asked my classmate.

I asked my teacher.

I never solved my problem.

2. I prefer to answer TOEFL practice questions:
a. directly on the website
b. on my own paper
c. using a worksheet

3. This TOEFL practice class was:
a. better than last week
b. worse than last week
c. about the same as last week

4. While using the Internet for learning, I prefer to work:
a. with one other student
b. in a group of students
c by myself

5. This is the fourth week of TOEFL Internet practice. I (do/ do not) expect a test to be given soon.

6. At this time, I am comfortable using the Internet for TOEFL practice. Y/N

7. After four weeks, I feel (better/worse) about using the Internet for studying.

I feel better because: 
I feel worse because:

8. During the last four weeks in this Internet class, what my teacher does (actions) is (similar/different) to teachers in traditional classrooms.

Tell about your teacher's actions in the regular classroom. Complete this sentence, "In the regular classroom, my teacher......

Tell about your teacher's actions in the Internet classroom. Complete this sentence, "In the Internet classroom, my teacher.......

9. In this class, I want my teacher to: 
Name

Number

URL http://www.toefl.org/rc-pq.html (TOEFL practice questions downloaded from this site)

Week \#5 Date: 6-21-99

Directions: Answer all of the following questions. Use the back of this paper if necessary.

1. This is the fifth week of TOEFL practice. Like last week, you worked on TOEFL questions that were downloaded from the above website. Did you have any problems with TOEFL practice problems? Y/N

If you had a problem, how did you get the answer?

I solved the problem by myself.

I asked my classmate.

I asked my teacher.

I never solved my problem.

2. This TOEFL practice class was:

a. better than last week

b. worse than last week

c. about the same as last week

3. This week I worked on practice questions for :

Structure

Reading Comprehension

4. I had enough time to complete all the practice questions. $Y / N$

5. Check one: Today I worked

By myself

With another student

6. I talked to my teacher today while using working on the practice questions. $\mathrm{Y} / \mathrm{N}$

7. What was the teacher doing while you were working on your practice questions? 
Name

Week \#6 Date: 6-28-99

Number

1. Directions: If you were absent last week work on the following TOEFL practice questions downloaded from this site:

http:/ / www.toefl.org/cbtutprq.html

2. If you were present last week and have completed all three practice questions sections from the above site, as a review, work on TOEFL practice questions from one of the following sites:

http://www.toeflcenter.com/practice.html

http://www.toefl.org/rc-pq.html

Directions: Answer all of the following questions. Use the back of this paper if necessary.

Circle one:

I was present last week.

I was absent last week.

1. This is the sixth week of TOEFL practice. Did you have any problems with TOEFL practice problems? Y/N

If you had a problem, how did you get the answer?

I solved the problem by myself.

I asked my classmate.

I asked my teacher.

I never solved my problem.

2. This TOEFL practice class was:

a. better than last week

b. worse than last week

c. about the same as last week

3. This week I worked on practice questions for :

Structure

Reading Comprehension

Writing Practice

4. I would like to use a textbook in addition to the Internet to complete the TOEFL practice questions. $\mathrm{Y} / \mathrm{N}$

5. Check one: Today I worked

By myself

With another student

6. I talked to my teacher today while using working on the practice questions. $\mathrm{Y} / \mathrm{N}$ 
7. What was the teacher doing while you were working on your practice questions?

8. After six weeks of using the Internet for studying, I feel..... 
Name

Week \#7 Date: 7-5-99

Number

Directions: TOEFL practice questions have been downloaded from the site: http://www.netsales.net/pk.wcgi/ets00003/prod/1228577-1. Choose one section and complete the TOEFL practice questions. Then answer the questions below.

1. This is the seventh week of TOEFL practice. This week you worked in a group. If you had a problem, how did you get the answer?

I solved the problem by myself.

I asked my group members.

I asked my teacher.

I never solved my problem.

2. This TOEFL practice class was:

a. better than last week

b. worse than last week

c. about the same as last week

3. This week I worked on practice questions for :

Structure

Reading Comprehension

Writing Practice

4. I would like to use a textbook in addition to the Internet to complete the TOEFL practice questions. $Y / N$

6. I talked to my teacher today while using working on the practice questions. $\mathrm{Y} / \mathrm{N}$

7. Today you completed the TOEFL practice questions while working in a group. Answer the following questions.

a. Working in a group is [more difficult/less difficult] than working by myself.

b. I learned [more/less] about the TOEFL questions while working in a group than working by myself.

c. I prefer to be in a group while working on the TOEFL practice questions. $\mathbf{Y} / \mathbf{N}$

d. Next week I want to work in a group. $Y / N$

e. I prefer to use the Internet [by myself/in a group].

8. Please feel free to write your ideas, opinions, and comments about the Internet TOEFL practice class. Use the back of this sheet, if necessary. 
Name

Week \#8 Date: 7-12-99

Number

Directions: Log on to tle following website: http://www.peakenglish.com. Click on the Placement Test link and complete the test. Write your score below.

Peak Placement Test Score $=$

This is the last week for TOEFL Internet practice. Please answer the following questions and use the back of this paper, if necessary.

1. Our TOEFL Internet practice course lasted for eight weeks. In your opinion, how much time should one Internet course continue, for example, three weeks, five weeks, one month, one year, etc.?

a. one week

b. one month

c. one semester

d.

2. While studying via the Internet, how often should assignments be given for example, once a week, twice a week, etc?

a. once a week

b. twice a week

c. once every two weeks

d.

3. How much time per week would you be willing to spend for studying via the Internet, for example, one hour a week, two hours a week, etc?

a. one hour

b. two hours

c. three hours

d.

4. While studying via the Internet, is it necessary for the teacher to be in the room with students? $\mathrm{Y} / \mathrm{N}$

5. From your experience using the Internet for TOEFL practice, is it necessary to use a textbook while studying via the Internet? $\mathrm{Y} / \mathrm{N}$

6. Do you prefer working in a group or by yourself while studying via the Internet?

a. in a group of two/three/four/

b. by myself

7. If you were working on an Internet class by yourself and there was no teacher around, how would you find the answers to your questions? 
I would

8. What does "working independently" mean to you? Choose one of the answers below or write your own answer.

a. Working independently means working by myself without any help from my classmates or the teacher.

b. Working independently means working by myself but the teacher and classmates should be in the same room.

c.

9. What was the best part about this TOEFL Internet practice class?

10. What was the worst part about this TOEFL Internet practice class?

11. What suggestions for improvement can you recommend for this class? 


\section{Cultural Influences}

\section{Appendix C}

\section{Informed Consent Form}




\section{Informed Consent Form}

The following points related to this study are described below.

1. This purpose of this study is to provide students the opportunity to voice their experiences, perceptions of learning, and attitudes toward web-based instruction through the interview process.

2. The one-hour interview will be held in private in the researcher's office at Toyoko Gakuen Women's College during regular school hours of the 1999-2000 school year.

3. The researcher, Theresa L. Lally, will be conducting the interview, taping the interview, and taking notes during the interview. Furthermore, I understand that the researcher will transcribe the interview and I will be able to review the transcription at any time.

4. No risks or benefits are expected from the interview and no agreement, written or verbal, extends beyond that expressed on this consent form.

5. Participation is voluntary and I understand that I am free to stop participation at any time. Prior to signing this consent form, I can ask questions about the study and receive answers. Not willing to participate will in no way affect my status as a student at Toyoko Gakuen Women's College.

6. There will be no expense involved for my participation in the study.

7. All interview material, including the tape recording and transcript, will be kept confidential. 
I, the undersigned, understand the above points and on that basis, I give my permission to voluntary participate in this study.

Signature of subject or Parent/guardian Date

Location

$\overline{\text { Signature of researcher }}$

Date

Signature of witness

Date 


\section{Appendix D}

\section{Interview Question Guides}




\section{Pretreatment (First) Interview Questions}

Interview questions were designed around the following five Confucian tenets:

1. Expected behavioral differences between teachers and students ( $(\omega)$

2. Reward over effort and competition within rank ( $\Delta)$

3. Use of memorization as a major learning technique $( \pm)$

4. Reliance on textbooks as a method of instruction ( $\infty)$

5. Use of exams as a means of ranking $(\Omega)$

Note that interview questions relate to one or more of the tenets listed above. The symbol(s) in front of each question correspond to the particular tenet(s) under discussion.

1. (\$) How do you think your relationship with your teacher will be affected by studying using web-based instruction? What behavior or actions do you expect of your teacher and what behavior or actions should the teacher expect of you while you are learning by web-based instruction?

2. ( $\Delta$ ) In our class, you will be working individually at a computer using websites for TOEFL practice. How do you think this type of individual and not group environment will affect your learning?

3. ( $\Delta \pm \infty \Omega$ ) Describe the biggest advantage you hope to gain by webbased instruction.

4. ( $(\Omega)$ Do you expect to have exams while learning by web-based instruction? If so, what kind of evaluation or exams are you anticipating?

5. ( $\infty$ For our purposes you will not be using a traditional textbook but will use the TOEFL practice websites as textbooks. What is your feeling about this?

6. ( \pm ) While studying over the web, you will not be memorizing facts but 
you will have to remember how to navigate through several websites. How do you plan to remember this? Will you take notes, use pictures, ask you classmates? How will you remember what to do? 
Second Interview Questions - Week \#4

Interview questions were designed around the following five Confucian tenets:

1. Expected behavioral differences between teachers and students ( $(\omega)$

2. Reward over effort and competition within rank ( $\Delta$ )

3. Use of memorization as a major learning technique ( \pm )

4. Reliance on textbooks as a method of instruction $(\infty)$

5. Use of exams as a means of ranking $(\Omega)$

Note that interview questions relate to one or more of the tenets listed above. The symbol(s) in front of each question correspond to the particular tenet(s) under discussion.

General Questions:

1. (\$) Describe how your behavior and actions are different in this class since you started studying via web-based instruction.

2. (\$) You've been in this class for four weeks. Describe how the teacher's behavior and actions in your web-based class are different from your other teachers' actions and behaviors who have been teaching you in the traditional way during the last four weeks.

3. (đ) Tell me about how you interact or communicate with your classmates during web-based instruction.

4. ( $\Delta$ ) At this time, what advantages and disadvantages can you see from learning through web-based instruction?

Specific questions:

5. (\$) Tell me the process you follow when learning via web-based instruction. For example what kinds of actions do you take when you enter the computer 
room. What do you do first, second, etc. How is this compared with a class you would take in a regular classroom?

6. $(\Delta \pm \infty)$ What techniques are you using to remember your websites and how to navigate through them?

7. $(\Delta+\infty)$ During the first interview, I mentioned that you would not be using a textbook but the websites would take the place of a textbook. Now that you've been learning this way for four weeks, describe your impression or feeling about not using a textbook. Is it the same or different as in our first interview?

8. ( ) Describe what the teacher actually does while you are studying by webbased instruction? Do the teacher's actions follow what you expected when we discussed this in our first interview? If no, please describe how the teacher's actions are different from what you expected.

9. ( $\Delta \pm$ ) What do you do if you do not understand something on website? Do you ask a classmate, ask the teacher, or do nothing?

10. $\Delta$ How do you get the teacher's attention and speak to the teacher while you are working on a website? Is this the same or different compared to a regular classroom? If different, how is it different?

11. (t) Because you have been working individually, interaction with your fellow students is different from that in a regular classroom. Describe your feelings about your interactions with your teacher and classmates while you are working on a web-based assignment.

12. $\left(\Omega \Delta_{ \pm}\right)$You have already had exams in some of your traditional classes but in this class exams are not an important part of the course. Based upon your 
experience so far in this class, do you feel that exams should be a part of the course in order to know where you now rank with your other classmates? Please give reasons for your answers. 
Post-treatment (Third) Interview Questions - Week \#8

Interview questions were designed around the following five Confucian tenets:

1. Expected behavioral differences between teachers and students ( $\phi)$

2. Reward over effort and competition within rank $(\Delta)$

3. Use of memorization as a major learning technique ( \pm )

4. Reliance on textbooks as a method of instruction $(\infty)$

5. Use of exams as a means of ranking ( $(\Omega)$

Note that interview questions relate to one or more of the tenets listed above. The symbol(s) in front of each question correspond to the particular tenet(s) under discussion.

General Questions:

1. $( \pm \infty \Delta \Omega)$ Please describe your overall impression of learning by webbased instruction?

2. ( $\pm \infty \Delta \Omega)$ What recommendations would you make to advise students who were going to take this web-based course for the first time beginning in October of this year.

3. $( \pm \infty \Delta \Omega)$ What suggestions can you make to improve the course? Specific questions:

1. ( $\pm \infty \Delta \Omega)$ Has your image about web-based instruction changed from the first interview and the beginning of the course? If so, how? If not, how has it remained the same as in the beginning of the course?

2. ( $\pm \infty \Delta \Omega)$ Now that the course is over, tell me (specifically) how this course was different from learning in a traditional classroom setting. 
3. $( \pm \infty \Delta \Omega)$ Describe how the teacher's actions helped or hindered your experience of learning by web-based instruction.

4. $( \pm \infty)$ You have completed the course completely without a textbook. Now that the course is over, what is your impression of using the web as a textbook? Would you be willing to take other courses using the web as a textbook?

5. (\$) As a student, what did you do to help your understanding of webbased instruction? For example, did you come to the computer room by yourself to practice the TOEFL questions using the websites? Did you work with a classmate on the TOEFL practice websites outside class time?

6. ( $( \pm \pm)$ What learning technique did you use to remember how to use the websites and would you recommend this technique to other students who were going to take this course for the first time?

7. ( $\Delta$ ) In this web-based course you had to work by yourself and not as a part of a group. How do you feel about working alone and not in a group?

8. ( $\Delta \Omega$ ) How do you feel about exams not being a major part of the course?

Did this bother you or was it a relief? What recommendations could you make about using exams in the course? 
Cultural Influences

Appendix E

Pre-TOEFL Pre and Posttest Scores 
Cultural Influences 237

\begin{tabular}{|c|c|c|c|c|c|c|c|c|}
\hline & \multicolumn{3}{|c|}{ Experimental Group } & \multirow{2}{*}{ 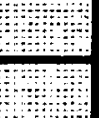 } & & \multicolumn{3}{|c|}{ Control Group } \\
\hline & Student \# & Pretest & Posttest & & & Student \# & Pretest & Posttest \\
\hline 1 & 995204 & 427 & 397 & & 1 & 995004 & 300 & 317 \\
\hline 2 & 991091 & 400 & 397 & & 2 & 991007 & 313 & 343 \\
\hline 3 & 995033 & 397 & 430 & & 3 & 995308 & 363 & 367 \\
\hline 4 & 995140 & 390 & absent & & 4 & 995238 & 363 & 400 \\
\hline 5 & 995161 & 390 & 403 & & 5 & 991025 & 353 & 370 \\
\hline 6 & 995243 & 380 & 397 & & 6 & 995204 & 383 & 387 \\
\hline 7 & 995047 & 373 & 397 & & 7 & 995030 & 430 & 433 \\
\hline 8 & 991201 & 367 & 370 & & 8 & 995091 & 357 & 397 \\
\hline 9 & 995195 & 367 & 350 & & 9 & 995120 & 320 & 373 \\
\hline 10 & 995287 & 367 & 340 & & 10 & 995111 & 357 & 363 \\
\hline 11 & 991005 & 363 & 360 & & 11 & 991146 & 367 & 380 \\
\hline 12 & 995012 & 360 & 377 & & 12 & 995101 & 337 & 390 \\
\hline 13 & 995085 & 360 & 377 & & 13 & 995260 & 350 & 380 \\
\hline 14 & 991021 & 357 & 377 & & 14 & 995268 & 333 & 330 \\
\hline 15 & 995232 & 357 & 347 & & 15 & 995302 & 357 & 373 \\
\hline 16 & 995003 & 350 & 373 & & 16 & 995216 & 370 & 407 \\
\hline 17 & 995039 & 347 & 380 & & 17 & 995062 & 333 & 387 \\
\hline 18 & 995266 & 347 & 383 & & 18 & 995138 & 437 & 423 \\
\hline 19 & 995279 & 343 & 387 & & 19 & 996168 & 313 & 340 \\
\hline 20 & 995156 & 340 & 347 & & 20 & 995035 & 357 & 353 \\
\hline 21 & 995180 & 340 & 333 & & 21 & 995147 & 373 & 397 \\
\hline 22 & 995184 & 340 & 337 & & 22 & 995141 & 367 & 407 \\
\hline 23 & 995146 & 337 & 357 & & 23 & 995153 & 350 & 373 \\
\hline 24 & 995104 & 333 & 327 & & 24 & 995158 & 390 & 397 \\
\hline 25 & 995093 & 327 & 320 & & 25 & 991210 & 387 & 393 \\
\hline 26 & 995300 & 327 & 347 & o & 26 & 995193 & 340 & 383 \\
\hline 27 & 995280 & 387 & 387 & & 27 & 995196 & 347 & 337 \\
\hline 28 & 995033 & 313 & 333 & & 28 & 995183 & 423 & 407 \\
\hline 29 & 995126 & 310 & 343 & & 29 & 995041 & 363 & 373 \\
\hline 30 & 995306 & 237 & 347 & 13 & 30 & 995299 & 373 & 393 \\
\hline
\end{tabular}

